\title{
ESTUDIO GENÉTICO DE PACIENTES DIAGNOSTICADOS DE ENFERMEDAD DE RENDU-OSLER-WEBER (HHT)
}



D. ROGELIO GONZÁLEZ SARMIENTO, CATEDRÁTICO DEL

DEPARTAMENTO DE MEDICINA DE LA UNIVERSIDAD DE SALAMANCA

CERTIFICA:

Que el trabajo titulado: “ESTUDIO GENÉTICO DE PACIENTES

DIAGNOSTICADOS DE ENFERMEDAD DE RENDU-OSLER-WEBER (HHT)” que presenta D. Antonio Cabezón Crespo, ha sido realizado bajo su dirección y reúne, a su juicio, todas las características necesarias, considerándolo apto para que sea presentado ante el tribunal correspondiente a fin de optar al título de Doctor por la Universidad de Salamanca.

Para que conste y a los efectos oportunos, expide el presente certificado en Salamanca a 1 de septiembre de 2011.

R. González Sarmiento 

“Lo que con mucho trabajo se adquiere, más se ama” Aristóteles (384 AC- 322 AC) 



\section{AGRADECIMIENTOS}

Dr. Rogelio González Sarmiento, por su dedicación y entrega, por permitirme dedicar parte de mi actividad profesional a la investigación y apoyarme en todo momento, sabiendo estimular y llevar a buen puerto toda iniciativa propuesta

A mis padres y hermano, por el apoyo constante en el día a día, por ser la fuerza y el empuje que siempre se necesita y por ser ejemplo de superación y constancia mantenida

Dr. Víctor Chimpén, por darme todas las facilidades y ayudarme en las revisiones de las historias y de los propios pacientes en la consulta, así como su empeño en sacar este trabajo adelante

Dr. Juan Carlos Olazábal, tutor y maestro, de quien aprendí que la investigación y la clínica son compatibles, aún cuando supone un gran esfuerzo compaginar ambas

Dra. Susana Olmos, por su experiencia y amistad, por hacerme ver que todo esfuerzo con la tesis merece la pena

Dra. Nerea Alonso, por enseñarme a dar mis primeros pasos y permitirme ser partícipe de su éxito profesional

Dra. Eva $\mathrm{M}^{\mathrm{a}}$ Sánchez Tapia, por ser ejemplo de disfrute con su trabajo y de superación diaria, manteniendo siempre buena cara incluso cuando se presentan adversidades

A Sara Ciria, Clara Cieza, Irene Rodríguez y todas las personas que trabajan diariamente para que la investigación en medicina tenga sentido y sobre todo, resultados

A Roberto Zarrabeitia, por permitir adentrarme en el complejo mundo de esta enfermedad y por demostrarme que con buena voluntad y mucho trabajo se consigue todo

A la gran familia del laboratorio 14 del Centro de Investigación del Cáncer y del Laboratorio de Genética de la Facultad de Medicina de Salamanca, por enseñarme una mínima parte de sus amplios conocimientos en genética y en otras muchas cosas, por estar siempre dispuestos cuando ha hecho falta.

A Nieves, por ser la "madre de todos"

A mis amigos, que han sido pacientes en las largas esperas porque "estaba en la facultad"

Al equipo de enfermería de la 6 a derecha del Hospital Clínico de Salamanca (Medicina Interna), por ayudarme siempre que lo he necesitado 
A mis compañeros residentes y adjuntos del Hospital Clínico de Salamanca, por prestar su colaboración siempre que la he pedido a lo largo de este camino

A mis compañeros del Servicio de Urgencias del Hospital General Yagüe de Burgos, por facilitarme la tarea

A los pacientes y sus familiares, porque sin ellos mi actividad profesional no tiene sentido 


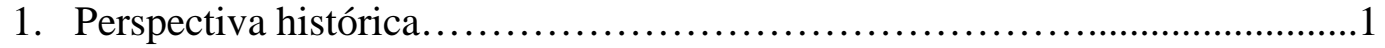

2. La enfermedad de Rendu-Osler.......................................... 2

2.1 Epidemiología....................................................... 2

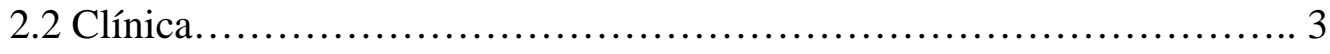

Epistaxis............................................................ 3

Malformaciones arteriovenosas cerebrales............................ 4

Malformaciones arteriovenosas pulmonares....................... 6

Sangrado gastrointestinal....................................... 7

Malformaciones vasculares hepáticas............................. 8

2.3 Diagnóstico.................................................. 9

Clínico.............................................................. 9

Genético.................................................... 10

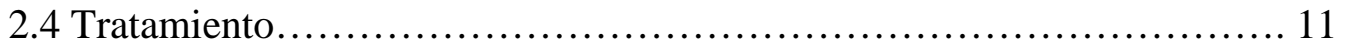

Epistaxis..................................................... 11

Malformaciones arteriovenosas cerebrales......................... 12

Malformaciones arteriovenosas pulmonares........................... 13

Sangrado gastrointestinal...................................... 13

Malformaciones vasculares hepáticas................................ 14

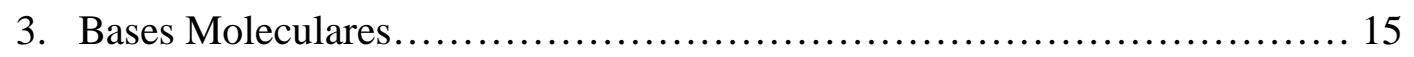

3.1 Conceptos básicos............................................. 15

Pared vascular................................................. 15

Remodelamiento vascular.......................................... 16

Angiogénesis..................................................... 20

3.2 Genes implicados............................................... 20

Endoglina.................................................... 22

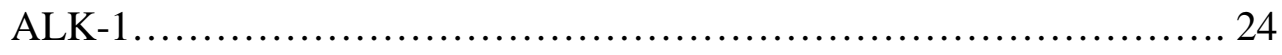

SMAD4........................................................... 26

3.3 Mecanismo de señalización vascular................................ 27

OBJETIVOS............................................................... 33

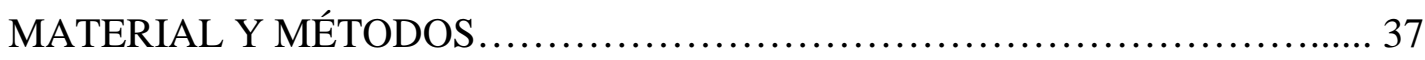

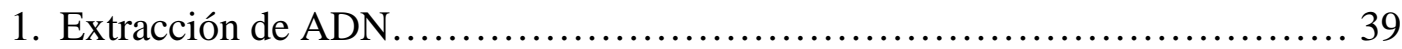

2. Amplificación de ADN............................................. 40

3. Electroforesis en gel de agarosa....................................... 43

4. Secuenciación automática.............................................. 44

5. Análisis Bioinformático de las secuencias............................... 45

6. Estudios poblacionales................................................ 45 
1. Paciente 17853 (ALK-1 c.1378-1 G>T; r.sp1) …............................................... 57

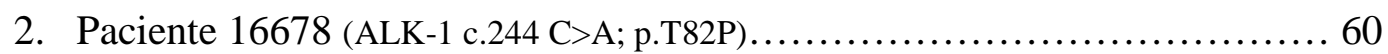

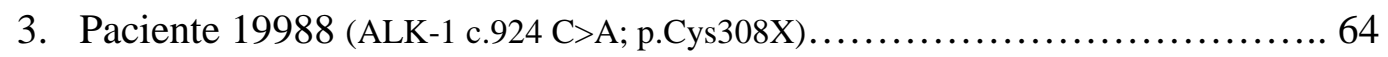

4. Paciente 17580 (ENG c.1686+1 G>A)..................................... 66

5. Paciente 18013 (ALK-1 c.641 G>A; p.Gly214Asp)........................... 69

6. Paciente 19822 (SMAD4 c.1082 A>G; p.Arg361His).......................... 73

7. Paciente 12241 (ENG c.1256_1268del13; p.S419MfsX490)..................... 76

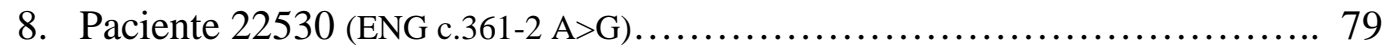

9. Paciente 23043 (ALK-1 c.656 G>A; p.Gly219Asp)............................ 81

10. Paciente 23120 (ALK-1 c.1135 G>A; p.Glu379Lys)........................... 83

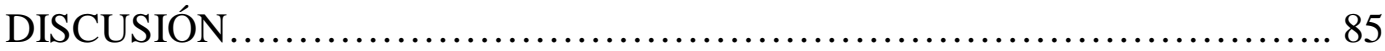

CONCLUSIONES ........................................................ 93

REFERENCIAS BIBLIOGRÁFICAS...................................... 97

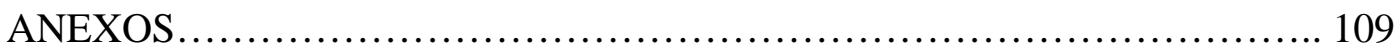

1. Anexo 1. Abreviaturas.............................................. 111

2. Anexo 2. Listado de figuras..................................... 115

3. Anexo 3. Listado de tablas........................................ 117 



\section{PERSPECTIVA HISTÓRICA}

La Enfermedad de Rendu-Osler-Weber, también conocida como Telangiectasia Hemorrágica Hereditaria (HHT), es una enfermedad de herencia autosómica dominante, que puede afectar a individuos de todas las razas y está presente en todo el mundo. Se caracteriza porque los individuos afectos presentan, como síntoma más común, epistaxis de repetición y como signo clínico más frecuente, telangiectasias mucocutáneas. Frecuentemente se asocia a complicaciones, como la presencia de malformaciones arteriovenosas, especialmente a nivel hepático, en el tracto gastrointestinal, en el pulmón y en el cerebro.

La primera descripción de la enfermedad la realizó Sutton en 1865, en un artículo publicado en la revista Lancet, donde analiza una familia con episodios de epistaxis violentas a lo largo de cinco generaciones consecutivas, causando la muerte en dos miembros de la misma (Sutton HG, 1865). Posteriormente, en 1876, Legg publicará, en la misma revista, el primer caso de pequeños nevus faciales en un paciente que también presentaba epistaxis de repetición y con historia familiar asociada, aunque en este caso lo relacionaba con el posible padecimiento de hemofilia (Legg JW, 1876). Fue Henri JLM Rendu quien, en 1896, a raíz de la presentación de un caso de un varón de 52 años que presentaba epistaxis de repetición, telangiectasias cutáneas e historia familiar asociada, realiza la primera descripción de HHT y la reconoce como una enfermedad hemorrágica distinta de la hemofilia, caracterizada por hemorragias debidas a un déficit en la coagulación sanguínea (Rendu HJML, 1896). Según Rendu, el problema de esta nueva enfermedad se debía a una alteración en la pared de los vasos sanguíneos pequeños, que tienden a romperse o desaparecer, lo que causa las hemorragias. Posteriormente, Osler en 1901 y Weber en 1907, publicaron las primeras series de casos (Osler W, 1901; Osler W, 1907; Weber FP, 1907). En 1909, Hanes propone el nombre definitivo de HHT, por el cual la conocemos hoy día (Hanes FM, 1909). Aunque al principio fue considerada como una enfermedad benigna, desde los años 40 y gracias al avance en las técnicas de imagen, comenzaron a observarse las malformaciones que hoy día sabemos que están presentes en la mayoría de los pacientes.

Desafortunadamente, la mayoría de las ocasiones la enfermedad no está diagnosticada y familias enteras no pueden acceder a técnicas de detección y 
beneficiarse de los diferentes tratamientos disponibles en el momento actual, tanto en niños como en adultos, lo que evitaría el desarrollo de las complicaciones ya descritas anteriormente.

\section{LA ENFERMEDAD DE RENDU-OSLER-WEBER}

\subsection{EPIDEMIOLOGÍA}

La enfermedad de Rendu-Osler-Weber tiene un patrón hereditario autosómico dominante; es decir, todas las generaciones pueden estar afectas en, al menos, el 50\% de sus miembros (Guttmacher AE et al., 1995).

La prevalencia estimada a nivel mundial es de 1 caso por cada 5.000 habitantes (Shovlin CL et al, 2010), aunque en determinadas regiones, dicho valor aumenta. La incidencia es elevada en la región de Akita, al norte de la isla de Japón, donde se estima entre 1 caso por cada 5000 - 8000 habitantes (Dakeishi M et al., 2002). En el Condado de Fyn (Dinamarca) dicho valor oscila entre 1 caso por cada 1641 y 1 por cada 7246 habitantes, valores entre los que oscilan la mayoría de países europeos y en Estados Unidos (Kjeldsen AD et al., 1999). En la región de Haut Jura, en Francia, los valores estimados son de 1 caso por cada 2351 habitantes (Bideau A et al.1992). La mayor prevalencia conocida en el mundo se haya entre la población Afro-Caribeña de las Islas Antillas, donde alcanza valores de 1 caso por cada 1331 habitantes (Westermann et al., 2003)

Existe una gran variabilidad en las manifestaciones clínicas entre diferentes familias y entre miembros de una misma familia. A pesar de ello, sabemos que las epistaxis están presentes en el 90\% de los pacientes, incrementándose la severidad y frecuencia de las mismas con la edad, lo que puede inducir a un estado de anemia que requiera transfusiones sanguíneas (Assar OS et al., 1991). Las malformaciones hepáticas están presentes en el 40\% de los pacientes, formando comunicaciones o shunts entre los principales vasos sanguíneos (arteria hepática, vena hepática y vena porta) (Buscarini E et al., 2004); mientras que las malformaciones pulmonares se pueden encontrar en aproximadamente el 50\% de los casos, principalmente entre la arteria pulmonar y las cuatro venas pulmonares, lo que puede desembocar en hipoxemia, infarto y abcesos cerebrales (Kjeldsen AD et al., 2000). A nivel cerebral es fácil encontrar aneurismas y angiomas cavernosos que, si sangran, causarán infartos cerebrales (Fullbright RK et al., 1998; Bayrak-Toydemir P et al., 2004). 


\subsection{CLÍNICA}

Durante muchos años se han estudiado las características clínicas que determinaban la enfermedad de Rendu-Osler, llegando a las siguientes conclusiones:

- Las epistaxis comienzan en torno a los 12 años, estando afectados el 100\% de los individuos a la edad de 40 años (Plauchu et al,1989; OS AA et al, 1991)

- La mayoría de los pacientes refieren la aparición de telangiectasias en boca, cara y manos entre 5 y 30 años después de iniciarse el sangrado nasal, especialmente durante la tercera década de la vida (Porteus et al, 1992). En ocasiones las lesiones desaparecen, pero lo normal es que aumenten con la edad (Letteboer $\mathrm{T}$ et al., 2008).

- Las malformaciones arteriovenosas cerebrales se desarrollan durante la infancia (Krings T et al., 2005)

- Las malformaciones arteriovenosas pulmonares se desarrollan en la pubertad (Shovlin CL et al., 2010)

- Las malformaciones arteriovenosas gastrointestinales aparecen con la edad, siendo muy rara su desarrollo en personas jóvenes (Kjeldsen A et al., 2000)

No se han realizado estudios longitudinales sobre la historia natural de aparición de las manifestaciones clínicas y cómo puede variar entre los diferentes genotipos conocidos (Berg et al, 2003)

\section{Epistaxis}

La aparición espontánea de epistaxis de repetición es el síntoma más común de la enfermedad de Rendu-Osler y, en la mayoría de los pacientes, acaba provocando un cuadro anémico por déficit de hierro (Shah et al, 2002). Aparece antes de los 20 años en el 50\% de los pacientes, aunque entre el 78 y el 96\% del total de pacientes pueden padecerlas de forma eventual (Plauchu et al, 1989). En diferentes cuestionarios sobre calidad de vida presentados a los enfermos, este síntoma es considerado como un importante elemento negativo que limita el desarrollo de su actividad habitual, ya que lo padecen a lo largo de toda su vida en cualquier momento (Pasculli et al, 2004).

Se han aplicado diferentes técnicas en el tratamiento de este importante síntoma sin que ninguno haya sido realmente eficaz como para considerarlo apropiado en todos los enfermos. 
No hay una pauta establecida sobre la indicación del uso de terapias antiagregantes o anticoagulantes en estos pacientes cuando sea necesario, no existiendo a día de hoy un consenso claro entre los expertos, de manera que las conclusiones se basan en experiencias personales en el manejo de los enfermos. La única recomendación aceptada hoy día es la establecida por los autores de la "International Guidelines of the Diagnosis and Management of Hereditary Hemorrhagic Telangiectasia” (Faughnan et al, 2009) donde se define que la presencia de epistaxis asociadas a la enfermedad no es una contraindicación absoluta para el uso de este tipo de terapias y que, en cualquier caso, la decisión de su aplicación debe ser valorada de forma individualizada en función de los riesgos y beneficios que pueda causar, aconsejando consultar a un experto en O.R.L. a fin de establecer un plan de tratamiento en el caso de que se produzca un sangrado catastrófico y establecer un plan de medidas preventivas

\section{Malformaciones vasculares cerebrales (CVM)}

Bajo este término se agrupan diferentes variedades de malformaciones vasculares, clasificadas según su morfología (Ojemann et al, 1995):

a) malformaciones arteriovenosas (CAVM): incluyendo aquellas que miden menos de $1 \mathrm{~cm}$ (micro AVMs)

b) malformaciones cavernosas

c) angiomas venosos/anomalías del desarrollo venoso (DVA)

d) telangiectasias capilares/alargamiento tamaño vasos capilares

e) malformaciones de la Vena de galeno

f) fístulas de alto flujo en la pía (AVF)

g) malformaciones mixtas

Todas ellas pueden encontrarse en los pacientes afectos de HHT, aunque las más frecuentes son las CAVM, AVF, micro AVM y las telangiectasias (Krings et al, 2005).

Se cree que hasta el 23\% de los pacientes desarrollarán estas alteraciones (Maher et al, 2001; Fulbright et al, 1998), por lo que aplicar las técnicas de rastreo a los pacientes está justificado por la posibilidad de detectarlas precozmente, antes de que haya un compromiso vital o una potencial complicación (Morgan et al, 2000). 
El riesgo de sangrado se ha estimado en un $0.5 \%$ al año, aunque no hay estudios prospectivos que aclaren la historia natural de estas malformaciones en el curso de la enfermedad (Willemse et al, 2000). La tasa anual de ruptura se sitúa en un 2-4\% al año (MacDonald et al, 2001). Se piensa que las CAVMs y las AVF tienen un curso natural más agresivo que las demás (Morgan et al, 2000), siendo las telangiectasias capilares y las malformaciones venosas las más benignas (Matsubara et al, 2000; Morgan et al, 2002). Se han descrito pocos casos donde haya ocurrido un sangrado masivo en la infancia (Mei-Zahav et al, 2006) y son menos los casos descritos donde haya ocurrido una resolución espontánea (Leung et al, 2006; Cloft et al, 2002).

La mejor técnica para el diagnóstico de estas alteraciones es la angiografía mediante catéter, pero conlleva un riesgo de sangrado del 0.5\% (Willinsky et al, 2003). El uso de Resonancia Magnética Nuclear (RMN) es considerada una prueba no invasiva adecuada para el estudio de estas malformaciones, aunque no hay estudios que avalen su uso de forma sistemática en HHT ya que, aunque presenta una sensibilidad aproximadamente del 80-95\% para las malformaciones de tamaño medio-grandes, se encuentra muy limitada en el diagnóstico de las de pequeño tamaño, pudiendo aumentar este porcentaje con el uso de contraste intravenoso (Gauvrit et al, 2006; Mori et al, 2003; Mukherji et al, 1995), lo que también favorece la detección de signos de hemorragias asintomáticas (Cullen et al, 2006). Otra técnica diagnóstica empleada es el Doppler transcraneal (TCD), que presenta una sensibilidad cercana al 80\% para las malformaciones de mediano y gran tamaño. No existen evidencias suficientes para recomendar un seguimiento posterior a un estudio cuyo resultado ha sido negativo, ya que no hay evidencias que sugieran que los pacientes afectados de HHT vayan a desarrollar nuevas malformaciones cerebrales en el futuro.

En los niños, la detección de malformaciones cerebrales se realiza mediante Resonancia Magnética Nuclear, pues el riesgo de anestesia o sedación en ellos para poder realizar la angiografía es alto y se asume que la RMN presenta unos valores de seguridad y eficacia suficientes. Debe realizarse en el momento del diagnóstico y preferiblemente antes de cumplir los primeros 6 meses de vida (Lundby et al, 1996). Tampoco hay evidencias que recomienden un seguimiento en el futuro para aquellos casos donde el estudio inicial sea negativo. 
No hay evidencia en el manejo de estas malformaciones durante el embarazo ni en el parto y, en cualquier caso, las actuaciones deben diferirse hasta que el feto esté formado por completo.

\section{Malformaciones arteriovenosas pulmonares (PAVMs)}

Este tipo de malformaciones están presentes en aproximadamente el 15-50\% de los pacientes con HHT y están asociadas a múltiples y graves complicaciones (Gossage et al, 1998; Cottin et al, 2004). La razón para llevar a cabo una detección precoz es la posibilidad de detectar y tratar malformaciones antes del desarrollo de las complicaciones asociadas a las mismas.

Entre las posibles complicaciones podemos encontrar infartos, accidentes isquémicos transitorios, abcesos cerebrales, hemoptisis masiva y hemotórax espontáneo (Gossage et al, 1998; Moussouttas et al, 2000). Las complicaciones neurológicas pueden surgir en el contexto de rupturas espontáneas de malformaciones pulmonares. En niños también se han podido demostrar estas alteraciones (Faughnan et al, 2004), así como durante el embarazo (Shovlin et al, 1995), donde el riesgo puede estar aumentado.

Para establecer el diagnóstico de estas alteraciones se han ensayado numerosas técnicas, entre las que se incluyen métodos fisiológicos de medida de comunicación (shunt) intrapulmonar, así como múltiples métodos de imagen. En comparación con las técnicas de referencia conocidas (TAC y angiografía pulmonar), la mejor técnica de estudio es la Ecocardiografía de Contraste Transtorácico (TTCE) mediante suero salino agitado, debido a su alta sensibilidad y su bajo riesgo de aplicación (Nanthakumar et al, 2001; Barzilai et al, 1991). El test se considera positivo si se detectan burbujas en la aurícula izquierda y, en estos casos, debe confirmarse la alteración mediante TAC torácico. En niños, esta comparación no ha sido estudiada y la aplicación de test diagnósticos debe individualizarse, empleando bien una evaluación clínica (cianosis, disnea...) o una pulsioximetría comparada en supino y decúbito, Rx simple torácica, e incluso TAC torácico.

En los casos donde se aprecie la presencia de estas malformaciones, se recomienda el uso de profilaxis antibiótica cuando se lleven a cabo procedimientos invasivos, debido al riesgo elevado de desarrollar abcesos cerebrales, debiendo tener especial cuidado si se realiza un acceso venoso para evitar la entrada de aire que pueda 
provocar embolismos gaseosos cerebrales. Además, estos pacientes deben evitar las técnicas de buceo tipo SCUBA, por el riesgo teórico de descompresión

En pacientes donde el estudio inicial haya sido negativo, se recomienda repetirlo después de la pubertad y después de cada embarazo. En el caso de los embarazos planificados, debe realizarse el estudio antes del mismo y mantener controles cada 5-10 años. Si se ha realizado embolización de las malformaciones, debe realizarse el estudio entre los 6 y 12 meses posteriores a la técnica y repetirlo cada 3 años a partir de entonces.

\section{Sangrado Gastrointestinal}

Apróximadamente el $80 \%$ de los pacientes con HHT presentan pequeñas telangiectasias a nivel gástrico o duodenal cuando se realiza un estudio mediante endoscopia (Ingrosso et al, 2004), aunque sólo el 25-30\% de ellos presentarán sintomatología derivada del sangrado de las mismas (Kjeldsen et al, 2000; Vase et al, 1986; Plauchu et al, 1989) y cuando se produce no suele suceder hasta la quinta o sexta décadas de la vida. Las mujeres están más afectadas que los hombres, con una diferencia aproximada de 2-3 casos por cada varón afecto (Longacre et al, 2003; Proctor et al, 2005).

Los pacientes con este tipo de sangrados pueden presentar sintomatología o no, pero el tipo de sangrado suele ser lento, crónico e intermitente en el tiempo, sin producir melenas en gran cantidad. Generalmente, suelen presentar pocos síntomas hasta el desarrollo de la anemia. En los casos de sangrado severo, la mortalidad es mayor y generalmente requieren transfusiones sanguíneas frecuentes (Longacre et al, 2003). La severidad del sangrado se suele medir en función de la severidad de la anemia que produzca y se sabe que las telangiectasias son más comunes a nivel gástrico y duodenal que a nivel colónico, lo que contribuye a que dicha anemia sea mayor, debido a la facilidad de sangrado a ese nivel (Proctor et al, 2001).

A día de hoy se considera que la técnica óptima en el diagnóstico de este tipo de alteración es la evaluación mediante endoscopia, pues es especialmente útil en pacientes con anemia por sangrado o por déficit de hierro. Gracias a ella podemos conocer el número de telangiectasias presentes a nivel gástrico y duodenal y en función de éste, predecir las que van a existir a nivel yeyunal, de manera que en la mayoría de pacientes, 
con realizar una endoscopia a nivel esófago-gastro-duodenal es suficiente para llegar al diagnóstico (Proctor et al, 2005).

\section{Malformaciones vasculares hepáticas}

En el momento actual, el diagnóstico y manejo de este tipo de complicaciones se rige por una guía de consenso publicada en el año 2006, la cual es aceptada internacionalmente por el conjunto de expertos en HHT (Buscarini et al, 2006).

Las malformaciones arteriovenosas hepáticas están presentes en el 32-78\% de los pacientes (Memeo et al, 2005; Ravard et al, 2004). Aunque no hay descrita una relación clara entre la historia natural de aparición de estas malformaciones y la enfermedad, se sabe que sólo el 8\% de los que las padecen presentan manifestaciones clínicas asociadas (Buscarini et al, 2004; Ocarn et al, 2004; Ianora et al, 2004) entre las que se incluye fallo cardiaco por alto gasto, hipertensión portal y necrosis biliar (GarciaTsao et al, 2000).

En pacientes con clínica sugerente de malformaciones hepáticas, es importante establecer el diagnóstico precoz para llevar a cabo las medidas terapeúticas correspondientes, así como establecer medidas preventivas. La aparición de estas malformaciones en un paciente también puede ayudar al propio diagnóstico de la enfermedad, pues uno de los criterios usados es la presencia de alteraciones viscerales (Shovlin et al, 2000)

Para llevar a cabo el diagnóstico se han utilizado múltiples pruebas de imagen, tanto de tipo invasivo como no invasivo, entre las que destacan la Ultrasonogarfía con Doppler (US), Resonancia Magnética Nuclear (RMN), Tomografía Axial Computerizada (TAC) y la Angiografía Mesentérica, siendo ésta última prueba la que se considera óptima, aunque debido precisamente a este carácter invasivo, apenas se usa en favor del Doppler, que no requiere contraste y presenta menor tasa de complicaciones.

Entre los diferentes tipos de malformaciones encontradas, destacan las telangiectasias, la dilatación de la arteria hepática y las comunicaciones o "shunts” entre los diferentes vasos (arterioportales, arteriovenosas y portovenosas) (Hashimoto et al, 2003; Matsumoto et al, 2004; Bernard et al, 1993).

No hay estudios que permitan establecer el grado de sensibilidad o especificidad de las diferentes pruebas, aunque el valor predictivo positivo del Doppler es cercano al 
100\% y permite describir entre el 32 y el 72\% de las malformaciones (Buscarini et al, 2004; Ocarn et al, 2004), frente al 67-78\% que se consigue con el TAC (Memeo et al, 2005; Ravard et al, 2004), lo que hace pensar que la sensibilidad de estas pruebas es alta. En niños no se han realizado estudios de despistaje suficientes como para obtener conclusiones.

El diagnóstico histológico no es necesario, ya que actualmente las técnicas de imagen permiten detectar la hiperplasia nodular focal, que es la alteración tisular más característica en estos enfermos, sin necesidad de realizar una biopsia, lo que conllevaría un claro riesgo de hemorragia (Buscarini et al, 2004).

\subsection{DIAGNÓSTICO}

Hacer un diagnóstico de HHT en un paciente permite aplicar diferentes tipos de tratamiento preventivo tanto en el propio paciente como en los miembros de su familia que se encuentren afectados.

Tradicionalmente, el diagnóstico de esta enfermedad se hacía en función de la clínica que presentasen los pacientes. Hoy día las perspectivas han cambiado y es posible hacer el diagnóstico basándonos también en test genéticos.

\section{Diagnóstico clínico}

En el año 2000, un grupo de expertos se reunió en la Isla de Curaçao, donde establecieron una serie de criterios que sirvieran de base para llevar a cabo el diagnóstico clínico de esta enfermedad de forma consensuada (Shovlin et al, 2000). De este modo, los “Criterios de Curaçao” son los usados actualmente para llevar a cabo el diagnóstico clínico de HHT:

- Epistaxis: espontáneas y recurrentes

- Telangiectasias: múltiples y en sitios característicos (labios, cavidad oral, dedos, nariz)

- Lesiones viscerales: telangiectasias gastrointestinales, malformaciones arteriovenosas pulmonares, hepáticas o cerebrales

- Historia familiar: pariente de primer grado con HHT diagnosticado según los criterios expuestos 
En función de la clínica manifestada, el diagnóstico se considera “definitivo” si presenta 3 o más criterios, "posible o sospechoso" si presenta 2 de estos criterios e “incierto” si están presentes menos de 2 criterios.

No hay estudios que establezcan el grado de sensibilidad o especificidad de estos criterios, pero los expertos señalan que son especialmente útiles en dos situaciones:

- Discriminar qué pacientes adultos están afectados de los que no lo están

- Diagnostico en adultos jóvenes y niños

El riesgo de que no se diagnostique la enfermedad en adultos jóvenes y niños es alto, debido a que pueden no haber iniciado aún la clínica característica de HHT, por lo que en estos grupos es especialmente útil el diagnóstico mediante test genéticos.

\section{Diagnóstico genético}

El objetivo de los test genéticos es identificar mutaciones causantes de HHT en una familia concreta, permitiendo el diagnóstico entre los diferentes familiares, especialmente niños y adultos jóvenes que no cumplan aún los criterios clínicos.

El test genético se aplica primero en el caso "índice” y se basa en la secuenciación del DNA buscando posibles alteraciones en los exones codificantes de los genes Endoglina (ENG), responsable de la primera variante conocida de la enfermedad (HHT1) y Activin A receptor type II-like 1 (ACVRL1 o ALK-1), responsable de la segunda variante conocida (HHT2). La mayoría de las mutaciones se han descrito en estos dos genes, aunque se sabe que hay al menos otros dos loci en los cromosomas 5 y 7 que podrían causar la enfermedad pero aún no se han identificado (Cole et al, 2005; Bayrak-Toydemir et al, 2006). Las mutaciones en el gen SMAD4 son responsables de un síndrome raro donde se combinan HHT y poliposis juvenil (Gallione et al, 2004).

El análisis de las secuencia de los genes ENG y ALK-1 permite encontrar aproximadamente el 75\% de las mutaciones causantes de HHT, valor que se incrementa en un $10 \%$ cuando se aplica un método adicional de detección para grandes delecciones y duplicaciones (Bossler et al, 2006; Prigoda et al, 2006). También se cree que entre el 1 y el 3\% de los pacientes diagnosticados clínicamente de HHT presentarán mutación en SMAD4, lo que correspondería al 10\% de aquellos pacientes donde el estudio para ENG y ALK-1 es negativo (Prigoda et al, 2006; Gallione et al, 2006; Lesca et al, 2006). 
Existe un solapamiento entre las manifestaciones clínicas presentadas por los pacientes con mutaciones en los genes ENG y ALK-1 (Kjeldsen et al, 2005; Letteboer et al, 2006; Bayrak-Toydemir et al, 2006), de modo que los expertos recomiendan no hacer diferencias en cuanto a la búsqueda de malformaciones vasculares si se encuentran mutaciones en uno u otro gen. A pesar de ello, sabemos que en HHT1 predominan las alteraciones pulmonares y cerebrales, frente a la mayor afectación hepática y pancreática en HHT2 (Kjeldsen AD et al., 2005; Letteboer TGW et al., 2006; Bayrak-Toydemir P et al., 2006; Sabba C et al., 2007; Lacout A et al., 2010). La mayoría de los pacientes con mutación en el gen SMAD4 presentan mayor riesgo de padecer alteraciones en el tracto gastrointestinal (Gallione et al, 2004; Prigoda et al, 2006; Gallione et al, 2006). La aparición de hipertensión pulmonar secundaria a la presencia de malformaciones pulmonares es exclusiva de HHT2 (Girerd B et al., 2010).

En el momento actual no hay evidencia sobre el impacto de los test genéticos prenatales, pues no se conoce cómo puede afectar el diagnóstico fetal de HHT sobre el curso del embarazo y el manejo sobre el mismo. Los expertos recomiendan que sea considerado como una alternativa al diagnóstico postnatal cuando ya exista otra razón para llevarlo a cabo.

\subsection{TRATAMIENTO}

El objetivo del tratamiento en los enfermos de HHT consiste en optimizar el manejo de las complicaciones.

Como recomendación general, los pacientes que presenten manifestaciones clínicas deben ser revisados por servicios especializados en el manejo de las mismas. En los pacientes asintomáticos, el objetivo debe ser la educación sanitaria (incluyendo recomendaciones sobre cuidados dentales y durante el embarazo) y hacerles partícipes de los programas de detección de malformaciones establecidos.

\section{Epistaxis}

a) Terapias no invasivas: se centran en mantener la integridad de la mucosa nasal con medidas como la humidificación, que favorece la protección de la cubierta endonasal, evitando que el flujo aéreo dañe la telangiectasia nasal y se produzca el sangrado. También se han empleado medicamentos tópicos intranasales (como lubricantes, antifibrinolíticos, cremas o aceites con estrógenos, etc) pero la 
evidencia sobre su efectividad es escasa (McCaffrey et al, 1977; McCabe et al, 1972; Bergler et al, 2002; Klepfish et al, 2001).

b) Terapias invasivas: en este grupo se incluyen procedimientos como láser endonasal, coagulación química o eléctrica, dermoplastia, embolización de arteria nasal y cierre de cavidad nasal (técnica de Young). La mayoría de las técnicas de coagulación son de bajo riesgo, causando una mejoría subjetiva en los pacientes (Mahoney et al, 2005; Karapantzos et al, 2005; Bergler et al, 1999). La cauterización química y el láser con CO2 genera peores resultados, incrementando el riesgo de sangrado intraoperatorio (McCaffrey et al, 1977). La embolización de la arteria nasal es poco usada, ya que su efecto es poco duradero y en pacientes con anemia crónica se ha observado un resangrado (Fischer et al, 1997; Elden et al, 1994). Otras opciones terapéuticas se han basado en la inyección de diferentes substancias a nivel submucoso o intravascular, aunque se han descrito casos de reacciones alérgicas severas y ceguera secundarios (Borsik et al, 1992; Jankowski et al, 1992). Otra opción consiste en realizar cirugía nasal, aplicando las técnicas empleadas para el control de otros síntomas. También existen dos estudios basados en el empleo de ácido tranexámico y de estrógenos, aunque los resultados no han sido muy satisfactorios (Vase et al, 1981; Geisthoff et al, 2006).

c) Manejo urgente: no hay estudios bien diseñados, aunque la tendencia es usar balones neumáticos que, tras lubricar adecuadamente, se introducen en la cavidad nasal y mediante la aplicación de bajas presiones, se consigue controlar el sangrado causando el mínimo daño isquémico en la mucosa.

\section{Malformaciones vasculares cerebrales}

No hay publicados estudios sobre la eficacia o la seguridad de ningún tratamiento en este campo. Lo que sugieren los expertos es que la obliteración de este tipo de malformaciones es necesaria para eliminar el riesgo de una posible hemorragia.

Se han ensayado diversos procedimientos, tales como embolización, microcirugía o radiación estereotáctica (Morgan et al, 2000; Berman et al, 19999; Lunsford et al, 1991; Suzuki et al, 1982; Yoshimoto et al, 1986; Spetzler et al, 1987) aplicados tanto de forma aislada como combinando varios de ellos y lo que parece 
seguro es que todos ellos deben aplicarse en centros con acreditada experiencia y siempre tomando la decisión de forma individualizada para cada caso.

En niños, especialmente antes de los 6 años, la mayoría de las malformaciones se transforman en fístulas de alto flujo (Krings et al, 2005), cuyo curso natural es más agresivo que otros tipos de malformaciones, causando alteraciones secundarias del tipo hemorragia cerebral, déficit cognitivo, insuficiencia cardiaca, epilepsia e hidrocefalia (Morgan et al, 2002; Weon et al, 2005; Yoshida et al, 2004). En estos casos, tanto la embolización como la microcirugía podrían aportar importantes beneficios para el paciente.

\section{Malformaciones arteriovenosas pulmonares}

La embolización ha resultado eficaz y aporta un buen perfil de seguridad, presentando mínimas complicaciones durante el seguimiento realizado en los siguientes 5 a 10 años a su aplicación (Mager et al, 2004; Pollak et al, 2006; Dutton et al, 1995; Chilvers et al, 1990; Gupta et al, 2002).

La seguridad y eficacia es similar tanto en adultos (Lee et al, 1997) como en niños (Faughnan et al, 2004), donde hay estudios incluso por debajo de los 4 años de edad.

La experiencia es escasa durante el embarazo (Gershon et al, 2001), donde el riesgo es mayor.

El seguimiento se realiza mediante técnicas de Tomografía Axial Computerizada (TAC), permitiendo la detección de reperfusión al año de la embolización y el crecimiento de pequeñas malformaciones residuales (Pollak et al, 2006).

\section{Sangrados gastrointestinales}

El manejo de este tipo de alteraciones se basa en medidas agresivas de reposición de hierro, mediante transfusiones sanguíneas periódicas en casos donde haya anemia ferropénica importante. No hay muchos estudios al respecto, pero los expertos piensan que el aporte oral de hierro es suficiente en los casos leves. No hay evidencias sobre el uso de eritropoyetina, aunque su uso puede ser considerado como adyuvante en casos extremos para acelerar el proceso de recuperación. 
Otras opciones se basan en la aplicación de terapias hormonales, mediante preparados de estrógenos más progesterona (van Cutsem et al, 1990) o con danacrina (Haq AU et al, 1988), antifibrinolíticos (ácido aminocaproico, ácido tranexámico) (Korzenik et al, 1994) y terapias endoscópicas, mediante el uso de coagulación con láser de Argón o con láser de ND-YAG (Bown et al, 1985; Sargeant et al, 1993). Se han informado casos aislados de tratamiento con tamoxifeno, interferón, thalidomida y sirolimus.

No hay evidencia sobre la necesidad de cambios en el estilo de vida ni en la dieta, ni para el screening de H. pylori.

Se recomienda evitar el uso de anticoagulantes y antiagregantes plaquetarios, aunque, si existe comorbilidad asociada, su uso puede tolerarse manteniendo dosis lo más bajas posibles.

En el momento actual no hay evidencia suficiente para recomendar el empleo de una u otra técnica como primera línea de tratamiento.

\section{Malformaciones vasculares hepáticas}

Existen dos técnicas de tratamiento: la embolización de la arteria hepática y el transplante de hígado.

Mediante la embolización parece controlarse el riesgo de fallo cardiaco por alto gasto y de isquemia mesentérica; sin embargo, este efecto es transitorio, ya que la mayoría de las veces el problema recurre (Chavan et al, 2004).

El transplante hepático está indicado cuando surjan complicaciones isquémicas (colangitis, colecistitis y necrosis hepática, principalmente), sin embargo, aunque la mayoría de los síntomas del paciente se resuelven con este tratamiento (Azoulay et al, 2002; Lerut et al, 2006), conlleva mayores requerimientos de transfusiones sanguíneas, mayor estancia hospitalaria y una alta tasa de complicaciones postoperatorias. Su aplicación debe reservarse para casos rebeldes y muy agresivos.

En cualquier caso, la supervivencia a los 5 años es del 83\% (Lerut et al, 2006). 


\section{BASES MOLECULARES}

\subsection{CONCEPTOS BÁSICOS}

\section{Pared vascular}

La pared vascular es un órgano activo, flexible e integrado por componentes celulares, como las células endoteliales, células musculares lisas y fibroblastos y componentes no celulares, como la matriz extracelular. Estos componentes modifican su forma, aumentan, disminuyen su tamaño o se reorganizan en respuesta a estímulos tanto fisiológicos como patológicos, manteniendo así la integridad del vaso o participando en las alteraciones vasculares que aparecen en enfermedades como la hipertensión y la aterosclerosis (Touyz RM, 2000). En la figura 1 se muestra de forma esquemática la organización de estos componentes:

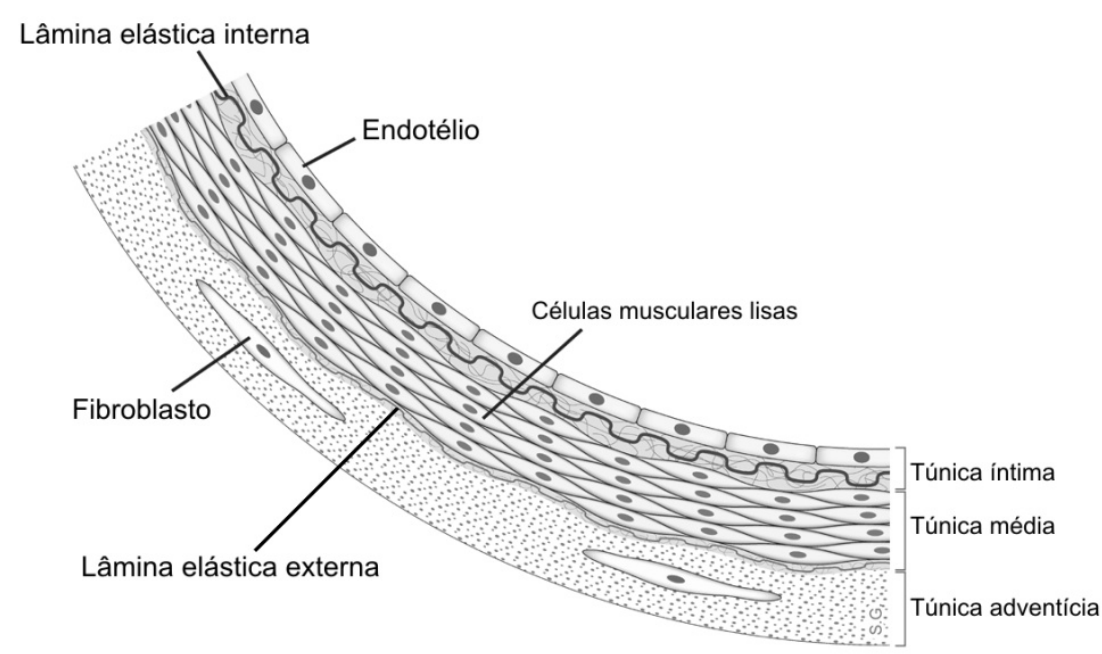

Figura 1. Componentes de la pared vascular

- Túnica Íntima. Constituida por el endotelio, una lámina basal y una capa conjuntiva subendotelial.

- Endotelio. Comprende una monocapa de células polarizadas con regiones de la superficie celular especializadas. Sirve para proveer al vaso sanguíneo de una capa de revestimiento no trombogénica formada por células que contactan entre sí y que en la superficie basal contactan con la membrana basal subyacente.

- Túnica media. Contiene células musculares lisas, en forma de huso, que forman una capa alrededor de la circunferencia del vaso. Estas células musculares lisas están recubiertas, de forma individual, por la membrana 
basal y dentro de la capa media están encastradas y conectadas a una red o malla de matriz extracelular.

- Membrana basal. Compuesta de diversas sustancias como laminina, colágeno tipo IV, proteoglicanos y heparán sulfato

- Matriz extracelular. Es el soporte estructural y funcional al cual se adhieren las células y sobre el cual proliferan, migran y se diferencian. La matriz extracelular está compuesta por una serie de sustancias entre las que se encuentran fibronectina, trombospondina, colágenos tipo I y III, proteoglicanos, laminina y condroitín dermatán sulfato, comportándose como un sistema biológicamente activo, siendo necesario un balance adecuado entre sus componentes para el funcionamiento normal de la vasculatura.

- Túnica adventicia. Compuesta fundamentalmente por fibroblastos y colágeno, últimamente han surgido evidencias que permiten atribuirla un papel potencial en la regulación de la función del óxido nítrico y en la fisiología vascular (Zhang $\mathrm{H}$ et al, 1999; Muller B et al, 2000, Ghosh M et al, 2004)

- Lámina elástica interna y externa. Limitan las tres capas entre sí.

Todos estos componentes de la pared vascular han adquirido importancia como protagonistas de los cambios que sufren los vasos en las diversas enfermedades y han dejado de ser considerados simples estructuras constituyentes de la pared vascular a medida que se ha ido conociendo su capacidad para producir sustancias o responder a ellas.

\section{Remodelamiento vascular}

El remodelamiento vascular es un fenómeno que aparece en muchas situaciones asociadas a cambios vasculares e incluye aquellas modificaciones estructurales en la pared de los vasos que dan lugar a una alteración de la relación existente entre el espesor de la pared y el diámetro de la luz vascular. Estos cambios pueden no estar relacionados con un crecimiento neto, sino con un proceso de reacomodamiento del material de la pared, especialmente a expensas de las células musculares lisas de la capa media. 
El remodelamiento vascular puede ocurrir de dos maneras, en función de lo que se vea afectado, el diámetro de la luz del vaso o el material de la pared. Si es la luz del vaso la que aumenta, hablaremos de crecimiento externo y si ésta disminuye, crecimiento interno. Del mismo modo, si existe un crecimiento neto de ambas estructuras a expensas de la capa media, hablaremos de remodelamiento hipertrófico, si no hay alteración del tamaño neto, manteniéndose constante el tamaño de la capa media, lo denominaremos eutrófico y si hay una pérdida neta de tejido a expensas de una disminución en el tamaño de la capa media, el remodelamiento se denominará hipotrófico (figura 2).

El remodelado interno eutrófico e hipertrófico asocia siempre un aumento del grosor de la pared, con un incremento de la relación entre el grosor de la pared y la luz del vaso. En cambio, en el remodelado externo eutrófico e hipotrófico, ocurre justo lo contrario

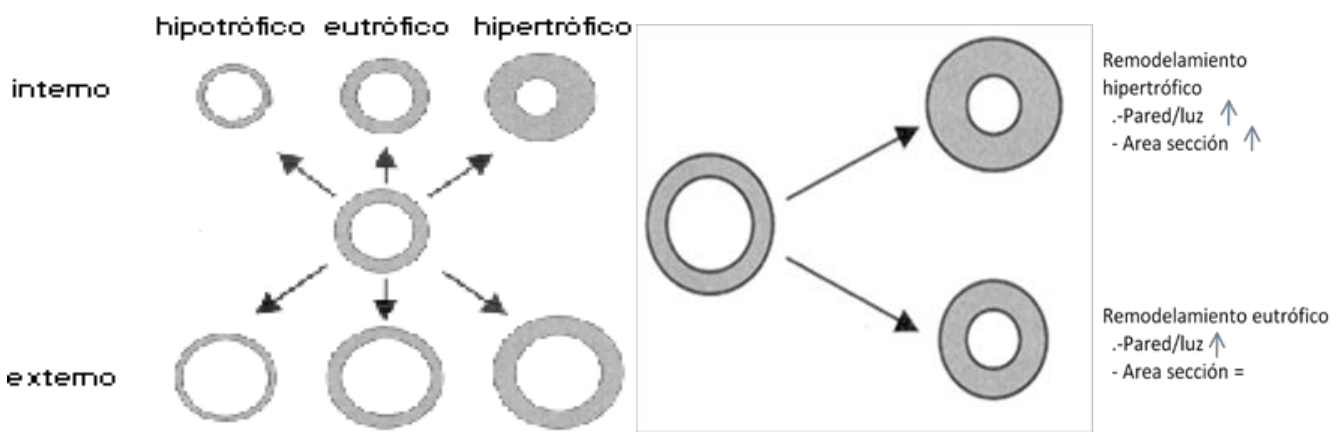

Figura 2: tipos de remodelamiento vascular

En el remodelado vascular eutrófico la pared vascular se reestructura de modo que las células musculares lisas se alinean más cerca y encierran la luz del vaso, aunque no haya cambios en el volumen de la capa media. El mantenimiento del volumen de la capa media puede ser consecuencia de una combinación de procesos de proliferación hacia adentro, con reducción de la luz y apoptosis en la periferia del vaso, y disminución del diámetro externo.

En el remodelado vascular hipertrófico hay proliferación o crecimiento de la media vascular, lo cual conduce a una disminución de la luz y esto puede ser debido a 
un aumento del número de células (hipertrofia), un aumento del tamaño de las células (hiperplasia) o a ambos procesos.

Los principales factores asociados con el remodelado hipertrófico, es decir, con la proliferación de las células musculares lisas, son cuatro:

- Presión arterial. A través de receptores del estiramiento en la pared vascular y por la presión de pulso.

- Factores nerviosos. Aumenta la actividad nerviosa simpática que ejerce su acción hipertrófica a través de estímulos tróficos.

- Factores genéticos. Se han observado cambios estructurales en arterias de resistencia de modelos experimentales (como las ratas espontáneamente hipertensas, donde el sistema renina-angiotensina juega un papel importante) antes del desarrollo de la hipertensión y en la vida fetal se expresan varios protooncogenes (c-fos, c-myc y c-fun) que llevan al aumento de la proliferación.

- Factores humorales. Se conocen múltiples sustancias de origen sistémico y/o local que pueden participar en el proceso de hipertrofia de la pared vascular. Los principales elementos involucrados en el proceso de remodelamiento son la angiotensina II, la aldosterona, las endotelinas $\left(E_{1} \mathrm{y} \mathrm{ET}_{3}\right)$ y el factor transformador del crecimiento- $\S_{1}$ (TGF- $\beta 1$ ), como factores estimulantes del crecimiento celular y las kininas, las prostaglandinas y el óxido nítrico como factores con efectos antiproliferativos (Chrysant SG, 1998) 


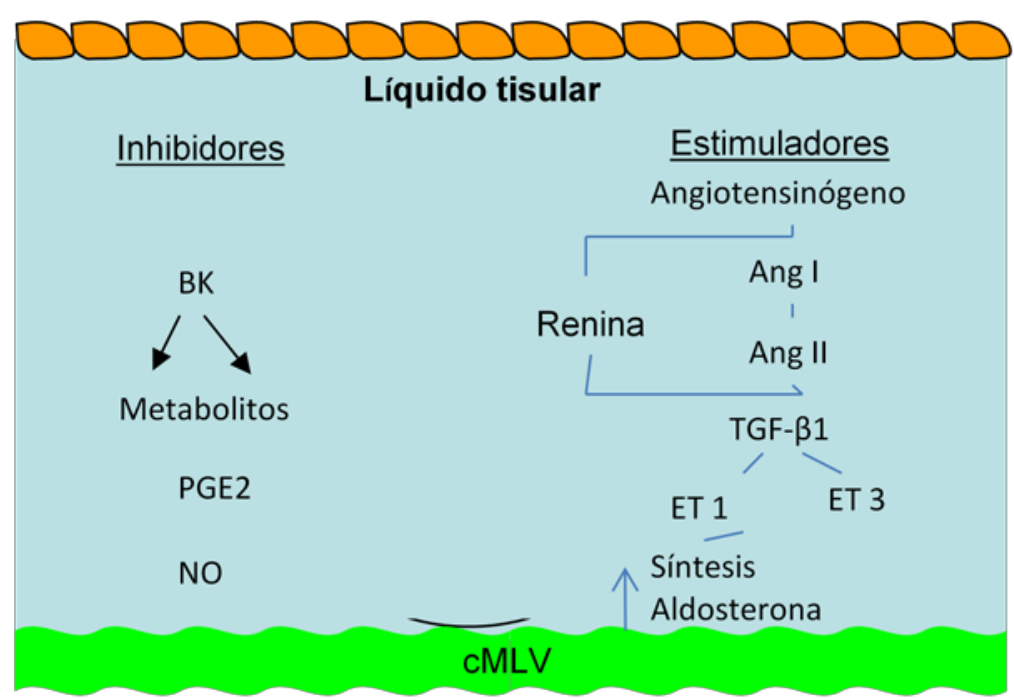

Figura 3: Factores asociados con las células lisas de la pared vascular. NO: oxido nítrico; Ang: angiotensina; PGE2: prostaglandina E2; BK: bradicinina; cMLV: capa de músculo liso vascular; ET: endotelinas; TGF- $\beta$ : factor transformador de crecimiento tipo beta

\section{Matriz extracelular}

La matriz extracelular es la responsable de las propiedades mecánicas de la pared vascular y también está implicada en procesos biológicos tales como la adhesión celular, la proliferación y la migración.

En la arteria normal, los principales constituyentes de la íntima, la media y la adventicia son los colágenos fibrilares tipos I y III, mientras que los colágenos IV y V se sitúan en las membranas basales del endotelio y del músculo liso vascular junto con los tipos I y III. Los proteoglicanos son componentes no fibrilares de la matriz extracelular que tienen una o más cadenas de glicosaminoglicanos; son sintetizados por las células musculares lisas del vaso en respuesta a factores de crecimiento, regulan varias actividades celulares, como la proliferación, la diferenciación, la adhesión y la migración y controlan la biodisponibilidad y la estabilidad de las citoquinas, proteínas responsables de la comunicación intercelular.

Las interacciones funcionales y estructurales entre las proteínas de la matriz y las células musculares lisas, a través de moléculas de adhesión, son importantes en el mantenimiento de la integridad de la pared vascular. Las alteraciones en estas 
interacciones, posiblemente por modificaciones en los sitios de unión celular, podrían contribuir en los cambios en la rigidez de la media vascular.

Se ha propuesto que, debido a cambios en los componentes de la matriz y de los correspondientes receptores de adhesión, las interacciones entre las células musculares lisas del vaso y las proteínas de matriz se modifican cuantitativa y/o topográficamente, produciéndose una reacomodación de las células musculares lisas y una reestructuración de la pared vascular.

Las integrinas actúan como puntos de unión entre la matriz y el citoesqueleto y también como receptores de señales, siendo posible que el remodelado vascular involucre cambios en estos sitios de anclaje.

\section{Angiogénesis}

La angiogénesis es un fenómeno que puede ser estudiado como integrado por dos fases diferentes equilibradas entre ellas; una primera fase de activación y otra posterior, denominada fase de resolución, donde tiene lugar la inhibición de la proliferación y la migración de células endoteliales, la reconstitución de la membrana basal y la estabilización del vaso mediante reclutamiento y diferenciación de las células mesenquimales dentro de los pericitos y células musculares lisas. Este reclutamiento de células mesenquimales en el nuevo vaso está mediado por numerosos factores, entre los que se encuentra el receptor TGF- $\beta$. Al contactar la célula mesenquimal con la célula endotelial, el receptor TGF- $\beta$, que estaba latente, queda activado y esto es lo que induce la diferenciación de las células mesenquimales dentro de los pericitos y células musculares lisas. Los pericitos contribuyen en parte a la supervivencia y estabilización mediante la expresión del factor de crecimiento del endotelio vascular (VEGF). Diversos estudios han demostrado que el incremento de producción del VEGF por los pericitos es dependiente, en las células de contacto heterotípicas, mediante la producción del TGF- $\beta$ activo.

\subsection{GENES IMPLICADOS}

Hasta el momento se han identificado 3 genes implicados en la patogenia de la enfermedad: 
- Endoglina (ENG; MIM \# 131195): localizado en el brazo largo del cromosoma 9 (posición 9q34.1) y responsable de la variante HHT 1 (OMIM: 187300)

- ALK1 (ACVRL1; MIM \# 601284): localizado en el brazo largo del cromosoma 12 (posición 12q11q14) y responsable de la variante HHT 2 (OMIM: 600376)

- SMAD4 (MADH4; MIM \# 600993): localizado en el brazo largo del cromosoma 18 (posición 18q21.1) y responsable de una rara variante que asocia HHT con poliposis juvenil (JPHT; OMIM: 175050 )

Se tiene conocimiento de que, al menos, existen otros dos genes aún no identificados que podrían causar la enfermedad (Govani et al, 2009):

- HHT 3: localizado en el brazo largo del cromosoma 5, entre las posiciones D5S2011 y D5S2490

- HHT 4: localizado en el brazo pequeño del cromosoma 7, entre las posiciones D7S2252 y D7S510

Tabla 1. Clasificación HHT

\begin{tabular}{|ccc|}
\hline GEN & VARIANTE & CROMOSOMA \\
\hline ENG & HHT1 & 9 \\
\hline ALK1 & HHT2 & 12 \\
\hline SMAD4 & JPHT & 18 \\
\hline- & HHT3 & 5 \\
\hline- & HHT4 & 7 \\
\hline
\end{tabular}

La mayoría de pacientes (>80\%) presentan mutación en los genes ENG o ALK1, siendo entre ellos más común en ENG (61\% del total) que en ALK1 (37\%). Se cree que un 2\% de los pacientes tendrán mutación en SMAD4.

La predominancia de mutaciones en uno u otro gen también muestra variedades geográficas dentro de Norte América y Europa, aunque no está muy claro si esta variación es natural o viene inducida por los estudios realizados en los propios centros de referencia (Lesca et al, 2007; Bayrak-Toydemir et al, 2006; Sabbá et al, 2007; Bossler et al, 2006). 
Existen más de 600 mutaciones diferentes descritas en ambos genes que presentan una característica excepcional: ningún gen muestra una mutación común o frecuente en la población, siendo descritas la mayoría de las mismas una única vez.

El tipo de mutación descrita en los genes ENG y ALK1 incluye delecciones, inserciones, mutaciones de cambio de sentido, mutaciones sin sentido y mutaciones en la zona promotora.

Las mutaciones descritas hasta la fecha en SMAD4 se localizan en los últimos 4 exones del gen (del 8 al 11), en el dominio MH2, e incluyen las de pérdida de sentido, cambio de sentido y mutaciones en el marco de lectura (frameshift), siendo la mayoría de ellas mutaciones no descritas anteriormente (Gallione et al, 2004; Gallione et al, 2006). No obstante, estudios recientes demuestran la posibilidad de encontrar mutaciones en otras regiones del gen diferentes al dominio MH2 (Gallione C et al., 2010).

El funcionamiento normal de las proteínas derivadas de los genes ENG, ALK1 y SMAD4 es fundamental para evitar el desarrollo de un fenotipo similar al que aparece en los enfermos con HHT y es probable que haya diferencias en los requerimientos habituales de las tres proteínas en los diferentes tipos de lecho vascular y tipos celulares.

\section{Endoglina (ENG)}

Los primeros estudios realizados para determinar la región del genoma donde se encuentra la alteración responsable de la primera variante de la enfermedad de RenduOsler (HHT1; OMIM 187300), localizaron la zona afectada en el brazo largo del cromosoma 9, entre las posiciones 9q33 y 9q34.1, que era la zona donde años antes se había localizado el gen de la Endoglina, estableciéndose así una relación directa entre ambos hallazgos y responsabilizando a este gen de la aparición de la enfermedad.

La endoglina fue descrita en 1990 (Gougos et al, 1990) como una glicoproteína integral de membrana tipo I, que forma un homodímero unido mediante enlace covalente, con un peso molecular de $180 \mathrm{kDa}$, compuesto por una cadena polipeptídica de 68 kDa y por puntos de glicosilación de tipo nitrogenado y oxigenado. Presenta 17 residuos cisteína y la mayoría de las mutaciones descritas en este gen provocan una inestabilidad estructural y una pérdida de función de la proteína. 
La proteína ENG está compuesta de 658 aminoácidos distribuidos de la siguiente manera: una pequeña región hidrofóbica inicial (residuos 1-25), un largo dominio extracelular (EC) que agrupa los aminoácidos 26 al 586, una región transmembrana (TM) también hidrofóbica de 25 aminoácidos y finalmente, un pequeño dominio citosólico (CYTO) que agrupa los residuos 612 al 658 fuertemente fosforilado, especialmente en los residuos serina (Lastres et al, 1994; Richards-Yutz et al, 2010)

El gen de la Endoglina consta de 14 exones (con el exón 9 desdoblado en 9a y 9b) y, hasta la fecha, prácticamente todas las mutaciones conocidas se concentran en los primeros 12 exones (que codifican el dominio extracelular). El número total de mutaciones descritas por exón es similar en todos, excepto en los exones 1, 9b y 12, que son de menor tamaño. En el exón 13, responsable de codificar el dominio transmembrana, sólo se han descrito 3 mutaciones, mientras que en el exón 14 (responsable del dominio citoplasmático) aún no se han descrito alteraciones (figura 4).

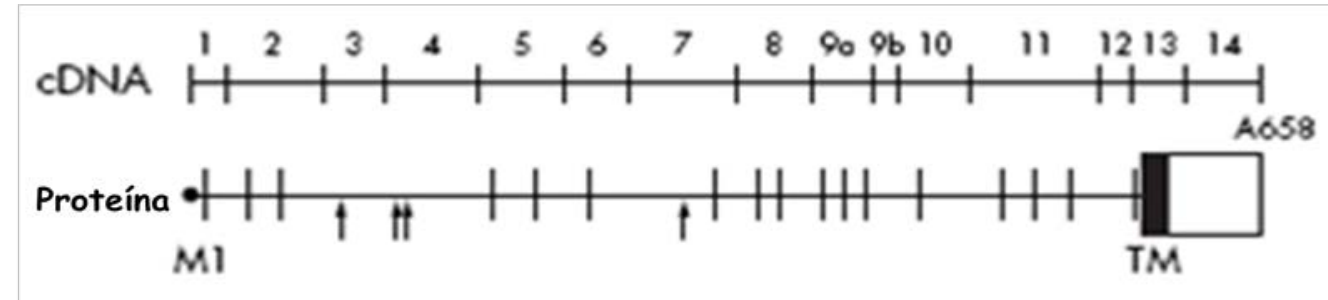

Figura 4. Exones de Endoglina

La mayoría de las mutaciones descritas en el gen ENG (80\%) causan codones de parada prematuros y polipéptidos truncados. Inicialmente se pensó que estas proteínas mutantes podrían secretarse a nivel local, ejerciendo un efecto dominante negativo, alterando la función normal de la Endoglina (McAllister et al, 1994; McAllister et al, 1995). Sin embargo, los estudios posteriores mostraron que los niveles de proteína mutada que se expresaban eran muy escasos y que, cuando lo hacían, no afectaban a la superficie celular (Shovlin et al, 1997; Paquet et al, 2001; Pece et al, 1997). También se ha demostrado que la mayoría de mutaciones que generan un cambio en el marco de lectura (frame shift) o una proteína truncada, probablemente producen una pérdida de sentido y niveles muy reducidos de mRNA, con lo que la proteína resultante será muy inestable (Frischmeyer et al, 1999). 
Hoy día, casi todas las mutaciones de cambio de sentido (missense) se consideran como polimorfismos (Letteboer et al, 2005; Abdalla et al, 2005; Cymerman et al, 2003; Brusgaard et al, 2004).

Respecto a la región promotora de la Endoglina, diversos estudios han confirmado que su actividad es estimulada por TGF- $\beta 1$, sin embargo, aún no está claro si todas las mutaciones en esta región son responsables de HHT1 ni cuáles son sus efectos sobre la función de la proteína.

\section{ALK1 (ACVRL1)}

La segunda variante de la enfermedad de Rendu-Osler (HHT2; OMIM: 600376) fue localizada en el brazo largo del cromosoma 12, en la zona 12q13, donde se encuentra situado el gen conocido como ALK1 (Johnson et al, 1996). Este gen se expande durante más de $15 \mathrm{~kb}$ a lo largo del genómico y codifica una proteína de 503 aminoácidos (Berg et al, 1997; ten Dijke et al, 1993). La región codificante incluye nueve exones, el codón de inicio se localiza en el exón 2 y el codón de parada en el exón 10. Todos los intrones siguen la regla GT-AG excepto el intrón 6. Se han descrito dos variantes de la secuencia no traducida a nivel 5'; en la primera de ellas, la secuencia 5’UTR forma parte del exón 2, mientras que en la segunda, se inicia en la zona promotora del exón 1 mediante una secuencia de 7 bp que enlaza con el codón de inicio del exón 2. El resto de secuencias son idénticas (figura 5).

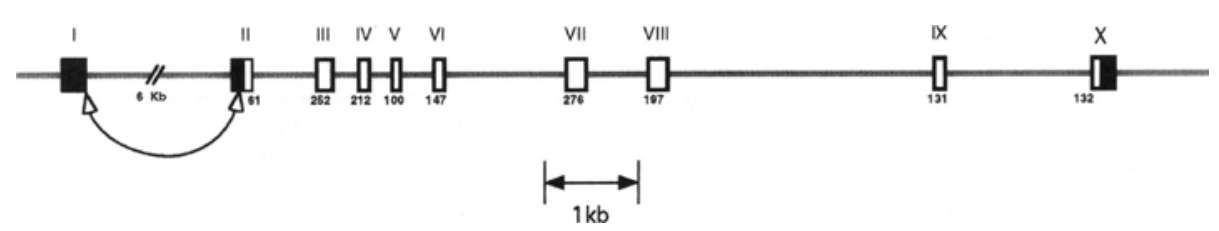

Figura 5. Estructura de ALK1

ALK1 es un receptor de células de superficie tipo I, que pertenece a la superfamilia de ligandos TGF- $\beta$, el cual media sus acciones a través de Smad 1, 5 y 8. Comparte con otros receptores tipo I una relativa similitud en cuanto a los subdominios serina/treonina kinasa, presentando una pequeña región inicial de 22 aminoácidos, seguida de un relativamente pequeño dominio extracelular (EC) que agrupa los residuos 22 al 118, un dominio transmembrana (TM) con los residuos 119 a 141 y finalmente un largo dominio citosólico (CYTO) con los residuos 142 a 503 (Attisano et al, 1993; ten 
Dijke et al, 1994; Richards-Yutz et al, 2010)). La región intracelular es un dominio kinasa que, a su vez, contiene 12 subdominios con residuos altamente conservados (Hanks et al, 1988; Abdalla et al, 2003)

Diversos estudios realizados sobre sangre extraída de cordón umbilical y otros tipos celulares han mostrado que, cuando existe una mutación, disminuye la actividad de señalización y se reducen los niveles de expresión de ALK1, lo que refleja la baja capacidad de expresión de la proteína mutante formada (Abdalla et al, 2000; Lux et al, 1999)

Muchas mutaciones afectan a los codones G48-A49-W50 y C51, por lo que estos sitios pueden considerarse "puntos calientes" por la alta concentración de alteraciones descritas en ellos (Abdalla et al, 2006). Existen otros residuos en el dominio kinasa donde también se han descrito bastantes alteraciones, aunque no con tanta frecuencia.

La mayoría de las mutaciones descritas en este gen (75\%) se localizan en el dominio kinasa intracelular (Fontalba et al, 2008; Sadick et al, 2009). El 65\% de las mutaciones descritas lo hacen en los exones 8, 7 y 3. La inmensa mayoría de mutaciones sin sentido en este dominio ocurren en residuos que se conservan entre ALK1 de diferentes especies y entre diferentes receptores tipo I. Los diferentes modelos usados para el estudio sugieren que esta alteración causa modificaciones en la polaridad, carga, hidrofobicidad y tamaño de los aminoácidos sustituidos y probablemente tengan efectos estructurales generando proteínas inestables por alteraciones en su estructura terciaria (Abdalla et al, 2003)

Mutaciones en este gen también se han descrito en un raro grupo de pacientes que padecían hipertensión pulmonar. Estos pacientes desarrollan dilataciones vasculares y malformaciones arteriovenosas características de HHT, pero también arteriopatías oclusivas típicos de la hipertensión pulmonar primaria (Trembath et al, 2001; Abdalla et al, 2004; Harrison et al, 2003)

Debido a que tanto ALK1 como ENG son receptores endoteliales pertenecientes a la vía de señalización celular mediada por TGF- $\beta$, se planteó la duda de si los niveles de endoglina también estarían alterados en HHT2, debido a un mecanismo de haploinsuficiencia similar al que genera HHT1. Tras diversos resultados, se ha llegado a 
la conclusión de que los niveles de endoglina son más bajos en HHT1 que en HHT2, de ahí que la primera variante sea más severa, aunque también se conoce que los valores disminuyen con la edad (Sanz-Rodríguez et al, 2004; Abdalla et al, 2006).

\section{SMAD4}

El Síndrome de poliposis juvenil y HHT (JPHT; OMIM: 175050) viene definido por la presencia de ambas alteraciones en el mismo individuo (Gallione et al, 2004). Las primeras publicaciones sobre la coexistencia de un desorden autosómico dominante, caracterizado por la presencia de poliposis gastrointestinal juvenil y malformaciones arteriovenosas pulmonares acompañado de acropaquias, data de principios de la década de 1980 (Cox et al, 1980; Baert et al, 1983). La poliposis juvenil, factor predisponente a padecer alteraciones gastrointestinales malignas, fue asociada con mutaciones en los genes SMAD4 o BMPR1A (Howe et al, 1998; Howe et al, 2001). Fue en 2004 cuando Gallione y colaboradores describieron una serie de 7 pacientes que cumplían criterios de poliposis juvenil y de HHT, portando mutaciones en SMAD4 y sin presentar alteraciones en ENG ni en ALK1 (Gallione et al, 2004). Desde entonces, diversos estudios han apoyado la idea de la existencia de una nueva variante que agrupa ambas enfermedades en el mismo paciente y que, debido a la severidad de la sintomatología presentada, debe seguir los mismos patrones de detección precoz que están aprobados para el resto de variantes de HHT (Gallione et al, 2004).

SMAD4 se compone de 552 aminoácidos y pertenece a la familia de proteínas encargadas de modular la señal de respuesta celular a través de la superfamilia TGF- $\beta$, actuando como factor de transcripción (Hahn et al, 1996). Además, es el único factor común de señalización en mamíferos conocido (co-SMAD).

Las proteínas SMAD están altamente conservadas interespecies, especialmente a nivel del extremo $\mathrm{N}$ - terminal o dominio MH1 y del extremo C-terminal o dominio MH2. El dominio MH1 tiene propiedades de unión específicas a determinados nucleótidos y facilita el enlace de SMAD4 al extremo C-terminal fosforilado de los RSMADs. El dominio MH2 es el responsable de reconocer el receptor y de oligomerizarse con otros SMADs e interactúa directamente con el dominio MH1 de los R- SMADs (figura 6) 


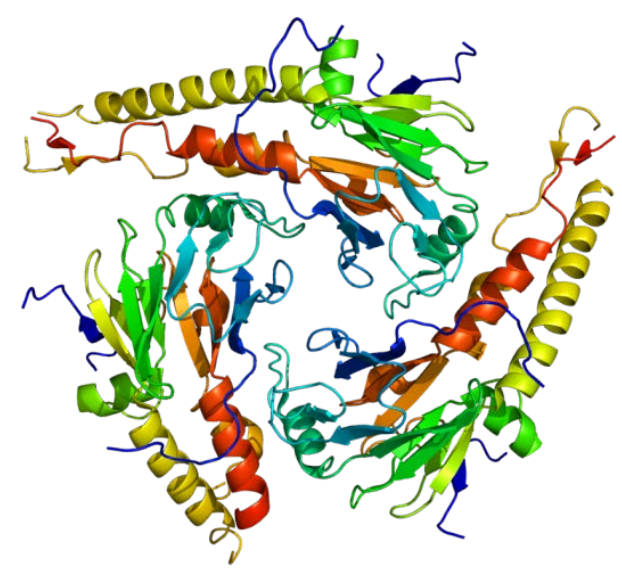

Figura 6. Estructura tridimensional de SMAD4

\subsection{MECANISMO DE SEÑALIZACIÓN CELULAR}

Los diferentes genes cuya mutación causan la enfermedad que estamos describiendo, codifican proteínas que están implicadas en un mismo mecanismo de señalización presente en las células endoteliales y su alteración es lo que produce la aparición de la enfermedad.

Dicha vía de señalización se inicia a través de la denominada superfamilia del factor transformador de crecimiento tipo $\beta$ (TGF- $\beta$ ), de la que se conocen hasta el momento tres variantes diferentes en humanos (Roberts and Sporn, 1993).

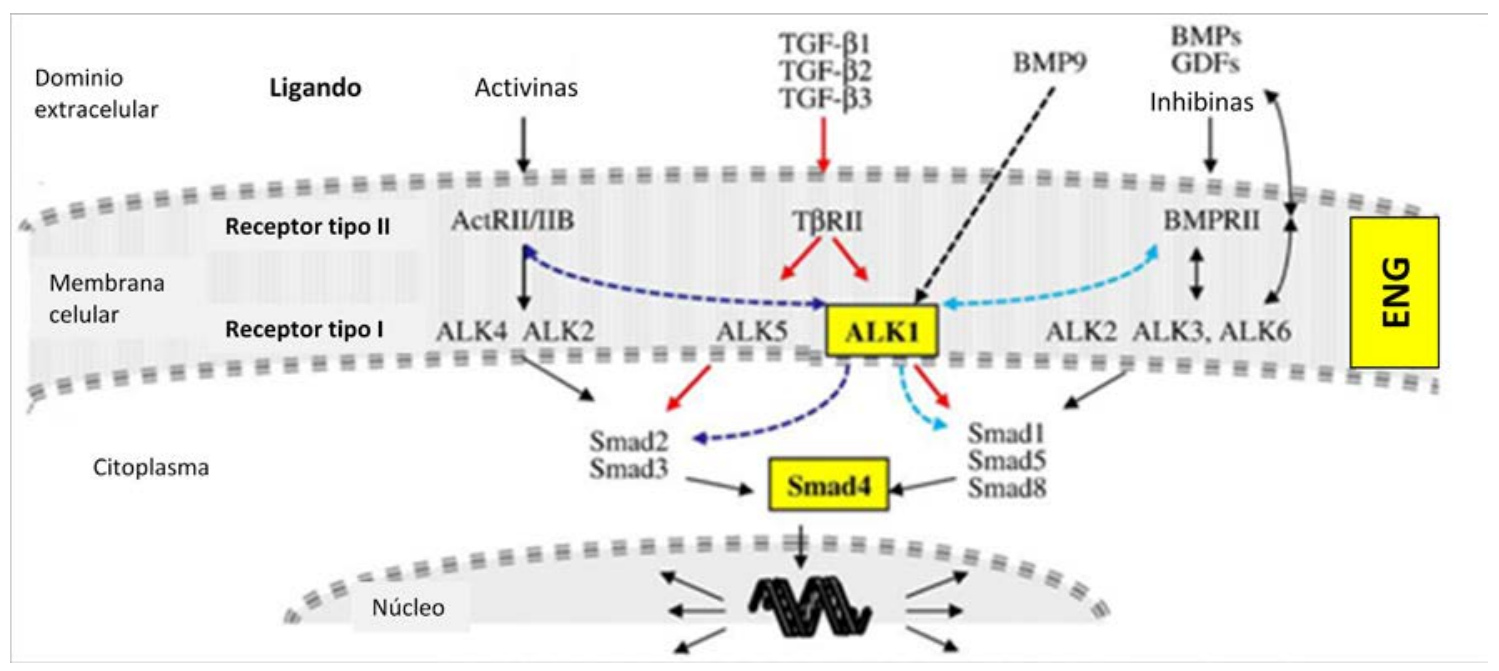

Figura 7. Mecanismo de señalización en células endoteliales 
La superfamilia de ligandos TGF- $\beta$ regulan diferentes funciones celulares, a través de su unión a receptores serina/treonina kinasa, localizados en la región transmembrana celular y que pueden ser de tipo I o de tipo II. En el caso de la superfamilia TGF- $\beta$ es necesario la presencia de una proteasa que active el ligando desde su estado precursor antes de iniciar la traducción de la señal, acción que lo distingue del resto de superfamilias, donde el ligando se secreta en forma activa.

Los dos tipos de receptores del TGF- $\beta$ poseen una estructura similar, estando formados por un dominio extracelular rico en cisteínas, un dominio transmemebrana y un dominio intracelular que ejerce la actividad serina/treonina kinasa (figura 8).

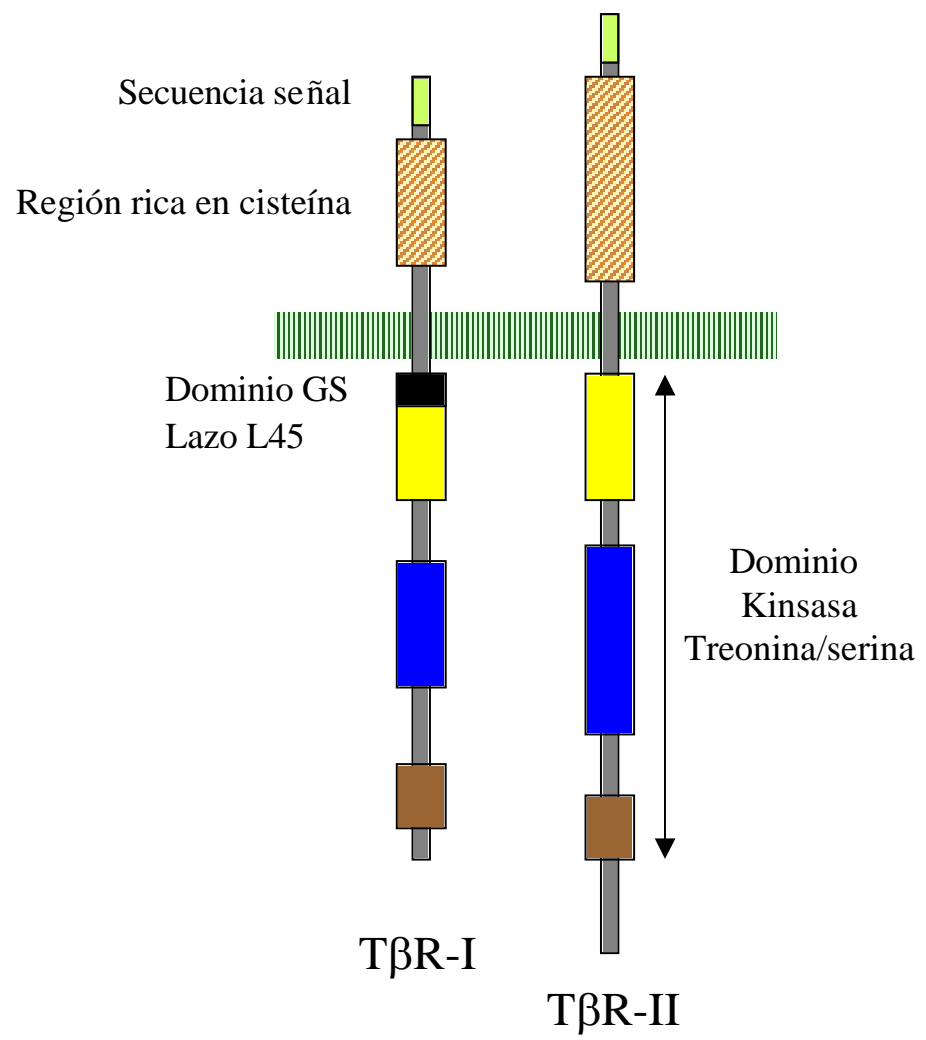

Figura 8. Estructura de los receptores TGF- $\beta$

Además, el receptor de TGF- $\beta$ contiene unas proteínas accesorias que modulan la trasducción de la señal por parte del receptor. Estas proteínas se conocen como receptores tipo III y son el betaglicano y la endoglina. Ambas proteínas son receptores transmembrana carentes de motivos enzimáticos, pero con muchos residuos de serina y treonina. 
El mecanismo de transmisión se basa en un ensamblaje cooperativo de ambos tipos de receptores, de modo que el receptor tipo II, que posee una gran afinidad por los ligandos, interacciona y transfosforila el receptor tipo I mediante un contacto directo del ligando con el extremo N- terminal del receptor tipo I, activándolo. Una vez realizado este proceso, la señal se puede propagar intracelularmente por dos vías diferentes, en función de si intervienen en la misma otras proteínas denominadas Smad o si lo hacen de forma independiente. En los diferentes estudios realizados se ha comprobado que en el caso de los tres genes identificados hasta el momento implicados en HHT, el mecanismo usado es el que depende de Smad (figura 9).

Existen tres tipos distintos de proteínas Smads: Reguladas por el receptor (R-), Mediadoras comunes (Co) e Inhibidoras (I-). Las R-Smads (Smad1, Smad2, Smad3, Smad5 y Smad8) son fosforiladas por el receptor tipo I en los residuos serina de su extremo carboxi terminal (Abdallah et al., 1997). Las R-Smads activadas interactúan con Smad4, que es una proteína del grupo Co-Smad. Este complejo actúa en el núcleo, donde participa en la regulación de la trascripción de los diferentes genes (Lagna et al., 1996; Nakao et al., 1997a). Las proteínas I-Smads (Smad6 y Smad7) se encargan de inhibir la activación de los R-Smads por diferentes mecanismos, generándose así un mecanismo de retroalimentación negativa, que permite mantener el equilibrio en la transcripción celular. 


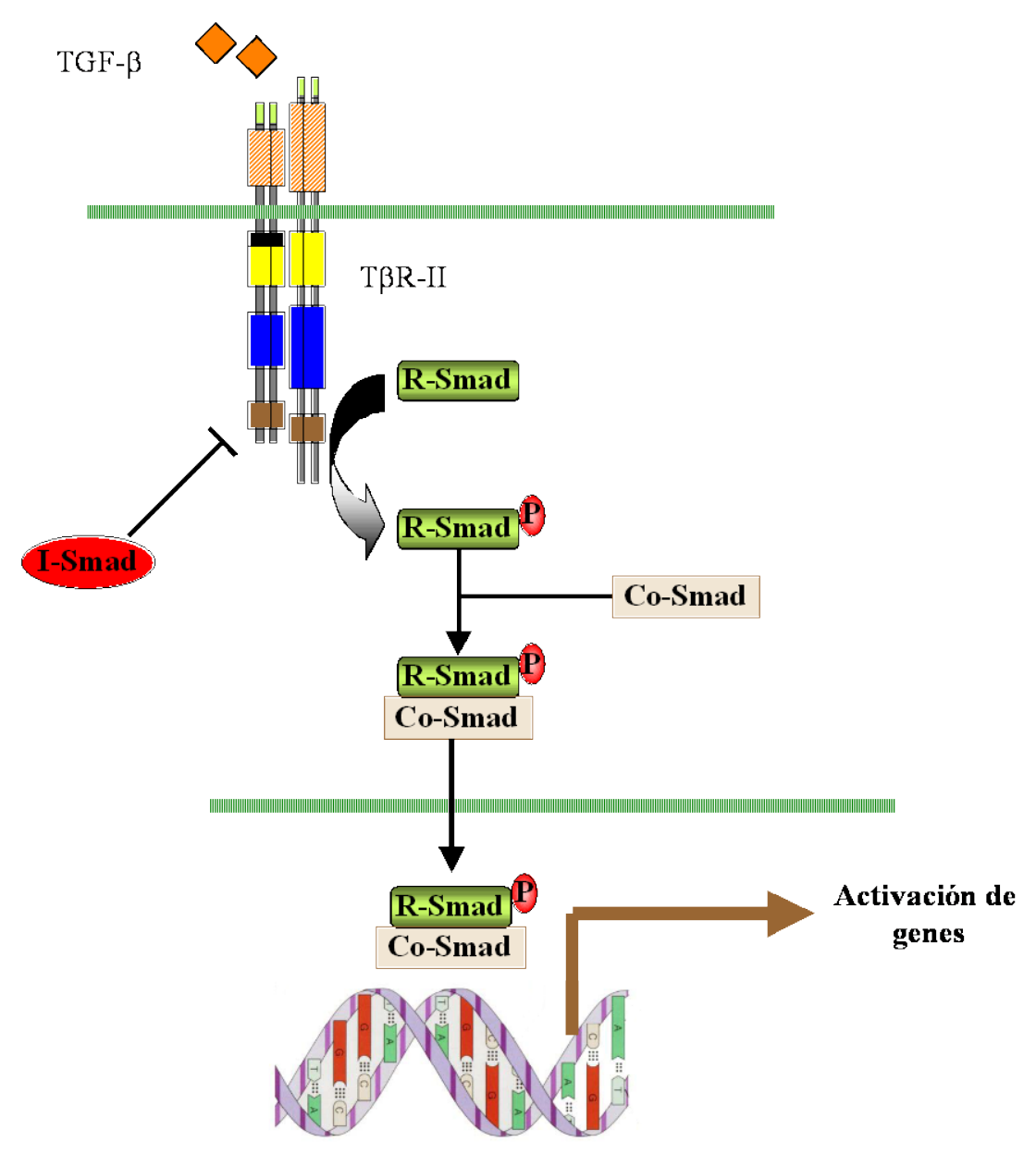

Figura 9. Vía de señalización celular mediada por proteínas SMAD

Mientras que Endoglina actúa como co-receptor relativamente específico de las células endoteliales para múltiples complejos de receptores de la superfamilia TGF- $\beta$, ALK es un receptor tipo I que estructural y funcionalmente podría englobarse dentro de la familia de receptores denominados BMP. ALK puede asociarse con, al menos, dos tipos diferentes de receptores tipo II: BMPR2 y T $\beta$ RII. A su vez, T $\beta$ RII se puede asociar con dos diferentes receptores tipo I: T $\beta$ RI (también denominado ALK5) y con ALK1. Endoglina es el factor que modula las consecuencias funcionales de dichas asociaciones.

ALK1 y ALK5 activan diferentes vías de señalización dependientes de Smad, que generan respuestas de la célula endotelial contrapuestas entre ellas en cuanto a la capacidad proliferativa, migratoria y anti-angiogénica de la misma se refiere. Así, ALK5 inhibe estas respuestas, mientras que ALK1 las favorece. El desequilibrio entre ambas vías es la causante de las malformaciones vasculares, ya que la activación excesiva genera la neoformación desorganizada (figura 10) 


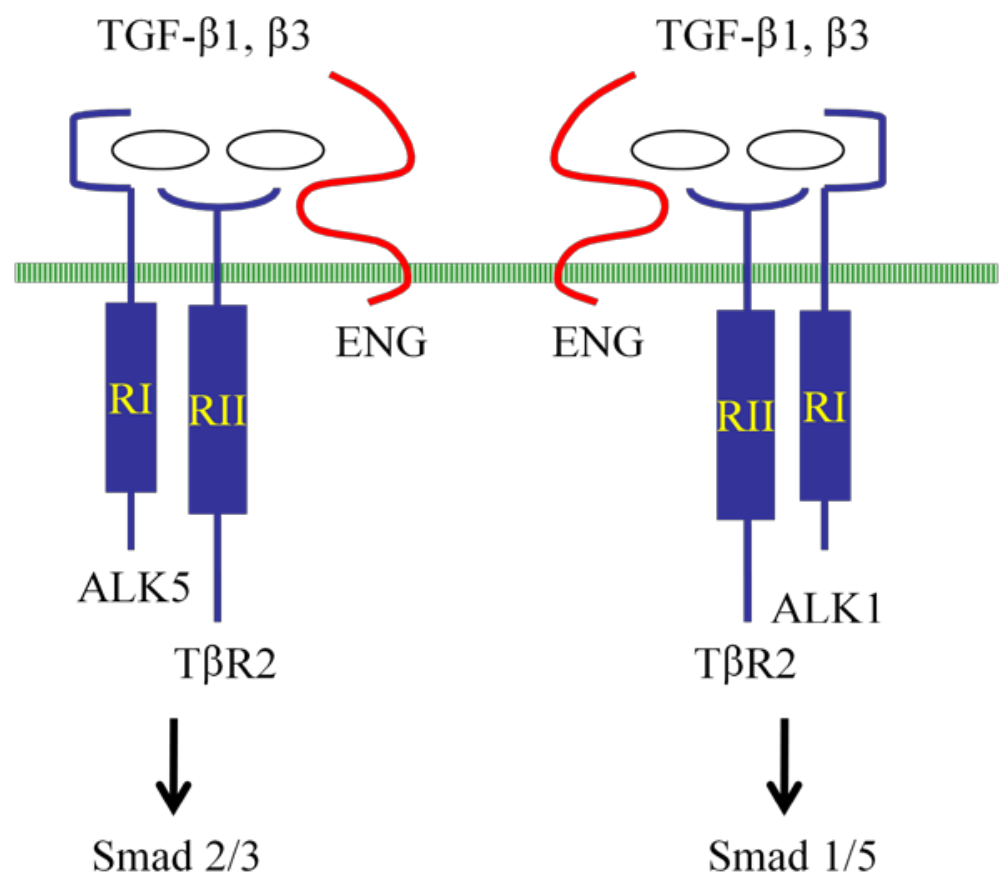

Figura 10. Vías de señalización mediada por ALK

El ligando TGF- $\beta 1$ puede activar tanto el complejo TßRI/ALK5 como el T $\beta R I / A L K 1$, lo que ha hecho que se plantee la hipótesis del balance, estableciéndose la teoría de que todas las mutaciones en HHT provocarían alteraciones en el receptor TGF$\beta$ de tipo I y en la vía Smad, modificando, en último término, la respuesta de la célula endotelial. También se incluye en esta hipótesis la posibilidad de que en la patogenia de la enfermedad intervengan los ligandos BMP9 y BMP10 que, aun siendo específicos para ALK, también pueden unirse a Endoglina, aunque los estudios más recientes no tienen tan claro este papel tan influyente.

Actualmente, se admite el modelo de haploinsuficiencia para explicar la patogenia de la enfermedad. Este consiste en la teórica insuficiente capacidad de los genes mutados para producir una cantidad de proteína normofuncionante, cuando uno de los alelos heredados es nulo o no funcionante. 


Aunque existen estudios previos que analizan la enfermedad de Rendu Osler Weber en pacientes españoles, en nuestro trabajo nos hemos propuesto analizar desde un punto de vista clínico y genético las características de pacientes controlados en el Hospital Universitario de Salamanca. Para ello nuestros objetivos han sido:

1. Realizar una revisión de las historias clínicas de los pacientes con diagnóstico de Rendu Osler Weber realizadas en el Hospital Universitario de Salamanca durante los últimos 7 años.

2. Estudiar los genes ENG, ALK1 y SMAD4 en pacientes con diagnóstico clínico de Rendu Osler Weber para determinar la incidencia de mutaciones en las mismas.

3. Caracterizar, mediante métodos bioinformáticos, la repercusión de las mutaciones encontradas en los pacientes incluidos en el estudio

4. Determinar la posible existencia de correlación fenotipo-genotipo 




\section{PACIENTES}

Se estudiaron 24 familias no relacionadas entre sí, tomando como paciente índice aquél que estaba diagnosticado de HHT siguiendo los criterios clínicos de Curaçao (Shovlin C et al., 2000). Los pacientes fueron debidamente informados de la naturaleza y objetivos del estudio y a todos se les solicitó su autorización para la extracción de una muestra de sangre o saliva para realizar el estudio genético. Las muestras fueron obtenidas previo consentimiento, siguiendo las normas legales para Estudios Clínicos en España y las del Comité de Ética del Hospital Universitario de Salamanca.

\subsection{EXTRACCIÓN DE ADN}

El ADN genómico de alto peso molecular se extrajo a partir de sangre periférica de los pacientes, excepto en 4 familiares, donde se extrajo a partir de una muestra de saliva, pues la edad de los mismos era muy corta y se optó por usar un método menos cruento.

a) Tras centrifugar y resuspender la muestra de $10 \mathrm{ml}$. de sangre periférica, conservada a $4^{\circ} \mathrm{C}$ tras la extracción, se aisló la interfase de células leucocitarias, las cuales se resuspendieron en tampón Fornace (0.25M sacarosa; 50mM Tris- $\mathrm{HCl} \mathrm{pH}$ 7.5; 25mM KCl; 5mM MgCl2); EDTA $0.5 \mathrm{pH}$ 8, que es un quelante de iones divalentes que posibilita la inactivación de las nucleasas; proteinasa K 20 mg/L, que degrada las proteínas; y SDS (dodecil sulfato sódico) al 10\%, que rompe las membranas celulares. Esta mezcla se incubó a $55^{\circ} \mathrm{C}$ durante unas 16 horas, tras lo cual se purificó el ADN tratándolo con una mezcla de fenol tamponado y CIAA (cloroformo: alcohol isoamílico 24:1). Con este proceso el ADN queda en la fase acuosa, la cual se limpió de otros residuos mezclándola con CIAA y centrifugando para separar las dos fases, una que contiene el ADN y otra que contiene los detritos celulares. Tras este paso se añadió etanol absoluto a la fase acuosa, precipitando el ADN, que se recuperó, se lavó con etanol al 70\% y finalmente, se resuspendió en $\mathrm{ddH}_{2} \mathrm{O}$.

b) Las células de la mucosa bucal fueron extraídas mediante hisopos sencillos, secos (sin medio) y estériles (Aptaca). Se mezcló Fornace, EDTA (0.5 M pH: $8)$, SDS (1\%) y proteinasa $\mathrm{K}(50 \mu \mathrm{g} / \mathrm{mL})$, resultando un volumen final de 232 
$\mu \mathrm{L}$. Se cortó el algodón del bastoncillo y se introdujo en la mezcla que fue incubada durante dos días a $55^{\circ} \mathrm{C}$.

La concentración y el grado de contenido proteico del ADN se calculó tras medir su absorbancia a 260 y 280nm, respectivamente, en el espectrofotómetro automático de ADN / ARN (GeneQuant, Pharmacia), siguiendo la fórmula:

$\mu \mathrm{g}$ de $\mathrm{ADN} / \mathrm{mL}=(\mathrm{DO} 260) \times($ factor de dilución $) \times 50$

El multiplicador 50 es un factor de corrección introducido, ya que la unidad de densidad óptica con una luz incidente de 260nm es un valor de absorbancia que tienen $50 \mu g$ de $\mathrm{ADN} / \mathrm{mL}$.

El cociente $\mathrm{DO}_{260} / \mathrm{DO}_{280}$ se utiliza para determinar el grado de contaminación proteica, considerando como valores adecuados un cociente entre 1.65 y 2. Valores inferiores a los señalados indican contaminación por proteínas o solventes orgánicos, realizándose en estos casos una nueva purificación del ADN. Valores superiores indican un exceso de ARN, que se elimina tratando la solución de ADN con ARNasa y purificando de nuevo, según el método descrito anteriormente (Sambrook et al., 1989).

La muestra de ADN obtenida, con una concentración aproximada entre 1000 y $1500 \mu \mathrm{g} / \mathrm{mL}$, se almacenó en tubos Eppendorf ${ }^{\circledR} \mathrm{a}-20^{\circ} \mathrm{C}$, con el fin de evitar tanto la degradación progresiva del ADN como la posible contaminación bacteriana.

\subsection{AMPLIFICACIÓN DE ADN}

Las muestras de ADN fueron amplificadas por PCR (reacción en cadena de la polimerasa).

La amplificación se llevó a cabo en un volumen de $25 \mu \mathrm{L}$ : $12.5 \mu \mathrm{L}$ de Master Mix (Promega) (ADN Taq polimerasa; dATP, dGTP, dCTP, dTTP; $\mathrm{MgCl}_{2}$ ); $9.5 \mu \mathrm{L}$ de agua libre de nucleasas; $2 \mu \mathrm{L}$ de cada oligonucleótido cebador (sentido y anti-sentido) y $1 \mu \mathrm{L}$ de ADN obtenido por el método anteriormente descrito (concentración $=0,1$ $0,2 \mu \mathrm{g} / \mathrm{mL}$ ). Como control negativo se utilizó un tubo de reacción con todos los componentes excepto el ADN molde.

Para amplificar los diferentes exones de los genes, partimos de un programa estándar de PCR, adaptado en cada caso al exón que se amplifica (tabla 2). 
Tabla 2. Programa de PCR

\begin{tabular}{lccc}
\hline & Temperatura & Tiempo & Ciclos \\
\hline Desnaturalización & $95^{\circ} \mathrm{C}$ & $5 \mathrm{~min}$. & 1 \\
\hline Desnaturalización & $95^{\circ} \mathrm{C}$ & $30 \mathrm{seg}$. & 40 \\
\hline Anillamiento & - & $30 \mathrm{seg}$. & \\
\hline Extensión & $72^{\circ} \mathrm{C}$ & $30 \mathrm{seg}$. & 1 \\
\hline Extensión final & $72^{\circ} \mathrm{C}$ & $10 \mathrm{~min}$. & \\
\hline
\end{tabular}

Todas las reacciones de amplificación se llevaron a cabo en un termociclador automático y la manipulación post-PCR se realizó en un laboratorio distinto de donde se llevó a cabo la extracción de ADN.

Los programas de amplificación utilizados en nuestro trabajo para las diferentes combinaciones de oligonucleótidos únicamente variaron en la temperatura de anillamiento (tablas 3 y 4).

Tabla 3. Relación de oligonucleótidos utilizados en este trabajo para la amplificación por PCR de los exones 2 al 10 del gen ALK1.

\begin{tabular}{llc}
\hline Localización & \multicolumn{1}{c}{$\begin{array}{c}\text { Secuencia de los oligonucleótidos } \\
\left(\mathbf{5}^{\prime}-\mathbf{3}^{\prime}\right)\end{array}$} & $\begin{array}{c}\text { Temperatura de } \\
\text { anillamiento }\end{array}$ \\
\hline ALK1 EX2 F & CTCTGTGATTTCCTCTGGGCA & $55^{\circ} \mathrm{C}$ \\
ALK1 EX2 R & TACATTCTCCCCAGCTTCTCAA & \\
ALK1 EX3 F & AGCTGGGACCACAGTGGCTGA & $58^{\circ} \mathrm{C}$ \\
ALK1 EX3 R & GGAGGCAGGGGCCAAGAAGAT & \\
ALK1 EX4 F & AGCTGACCTAGTGGAAGCTGA & $58^{\circ} \mathrm{C}$ \\
ALK1 EX4 R & CTGATTCTGCAGTTCCTATCTG & \\
ALK1 EX5 F & AGGAGCTTGCAGTGACCCAGCA & $55^{\circ} \mathrm{C}$ \\
ALK1 EX5 R & ATGAGAGCCCTTGGTCCTCATCCA & \\
ALK1 EX6 F & AGGCAGCGCAGCATCAAGAT & $53^{\circ} \mathrm{C}$ \\
ALK1 EX6 R & AAACTTGAGCCCTGAGTGCAG & \\
ALK1 EX7 F & TGACGACTCCAGCCTCCCTTAG & $55^{\circ} \mathrm{C}$ \\
ALK1 EX7 R & CAAGCTCCGCCCACCTGTGAA & \\
ALK1 EX8 F & AGGTTTGGGAGAGGGGCAGGAGT & $62^{\circ} \mathrm{C}$ \\
ALK1 EX8 R & GGCTCCACAGGCTGATTCCCCTT & \\
ALK1 EX9 F & TCCTCTGGGTGGTATTGGGCCTC & $62^{\circ} \mathrm{C}$ \\
ALK1 EX9 R & CAGAAATCCCAGCCGTGAGCCAC & \\
ALK1 EX10 F & TCTCCTCTGCACCTCTCTCCCAA & $59^{\circ} \mathrm{C}$ \\
ALK1 EX10 R & CTACCTCTACCCAGATAGGG & \\
\hline
\end{tabular}

F: Oligo forward (sentido) R: Oligo reverse (anti-sentido). 
Tabla 4. Relación de oligonucleótidos utilizados en este trabajo para la amplificación por PCR de los exones del 1 al 13 del gen ENG.

\begin{tabular}{|c|c|c|}
\hline Localización & $\begin{array}{l}\text { Secuencia de los oligonucleótidos } \\
\left(5^{\prime}-3^{\prime}\right)\end{array}$ & $\begin{array}{c}\text { Temperatura de } \\
\text { anillamiento }\end{array}$ \\
\hline $\begin{array}{l}\text { ENG EX1 F } \\
\text { ENG EX1 R }\end{array}$ & $\begin{array}{l}\text { ACTGGACACAGGATAAGGCCCAG } \\
\text { AATACTTGGGGCCTGGTCCGTG }\end{array}$ & $55^{\circ} \mathrm{C}$ \\
\hline $\begin{array}{l}\text { ENG EX2 F } \\
\text { ENG EX2 R }\end{array}$ & $\begin{array}{l}\text { CACСTTATTCTCACСTGGCСТCTT } \\
\text { CTGCСTTGGAGCTTCСTCTGAG }\end{array}$ & $57^{\circ} \mathrm{C}$ \\
\hline $\begin{array}{l}\text { ENG EX3 F } \\
\text { ENG EX3 R }\end{array}$ & $\begin{array}{l}\text { GGGTGGCACAACCTATACAAAT } \\
\text { CAGAGATGGACAGTAGGGACCT }\end{array}$ & $55^{\circ} \mathrm{C}$ \\
\hline $\begin{array}{l}\text { ENG EX4 F } \\
\text { ENG EX4 R }\end{array}$ & $\begin{array}{l}\text { TTCCTGACСTCСTACATGGG } \\
\text { TTCAGCTCAGCAGCAGAGG }\end{array}$ & $54^{\circ} \mathrm{C}$ \\
\hline $\begin{array}{l}\text { ENG EX5 F } \\
\text { ENG EX5 R }\end{array}$ & $\begin{array}{l}\text { TGAGGGAAGGGACTGAGGTG } \\
\text { GTGGGGACTAGTGTCAGGGGC }\end{array}$ & $58^{\circ} \mathrm{C}$ \\
\hline $\begin{array}{l}\text { ENG EX6 F } \\
\text { ENG EX6 R }\end{array}$ & $\begin{array}{l}\text { GGCCTGTCCGCTTCAGTGTT } \\
\text { GTTTTGTGTCCCGGGAGCTG }\end{array}$ & $55^{\circ} \mathrm{C}$ \\
\hline $\begin{array}{l}\text { ENG EX7 F } \\
\text { ENG EX7 R }\end{array}$ & $\begin{array}{l}\text { CССССТGTTCTGCСTCTCTC } \\
\text { CTGATCCAAGGGAGGGGAAG }\end{array}$ & $55^{\circ} \mathrm{C}$ \\
\hline $\begin{array}{l}\text { ENG EX8 F } \\
\text { ENG EX8 R }\end{array}$ & $\begin{array}{l}\text { ACACATATCACACAGTGACCAGC } \\
\text { CTAGGGGAGGAACCAGATGTC }\end{array}$ & $55^{\circ} \mathrm{C}$ \\
\hline $\begin{array}{l}\text { ENG EX9A F } \\
\text { ENG EX9A R }\end{array}$ & $\begin{array}{l}\text { CTCCTGATGGTGCCCСTCTCTT } \\
\text { TTGTCTTGTGTTCTGAGCCCCTG }\end{array}$ & $55^{\circ} \mathrm{C}$ \\
\hline $\begin{array}{l}\text { ENG EX9B F } \\
\text { ENG EX9B R }\end{array}$ & $\begin{array}{l}\text { GACAAGCTTGGCCATTGGTTG } \\
\text { AGTCCTGCTCCGGTCATACAG }\end{array}$ & $52^{\circ} \mathrm{C}$ \\
\hline $\begin{array}{l}\text { ENG EX10 F } \\
\text { ENG EX10 R }\end{array}$ & $\begin{array}{l}\text { ATTGACCAAGTCTCССТССС } \\
\text { GAAAGGCGGAGAGGAAGTTC }\end{array}$ & $55^{\circ} \mathrm{C}$ \\
\hline $\begin{array}{l}\text { ENG EX11 F } \\
\text { ENG EX11 R }\end{array}$ & $\begin{array}{l}\text { GGTGGGGTGAAGAGCAGCTG } \\
\text { GACCTGGAAGCTCCCACTTGAA }\end{array}$ & $55^{\circ} \mathrm{C}$ \\
\hline $\begin{array}{l}\text { ENG EX12 F } \\
\text { ENG EX12 R }\end{array}$ & $\begin{array}{l}\text { GAGTAAACCTGGAAGCCGC } \\
\text { GCCACTAGAACAAACCCGAG }\end{array}$ & $55^{\circ} \mathrm{C}$ \\
\hline $\begin{array}{l}\text { ENG EX13 F } \\
\text { ENG EX13 R }\end{array}$ & $\begin{array}{l}\text { CTCCTGATGGTGCCССТСTCTT } \\
\text { CTCAGAGGCTTCACСTGGGCTCC }\end{array}$ & $57^{\circ} \mathrm{C}$ \\
\hline
\end{tabular}

F: Oligo forward (sentido) R: Oligo reverse (anti-sentido). 
Tabla 5. Relación de oligonucleótidos utilizados en este trabajo para la amplificación por PCR de los exones del 1 al 11 del gen SMAD4

\begin{tabular}{|c|c|c|}
\hline Localización & $\begin{array}{c}\text { Secuencia de los oligonucleótidos } \\
\left(5^{\prime}-3^{\prime}\right)\end{array}$ & $\begin{array}{c}\text { Temperatura de } \\
\text { anillamiento }\end{array}$ \\
\hline SMAD4 EX1 F & CGTTAGCTGTTGTTTTTCACTG & \\
\hline SMAD4 EX1 R & AGAGTATGTGAAGAGATGGAG & $54^{\circ} \mathrm{C}$ \\
\hline SMAD4 EX2 F & TGTATGACATGGCCAAGTTAG & \multirow{2}{*}{$54^{\circ} \mathrm{C}$} \\
\hline SMAD4 EX2 R & CAATACTCGTTTTAGCAGTC & \\
\hline SMAD4 EX3 F & CTGAATTGAAATGGTTCATGAAC & \multirow{2}{*}{$48^{\circ} \mathrm{C}$} \\
\hline SMAD4 EX3 R & GССССТААССТСААААТСТАС & \\
\hline SMAD4 EX4 F & CTGGGAATAGAAGCTTATTAAAAT & \multirow{2}{*}{$54^{\circ} \mathrm{C}$} \\
\hline SMAD4 EX4 R & CCCCCAAGTGACTACACAT & \\
\hline SMAD4 EX5 F & GATGACATCTATGAATGTACC & \multirow{2}{*}{$54^{\circ} \mathrm{C}$} \\
\hline SMAD4 EX5 R & GCTTTTATAAAGGCTGCCTAC & \\
\hline SMAD4 EX6 F & GTAGGCAGCCTTTATAAAAGC & \multirow{2}{*}{$54^{\circ} \mathrm{C}$} \\
\hline SMAD4 EX6 R & CAGAAAACAAAGCCCTACCAA & \\
\hline SMAD4 EX7 F & TGAAAGTTTTAGCATTAGACAAC & \multirow{2}{*}{$54^{\circ} \mathrm{C}$} \\
\hline SMAD4 EX7 R & CCTGTGTTTGTCGTTTCAATC & \\
\hline SMAD4 EX8 F & CATGGGAGGATGTTCTTTCC & \multirow{2}{*}{$54^{\circ} \mathrm{C}$} \\
\hline SMAD4 EX8 R & CATGGGAAAACATAACCTTGA & \\
\hline SMAD4 EX9 F & TATTAAGCATGCTATACAATCTG & \multirow{2}{*}{$54^{\circ} \mathrm{C}$} \\
\hline SMAD4 EX9 R & СTTCСАСССАGАTTTСАATTC & \\
\hline SMAD4 EX10 F & GGCATTGGTTTTTAATGTATGGA & \multirow{2}{*}{$54^{\circ} \mathrm{C}$} \\
\hline SMAD4 EX10 R & TGCTCAAAGAAACTAATCAACTGAG & \\
\hline SMAD4 EX11 F & TGGGAAGAGATCACССТGTC & \multirow{2}{*}{$54^{\circ} \mathrm{C}$} \\
\hline SMAD4 EX11 R & TTTTGTAGTCCACCATCCTGA & \\
\hline
\end{tabular}

F: Oligo forward (sentido) R: Oligo reverse (anti-sentido).

\subsection{ELECTROFORESIS EN GEL DE AGAROSA}

Los fragmentos amplificados mediante PCR fueron separados, por su tamaño, mediante electroforesis en geles horizontales de agarosa al 1-2\% (Gibco-BRL) preparados con tampón TBE (Tris 0.044 M, ácido bórico 0.044 M, EDTA 1.0mM $\mathrm{pH}=8.3$ ). El primer pocillo del gel se reservó para separar, en paralelo con las muestras a estudiar, un marcador de tamaño que corresponde con el ADN del fago ФX-174 cortado con la endonucleasa HaeIII. Este marcador de tamaño genera fragmentos de 1.353, 1.078, 0.872, 0.603, 0.310, 0.281, 0.271, 0.234, 0.194, 0.118 у $0.072 \mathrm{~Kb}$. La electroforesis se llevó a cabo con una diferencia de potencial constante de 120 voltios durante 40 minutos.

Para monitorizar la migración del ADN en el gel utilizamos dos colorantes que se incluyeron en el tampón de carga: el xyleno cianol, que migra aproximadamente con los 
fragmentos de $5 \mathrm{~Kb}$ en un gel de agarosa al 0.8\%, y el azul de bromofenol, que migra aproximadamente con los fragmentos de $0.5 \mathrm{~Kb}$.

Tras la electroforesis, los fragmentos amplificados se visualizaron en el gel de agarosa utilizando Sybr Safe ${ }^{\circledR}(0,5 \mu \mathrm{L} / \mathrm{mL})$, que actúa intercalándose entre las bases nitrogenadas del ADN y emitiendo fluorescencia al ser expuesto a la luz UV (254nm). Los resultados obtenidos fueron almacenados mediante un sistema de fotografía digital (Kodak DC40) acoplado a un programa informático de tratamiento de imágenes (Kodak Digital Science 1D) (fig.11).

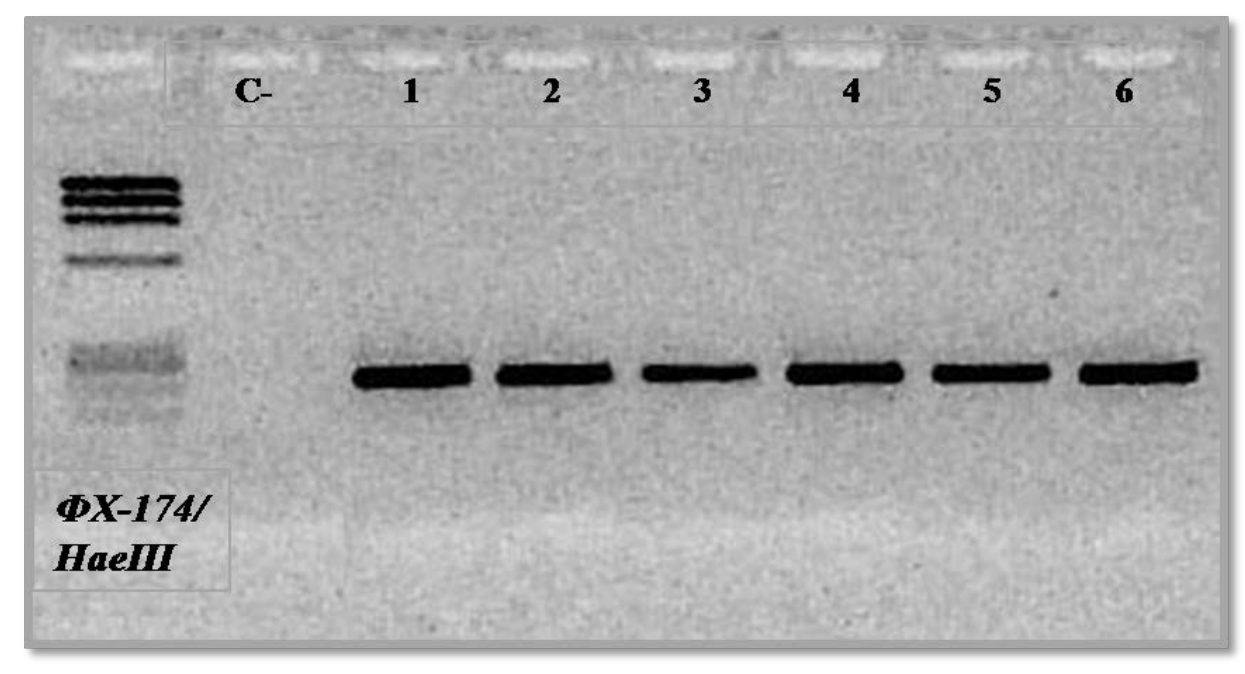

Figura 11. Electroforesis de fragmentos amplificados por PCR.

\subsection{SECUENCIACIÓN AUTOMÁTICA}

Se llevó a cabo en un secuenciador ABI PRISM 310 Genetic Analyser (Applied Biosystems) en el Servicio Central de Secuenciación de la Universidad de Salamanca.

Para la preparación de las muestras, se purificaron las PCRs para obtener el fragmento correspondiente a cada exón con el kit comercial High Pure Product Purification Kit de Roche, siguiendo las instrucciones del fabricante. Se preparó una muestra con el oligo sentido y otra con el oligo antisentido usando 40-60 ng del ADN amplificado con 3pmol del oligonucleótido correspondiente, logrando un volumen final de $8 \mu \mathrm{L}$ de reacción. 


\subsection{ANALISIS BIOINFORMATICO DE LAS SECUENCIAS}

El diseño de oligonucleótidos específicos para PCR o secuenciación se llevó a cabo con el programa Oligo 4.05 Primer Analysis Software (National Biosciences, Inc.).

La lectura y tratamiento de las secuencia automáticas se llevó a cabo con ayuda del programa Chromas lite (http://www.technelysium.com.au/chromas_lite.html).

Para la actualización bibliográfica se utilizó la base de datos Medline de la Nacional Library of Medicine (http://www.ncbi.nih.gov/entrez/query.fcgi).

Para determinar si las mutaciones encontradas eran conocidas o no, se usó la base datos publicada en internet, que agrupa todas las alteraciones encontradas para esta enfermedad (http://www.hhtmutationdatabase.com), así como la base de datos The Human Gene Mutation Database at the Institute of Medical Genetics in Cardiff “HGMD” (http://www.hgmd.cf.ac.uk)

\subsection{ESTUDIOS POBLACIONALES}

Para llevar a cabo la confirmación de la patogenicidad de las mutaciones no descritas en la literatura y con el fin de descartar que la alteración se deba a un polimorfismo presente en la población española, se procedió a su estudio en 100 pacientes control, tomados al azar, mediante la técnica de análisis de los fragmentos amplificados por Heterodúplex. Para ello usamos la técnica descrita por Orita, con algunas modificaciones (Orita et al., 1989). El gel fue teñido con nitrato de plata.

El paso inicial del análisis consiste en desnaturalizar el producto de PCR a $95^{\circ} \mathrm{C}$ y volver a renaturalizarlo, para permitir la formación de heterodúplex (apareamiento entre cadenas que difieren en su secuencia) en el caso de individuos heterocigotos (fig.12). Heterodúplex y homodúplex migran de manera diferencial en geles de acrilamida (fig.12). 


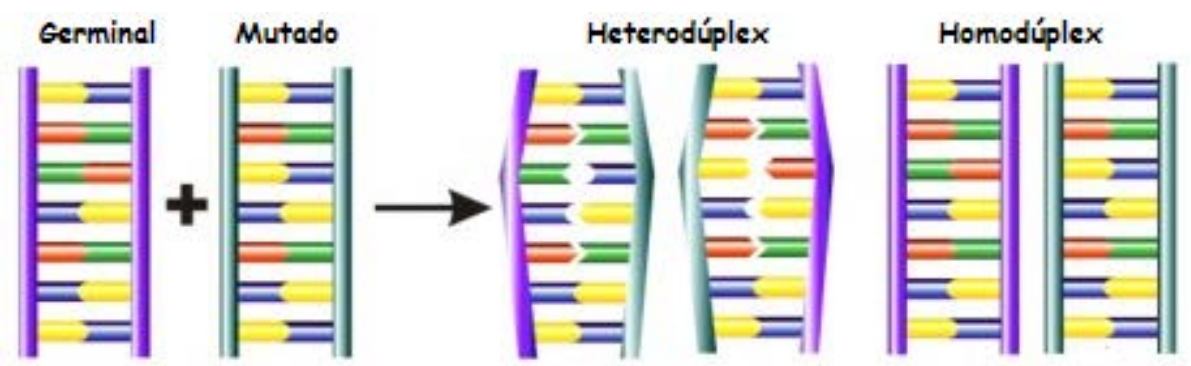

Figura 12. Formación de heterodúplex tras la desnaturalización y posterior renaturalización del producto de PCR en un individuo heterocigoto.

Los geles para electroforesis fueron hechos con MDE ${ }^{\mathrm{TM}} 2 \mathrm{X}$ (AT Biochem, Inc. USA), que es un polímero modificado derivado del vinilo. Se utilizaron las siguientes cantidades para preparar cada gel: agua destilada $7.705 \mathrm{~mL}$, formamida $99 \% 5.98 \mathrm{~mL}$, etilenglicol 99\% 4.025mL, TBE 10X 2.415mL, MDE ${ }^{\mathrm{TM}} 2 \mathrm{X} 20.125 \mathrm{~mL}$, TEMED (N, N, N, N’ Tetrametilendiamina) $36.8 \mu \mathrm{L}$, AMPS 25\% $138 \mu \mathrm{L}$. La electroforesis se llevó a cabo a 180 voltios durante aproximadamente 21 horas (el tiempo varía dependiendo del tamaño del fragmento de PCR).

Para la tinción de plata se utilizó el kit comercial DNA Silver Staining Kit de Amershan Pharmacia, con un volumen de 250mL, siguiendo las instrucciones del comerciante.

Los fragmentos de PCR de un mismo exón de distintos pacientes, con distintos patrones de migración en el gel de acrilamida, fueron posteriormente secuenciados (fig. 13).

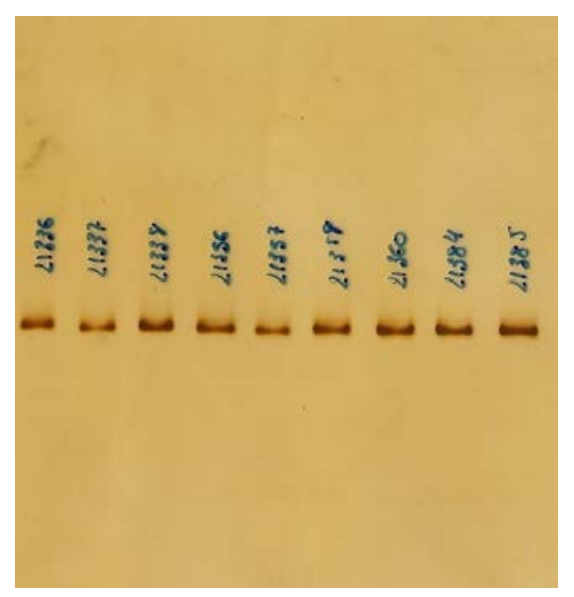

Figura 13. Heterodúplex sin alteraciones correspondiente al exón 3 del gen ALK1 
Posteriormente, también se realizó un estudio In Sílico de las mutaciones missense no descritas, buscando conocer el comportamiento teórico de las mismas en los genes y su grado de implicación en la función de la proteína. Para llevarlo a cabo se usaron los siguientes programas informáticos:

PolyPhen (http://www.bork.emblheidelberg.de/Polyphen)

Predice el posible impacto de una sustitución aminoacídica en la estructura y función de una proteína humana, empleando consideraciones físicas y comparativas. Para llevar a cabo la predicción realiza un alineamiento de secuencias pertenecientes a proteínas homólogas en las especies que se encuentran descritas en BLAST. El resultado del mismo es empleado por el software PSIC (Position Specific Independent Counts) para calcular la matriz del perfil. Los elementos de la matriz (valores del perfil) son ratios logarítmicos que indican la probabilidad de que en una posición determinada se encuentre un aminoácido, frente a que este aminoácido se localice en cualquier posición (frecuencia de fondo). PolyPhen analiza los valores absolutos de la diferencia entre los valores de perfil de las dos variantes alélicas en la posición polimórfica. Un valor muy alto de esta diferencia podría indicar que la sustitución estudiada aparece poco o nada en la familia de proteínas.

Los resultados del estudio pueden determinar que el cambio es:

- Probablemente patogénico: existe una gran probabilidad de que afecte a la estructura o a la función de la proteína

- Posiblemente patogénico: se cree que podría afectar a la función o estructura proteica

- Benigno: es muy probable que carezca de efecto fenotípico

- Desconocido: en algunos casos, cuando por carencia de datos no se puede hacer una predicción

PolyPhen también muestra un número de secuencias alineadas en la posición de búsqueda para el análisis de la conservación interespecie ordenadas de mayor a menor homología en la secuencia de la proteína dada.

SNPS3D (hhtp://www.snps3d.org/)

Este programa basa su predicción en la hipótesis de que muchos SNPs patogénicos afectan a la función de la proteína disminuyendo su estabilidad. Emplea el 
software SVM (support Vector Machine) para encontrar el patrón de diferenciación entre los SNPs asociados a enfermedad y los neutrales. La tasa de falsos positivos y negativos es de $15 \%$ y $26 \%$, respectivamente.

También emplea un segundo modelo que se basa en el análisis de la homología de secuencia en familias de proteínas relacionadas con proteínas humanas. El nivel de conservación de una posición y la probabilidad de observar una variación en una familia hace posible distinguir entre mutaciones patogénicas y neutrales, con unas tasas de falsos positivos y negativos del 10 y 20\%, respectivamente.

Un resultado positivo para el valor de SVM indica que se trata de una variante clasificada como neutral, mientras que un valor negativo la identifica como un cambio patogénico. Cuanto mayor es el valor, más probable es la clasificación. La precisión es significativamente mayor cuando los valores están por encima de 0,5 o por debajo de 0,5. Para las variantes que afectan más a la función de la proteína que a la estabilidad, el modelo de estabilidad es positivo y el modelo del perfil debe ser negativo. La precisión es significativamente mayor cuando los dos métodos coinciden.

Pmut (http:// mmb2.pcb.ub.es:8080/PMut)

Este programa predice si una mutación puede ser patogénica o neutral. Se basa en las características de la secuencia y en un software de una o dos redes neurales NN (neural network) que emplean bases de datos internas y predicen la estructura secundaria y la conservación de la secuencia. En los resultados proporciona una respuesta afirmativa o negativa y un índice de credibilidad. Estos resultados varían en un rango de 0 a 1 , donde un valor 0 indica que la mutación es neutral, mientras que los valores más altos indican patogenicidad. También permite relacionar la mutación con la estructura proteica. La tasa de error de esta predicción oscila entre un 12 y un 21\% para los falsos positivos y entre un 10 y un $17 \%$ para los falsos negativos.

\section{SIFT (http://sift-dna.org)}

Este programa es una herramienta que clasifica las sustituciones de aminoácidos en una proteína y predice si estos cambios provocarán un efecto en el fenotipo. Se basa en la premisa de que los aminoácidos importantes de una proteína están conservados en la evolución, por lo que los cambios en los mismos deben afectar a la funcionalidad de la proteína. Con una secuencia proteica dada, SIFT escoge proteínas relacionadas y 
forma un alineamiento múltiple de éstas y basándose en los aminoácidos presentes en cada posición del alineamiento, realiza una predicción de las sustituciones que afectarán a la proteína. Las sustituciones en una posición conservada en el alineamiento serán consideradas "no toleradas” para la mayoría de los cambios, mientras que las posiciones que no están conservadas en el alineamiento tolerarán mejor los cambios de aminoácido.

Esta premisa se realiza calculando las probabilidades normalizadas para todas las posibles sustituciones del alineamiento. Las sustituciones con una puntuación menos de 0,05 serán clasificadas como deletéreas y las puntuaciones mayores o iguales a 0,05, “tolerables” o neutrales.

La precisión en las predicciones de SIFT oscila entre 60-80\%, obteniéndose un $30 \%$ de falsos positivos, aproximadamente. No obstante, la precisión de las predicciones depende del alineamiento que se obtenga en cada caso. 


Hemos estudiado 24 familias, estableciéndose como caso índice aquél que cumplía, al menos, 1 de los 4 criterios de Curaçao ya descritos.

La distribución por síntomas presentados en el momento del diagnóstico se establece en la figura 14:

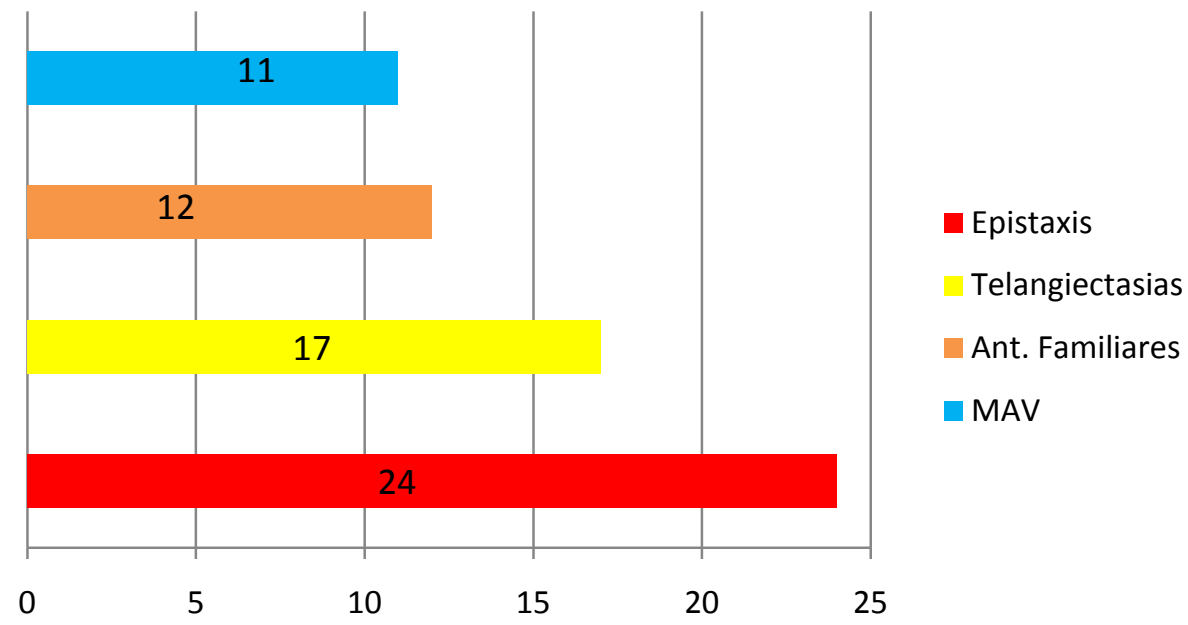

Figura 14. Distribución de pacientes por síntomas

Como puede observarse, la totalidad de los pacientes presentaban epistaxis en el momento del diagnóstico, hallazgo en consonancia con lo descrito hasta el momento en otras series, donde se considera este síntoma como el mayoritariamente presente en todos las personas afectas de este síndrome. Junto a este síntoma, una gran mayoría de los pacientes presentaban telangiectasias en lugares típicos (figura 15a), apareciendo predominantemente en los labios, seguido de la zona malar, los dedos de ambas manos y ya con menor frecuencia, en lengua, paladar y pabellón auricular (figura 15b)

De los 12 casos que presentaban familiares con lesiones sugerentes de HHT, sólo uno refería que su hermana había sido estudiada en otra unidad genética diferente a la nuestra. Sin embargo, los datos obtenidos fueron únicamente verbales, sin tener acceso a ningún informe oficial donde se estableciese el diagnóstico clínico ni genético, por lo que el estudio que llevamos a cabo se hizo como si el diagnóstico fuera “de novo”, aplicando el mismo protocolo de actuación que en el resto de los casos presentados. 


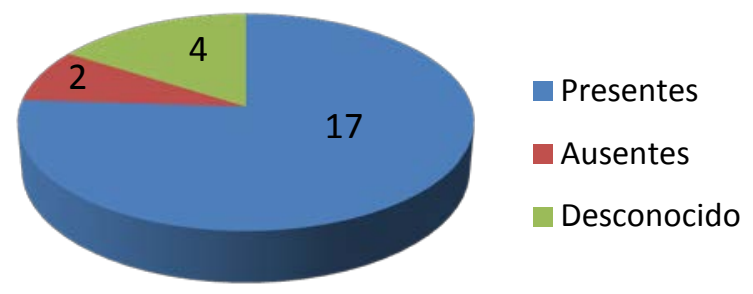

Figura 15a. Pacientes con telangiectasias

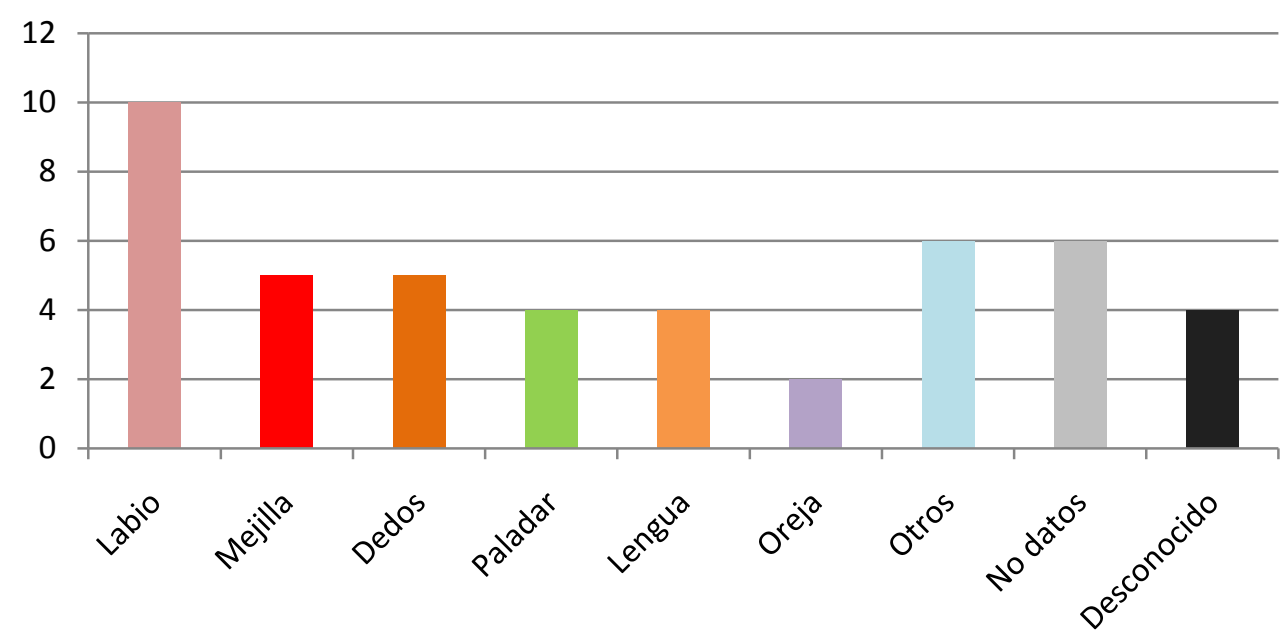

Figura 15b. Localización de telangiectasias

11 de los 24 casos presentaban en el momento del diagnóstico algún tipo de malformacion arteriovenosa mayor (MAV) en los órganos considerados diana de esta enfermedad (pulmón, cerebro, tracto gastrointestinal y mucosa nasal). De todos ellos, predominaron las lesiones a nivel digestivo (6 casos, 3 de ellos con lesiones a nivel hepático exclusivamente), recibiendo diferentes tratamientos en cada caso dependiendo del momento histórico en que fueron diagnosticadas. Sólo un paciente presentaba una lesión a nivel nasal, que había sido embolizada muchos años atrás, después de ser considerada como un hallazgo casual sin relacionarlo con otros síntomas que iría desarrollando el paciente con la edad.

En el caso de las malformaciones cerebrales, el único paciente que las presentaba aún no había recibido tratamiento alguno en el momento de solicitar el 
estudio genético y había padecido un ingreso por crisis convulsivas asociado a hemorragia subaracnoidea aguda.

De los 3 pacientes que presentaban malformaciones pulmonares, sólo tenemos datos de un caso que estaba siendo tratado en el momento del diagnóstico mediante embolización y colocación de “coils” que obliteraran la lesión (figura 16).

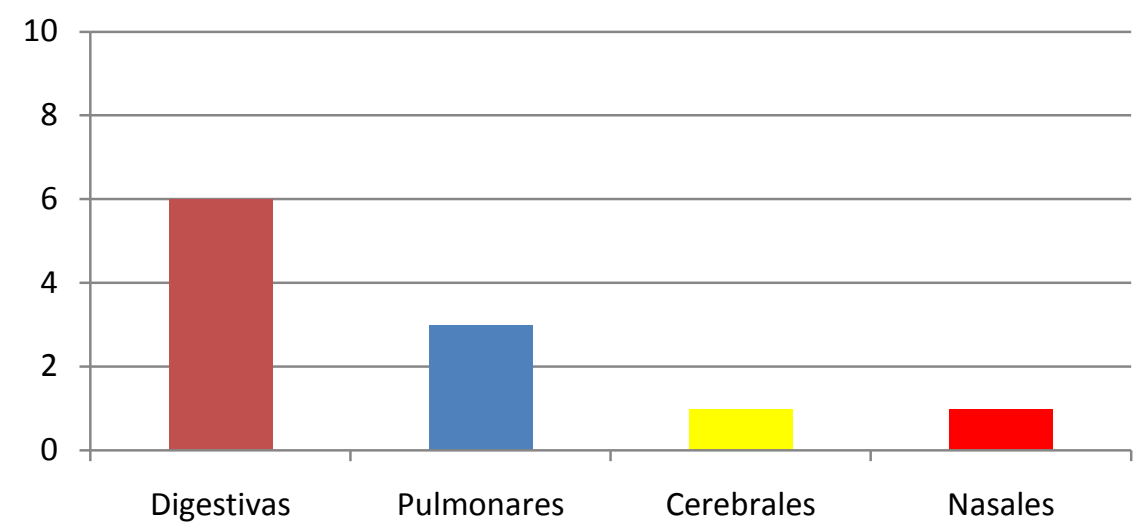

Figura 16. Localización de las MAVs en órganos diana

Una vez determinadas las características clínicas de los diferentes pacientes, realizamos el estudio molecular mediante la búsqueda de mutaciones, analizando los genes Endoglina (ENG), ALK1 (ACVRL1) y SMAD4. El orden de búsqueda en cada familia se estableció en función de la clínica presentada y la edad de inicio de los síntomas. En aquellos casos en los que no se disponía de información clínica precisa, el estudio se inició por ALK1 pues, según se describe en la literatura, es el gen mutado con más frecuencia en los pacientes nacidos en los países del área mediterránea. En todos los casos, el estudio se realizó mediante secuenciación directa de todos los exones codificantes de cada gen.

En nuestro trabajo hemos encontrado un total de 20 mutaciones, de las cuales 14 han sido descritas previamente por otros grupos (tablas 6a y 6b) y 6 eran desconocidas (tablas 7a y 7b). Entre las ya descritas, 6 eran patogénicas, 4 localizadas en la región exónica y 2 en regiones intrónicas implicadas en el procesamiento del ARN. El resto de mutaciones conocidas están descritas como polimorfismos y se localizan tanto en región intrónica (4 casos), como exónica (4 casos)

De las 5 mutaciones no descritas hasta el momento, 4 se localizaron en exones y una en zona intrónica alejada de la región codificante. De las 4 exónicas, una se localizó 
en el exón 14, en dos hemos realizado estudios bioinformáticos para determinar su carácter y la restante era una deleción de pequeño tamaño. La mutación en la posición +22 de la zona intrónica se consideró como un polimorfismo, ya que estaba presente en varios individuos, incluyendo alguno que presentaba otra mutación patogénica.

Tabla 6a. Mutaciones patogénicas conocidas

\begin{tabular}{|c|c|c|c|c|c|}
\hline $\begin{array}{l}\text { Paciente } \\
\text { Índice }\end{array}$ & Gen & Exón & $\begin{array}{l}\text { Mutación } \\
\text { cDNA }\end{array}$ & $\begin{array}{l}\text { Mutación } \\
\text { Proteína }\end{array}$ & $\begin{array}{c}\text { Referencia } \\
\text { bibliográfica }\end{array}$ \\
\hline 17853 & ALK1 & Intrón 9 & c. $1378-1 \mathrm{G}>\mathrm{T}$ & r.sp1 & $\begin{array}{c}\text { Fontalba et } \\
\text { al,2008 }\end{array}$ \\
\hline 19988 & ALK1 & 7 & c. $924 \mathrm{C}>\mathrm{A}$ & p.C308X & $\begin{array}{c}\text { Berg JN et al, } \\
1997\end{array}$ \\
\hline 22530 & ENG & Intrón 3 & c. $361-2$ A>G & - & $\begin{array}{c}\text { Gallione et al, } \\
1998\end{array}$ \\
\hline 19822 & SMAD4 & 8 & c. $1082 \mathrm{~A}>\mathrm{G}$ & p.R361H & $\begin{array}{c}\text { Kim IJ et al, } \\
2000\end{array}$ \\
\hline 23043 & ALK1 & 6 & c. $656 \mathrm{G}>\mathrm{A}$ & p.Gly219Asp & $\begin{array}{l}\text { Lenato et al, } \\
2006\end{array}$ \\
\hline 23120 & ALK1 & 8 & c. $1135 \mathrm{G}>\mathrm{A}$ & p.Glu379Lys & $\begin{array}{l}\text { Lesca et al, } \\
2004\end{array}$ \\
\hline
\end{tabular}

Tabla 6b. Polimorfismos conocidos

\begin{tabular}{|c|c|c|c|c|c|}
\hline $\begin{array}{l}\text { Número de } \\
\text { casos }\end{array}$ & Gen & Exón & $\begin{array}{c}\text { Mutación } \\
\text { cDNA }\end{array}$ & $\begin{array}{l}\text { Mutación } \\
\text { Proteína }\end{array}$ & $\begin{array}{c}\text { Referencia } \\
\text { bibliográfica }\end{array}$ \\
\hline 15 & ALK1 & Intrón 3 & c. $313+11 \mathrm{C}>\mathrm{T}$ & - & $\begin{array}{c}\text { Olivieri et al, } \\
2002\end{array}$ \\
\hline 3 & ENG & 8 & c. 1029 C>T & p.T343T & $\begin{array}{c}\text { Shovlin et al, } \\
1997\end{array}$ \\
\hline 16 & ALK1 & Intrón 9 & $\begin{array}{c}\text { c. } 1377+45 \\
\mathrm{~T}>\mathrm{C}\end{array}$ & - & $\begin{array}{c}\text { Gedge } \mathrm{F} \text { et al, } \\
2007\end{array}$ \\
\hline 2 & ENG & 1 & c. $14 \mathrm{C}>\mathrm{T}$ & p.T5M & $\begin{array}{c}\text { Shovlin et al, } \\
1997\end{array}$ \\
\hline 3 & ALK1 & Intrón 1 & c. $1-38 \mathrm{C}>\mathrm{T}$ & - & $\begin{array}{c}\text { Abdalla et al, } \\
2003\end{array}$ \\
\hline 2 & ENG & 8 & c. 1038 C>T & p.T343T & \\
\hline 1 & ENG & Intrón 3 & c. $360+21 \mathrm{C}>\mathrm{T}$ & - & $\begin{array}{c}\text { Gedge F et al, } \\
2008\end{array}$ \\
\hline 2 & ENG & 2 & c. $207 \mathrm{G}>\mathrm{A}$ & p.L69L & $\begin{array}{c}\text { Shovlin et al, } \\
1997\end{array}$ \\
\hline
\end{tabular}


Tabla 7a. Mutaciones no conocidas

\begin{tabular}{|c|c|c|c|c|}
\hline Paciente & Gen & Exón & $\begin{array}{c}\text { Mutación } \\
\text { cDNA }\end{array}$ & $\begin{array}{l}\text { Mutación } \\
\text { Proteína }\end{array}$ \\
\hline 16678 & ALK1 & 3 & c. $244 \mathrm{C}>\mathrm{A}$ & p.T82P \\
\hline 17580 & ENG & Intrón 11 & c. $1686+1 \mathrm{G}>\mathrm{A}$ & - \\
\hline 18013 & ALK1 & 6 & c.641 G>A & p.G214A \\
\hline 12241 & ENG & $9 \mathrm{~A}$ & c.1256_1268del13 & p.S419MfsX490 \\
\hline
\end{tabular}

Tabla 7b. Polimorfismos no conocidos

\begin{tabular}{|c|cccc|}
\hline \multirow{2}{*}{$\mathrm{N}^{\text {a de casos }}$} & Gen & Exón & $\begin{array}{c}\text { Mutación } \\
\text { cDNA }\end{array}$ & $\begin{array}{c}\text { Mutación } \\
\text { Proteína }\end{array}$ \\
\hline 1 & ENG & 14 & c.1893 C>T & p.S630S \\
\hline & ENG & Intrón 9B & c.1311+22 insT & - \\
\hline
\end{tabular}

\section{PACIENTE 17853 (ALK-1 c.1378-1 G>T; r,sp1)}

El probando es una mujer de 61 años de edad, natural de la provincia de Zamora (Castilla y León, España), de raza caucásica, con antecedentes personales de enfermedad celiaca, que mantenía revisiones periódicas en el Servicio de Aparato Digestivo del Hospital Universitario de Salamanca (HUS) por este motivo.

En la historia clínica refiere epistaxis de repetición que se habían iniciado en torno a los 40 años de edad, acompañadas por la aparición progresiva de telangiectasias en labios, lengua y área malar. Las epistaxis le habían producido cuadros de anemia severa que, en alguna ocasión, habían requerido transfusión de concentrados de hematíes.

Su madre, su hermana, dos de sus hijos y varios sobrinos presentaban manifestaciones clínicas compatibles con HHT (figura 17). 


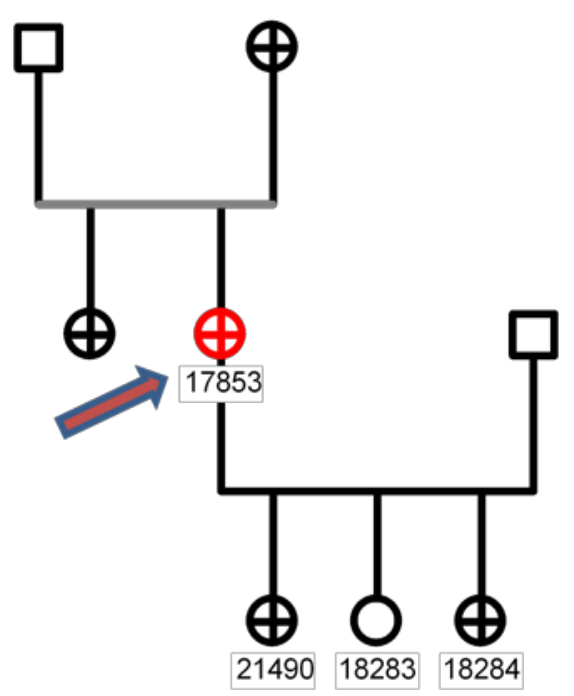

Figura 17. Árbol genealógico del probando 17853

Se realizaron exploraciones complementarias con el fin de hallar malformaciones vasculares que mostraron:

a) TC abdominal: estructuras vasculares en hilio hepático y peripancreático, con aumento de calibre en tronco celiaco y arteria hepática, compatible con fístula arteriovenosa (figura 18)

b) Angiografía hepática: dilatación arteria hepática y sus ramas. Pequeñas telangiectasias intrahepáticas

c) Endoscopia: varices esofágicas. Lesiones vasculares en estómago y duodeno

d) Colonoscopia: hemorroides. Telangiectasias en colon

e) Biopsia hepática: lesiones vasculares múltiples

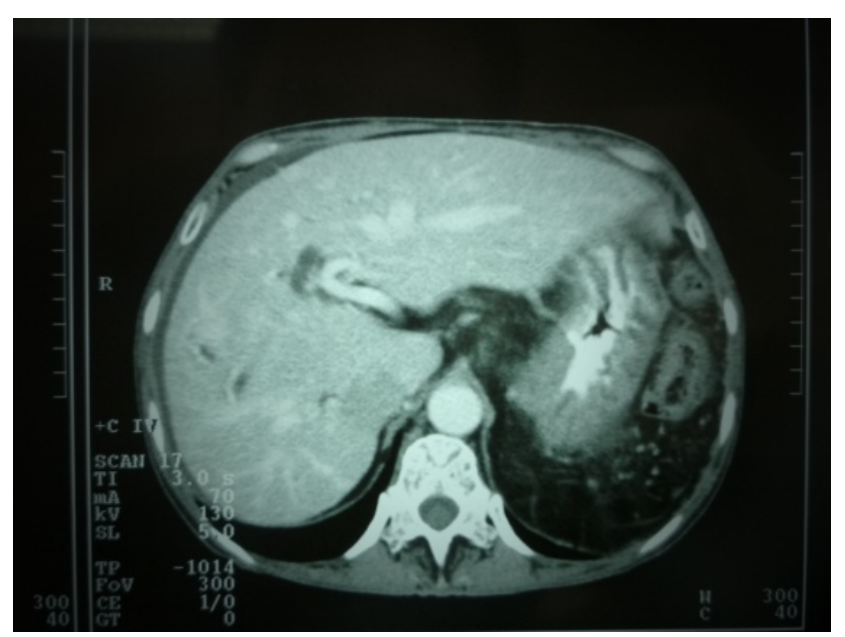

Figura 18. Corte axial de TC abdominal donde se observa malformación vascular hepática 
Dada las características clínicas de la paciente, se decidió incluirla dentro del grupo HHT-2 y en consecuencia, iniciar el estudio por el gen ALK1 para lo que se amplificaron los 9 exones codificantes del gen ALK1 con los oligonucleótidos descritos en el apartado de material y métodos. Los fragmentos amplificados fueron separados mediante electroforesis en geles de agarosa al $2 \%$.

Para confirmar la existencia de mutaciones, procedimos a la purificación de los fragmentos de PCR y a su secuenciación, encontrando una alteración en el intrón 9 del gen ALK1 (figura 19):

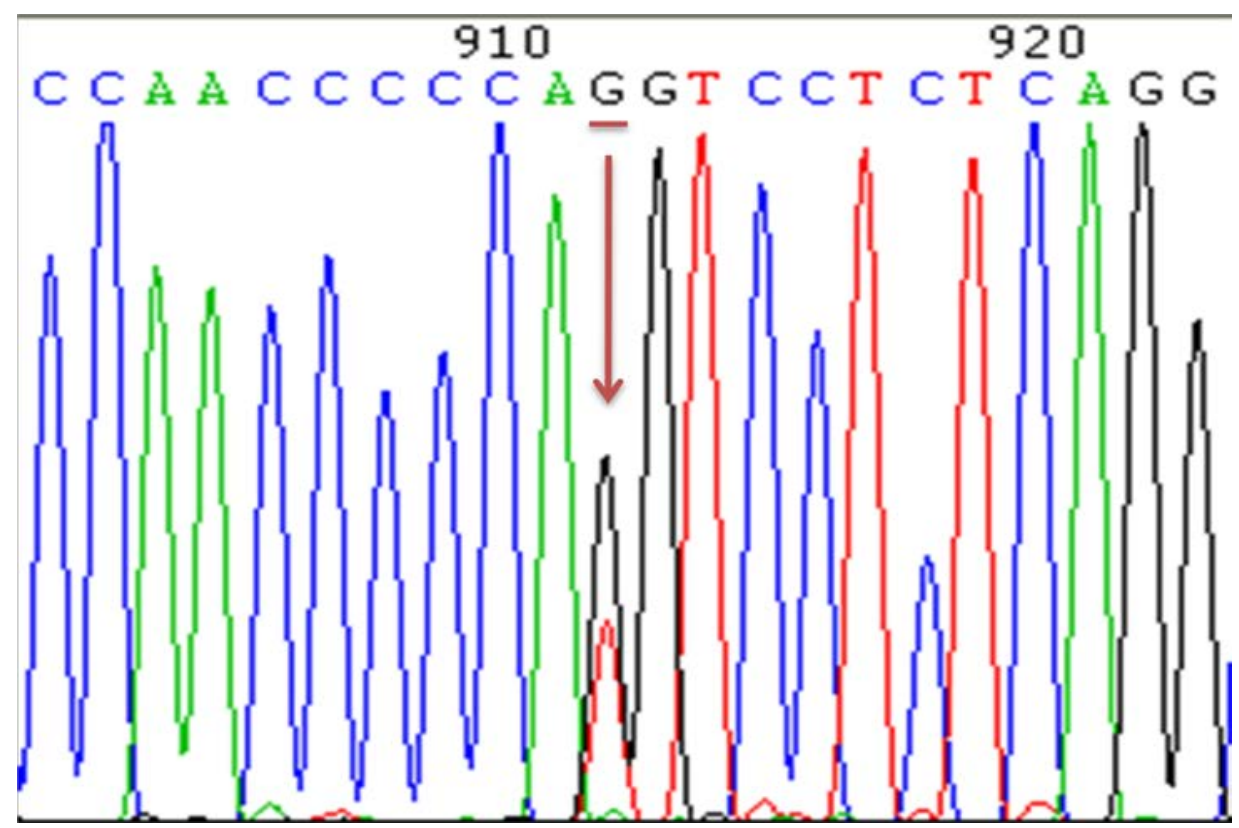

Figura 19. Cromatograma del exón 10 del gen ALK1 en paciente 17853 donde se observa mutación en heterocigosis

La alteración encontrada consiste en un cambio de base en la posición 1378-1 de una Guanina (G) por una Timina (T).

Una vez encontrada la alteración, se amplió el estudio familiar realizándose el análisis en sus 3 hijas, encontrando la mutación en dos de ellas que cumplían tres criterios de Curaçao, aunque ninguna presentaba aparentemente AVM (tabla 8): 
Tabla 8. Estudio mutacional en descendientes paciente 17853

\begin{tabular}{|ccc|}
\hline FAMILIAR & $\begin{array}{c}\text { CRITERIOS } \\
\text { CURAÇAO }\end{array}$ & MUTACIÓN \\
\hline $\mathbf{1 8 2 8 3}$ & 3 & Ausente \\
\hline $\mathbf{1 8 2 8 4}$ & $1+2+3$ & Presente \\
\hline $\mathbf{2 1 4 9 0}$ & $1+2+3$ & Presente \\
\hline 1.Epistaxis; 2. Telangiectasias; 3. Historia familiar; 4. Malformaciones arteriovenosas
\end{tabular}

Esta mutación está descrita previamente en población española y es considerada como patogénica (Fontalba A et al, 2008).

\section{PACIENTE 16678 (ALK-1 c.244 C>A; p.T82P)}

El probando es una mujer de 61 años de edad, natural de la provincia de Salamanca (Castilla y León, España), de raza caucásica, con antecedentes personales de asma bronquial y artrosis, alérgica a las picaduras de abeja, que mantenía revisiones periódicas en el Servicio de Digestivo del Hospital Universitario de Salamanca (HUS) por episodios de hemorragia digestiva alta de repetición (HDA).

Los síntomas de la enfermedad comenzaron cuando tenía 33 años, manifestándose como hemorragia digestiva alta (HDA). Al realizar gastroscopia se comprobó la presencia de una lesión en la mucosa del cuerpo gástrico. Con los años se fueron haciendo frecuentes los episodios de epistaxis y la aparición de telangiectasias en varios dedos de la mano, motivo por el que consultó con el Servicio de Dermatología del HUS, quien realiza el diagnóstico clínico de la enfermedad tras la realización de biopsia de varias de las lesiones descritas. Con el tiempo, las lesiones fueron apareciendo también en lengua y cavidad oral.

Dos de sus hijos y dos nietos presentaban manifestaciones clínicas compatibles con diagnóstico de HHT (figura 20). 


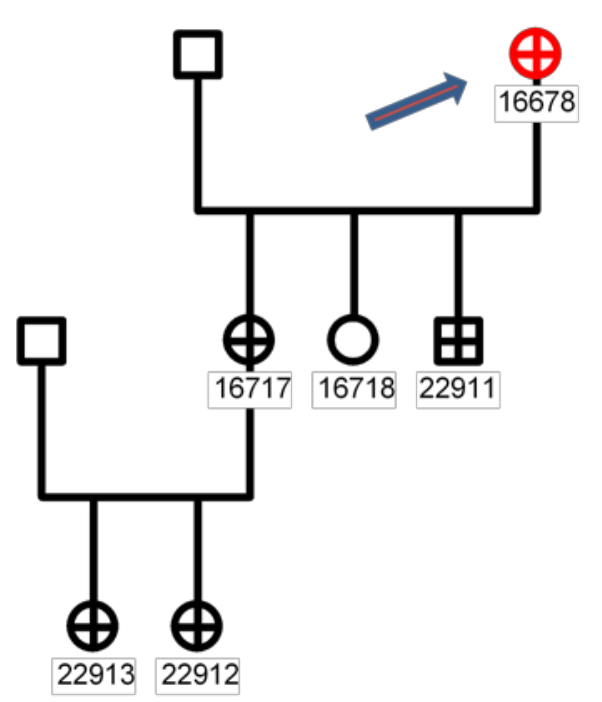

Figura 20. Árbol genealógico paciente 16678

La paciente ha sufrido numerosas HDA a lo largo de su vida, realizándose diferentes gastroscopias en las que se visualizaron numerosas lesiones vasculares que, en alguna ocasión, requirieron coagulación con láser de Argón (figura 21).
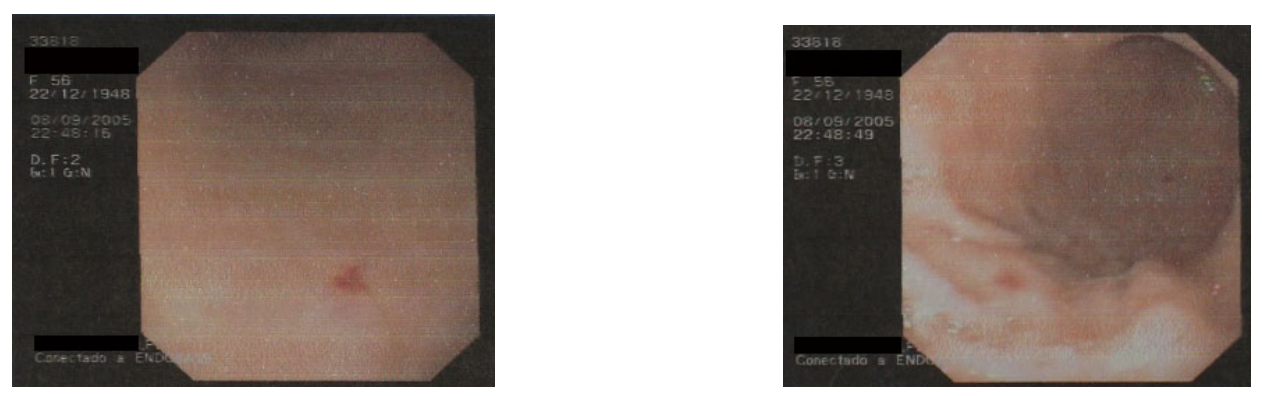

Figura 21. Imágenes de malformaciones vasculares en mucosa gástrica

El rastreo de otras manifestaciones vasculares mostró:

a) O.R.L.: ectasias vasculares en área de Kiesselbach

b) Oftalmología: atrofia peripapilar y esclerosis vascular en ojo derecho. No signos de retinopatía hipertensiva.

c) Tránsito intestinal: sin hallazgos

d) Ecografía abdominal: tamaño normal. Múltiples imágenes sugerentes de fístulas arterio-venosas, sin definir lesiones focales. Dilatación leve de vena cava y arterias suprahepáticas (figura 22)

e) TC cerebral: sin hallazgos

f) R.M.N.: sin hallazgos 

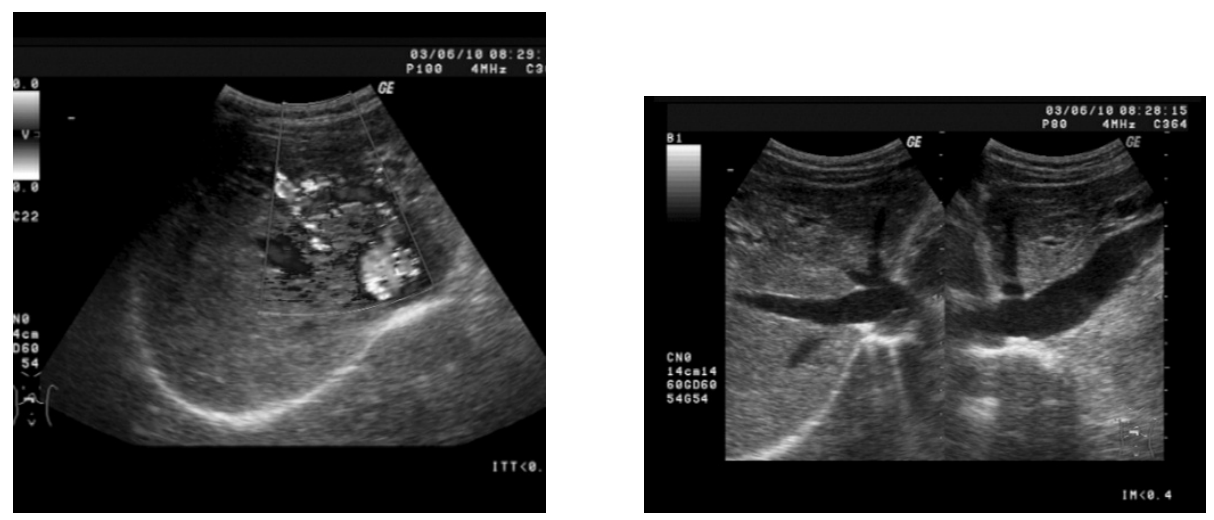

Figura 22. Fístulas arteriovenosas hepáticas

Dada las características clínicas de la paciente, se decidió incluir dentro del grupo HHT-2 y, en consecuencia, iniciar el estudio genético por el gen ALK1.

Tras la purificación de los fragmentos de PCR y su secuenciación, encontramos una mutación en el exón 3 del gen ALK1 (fig. 23):

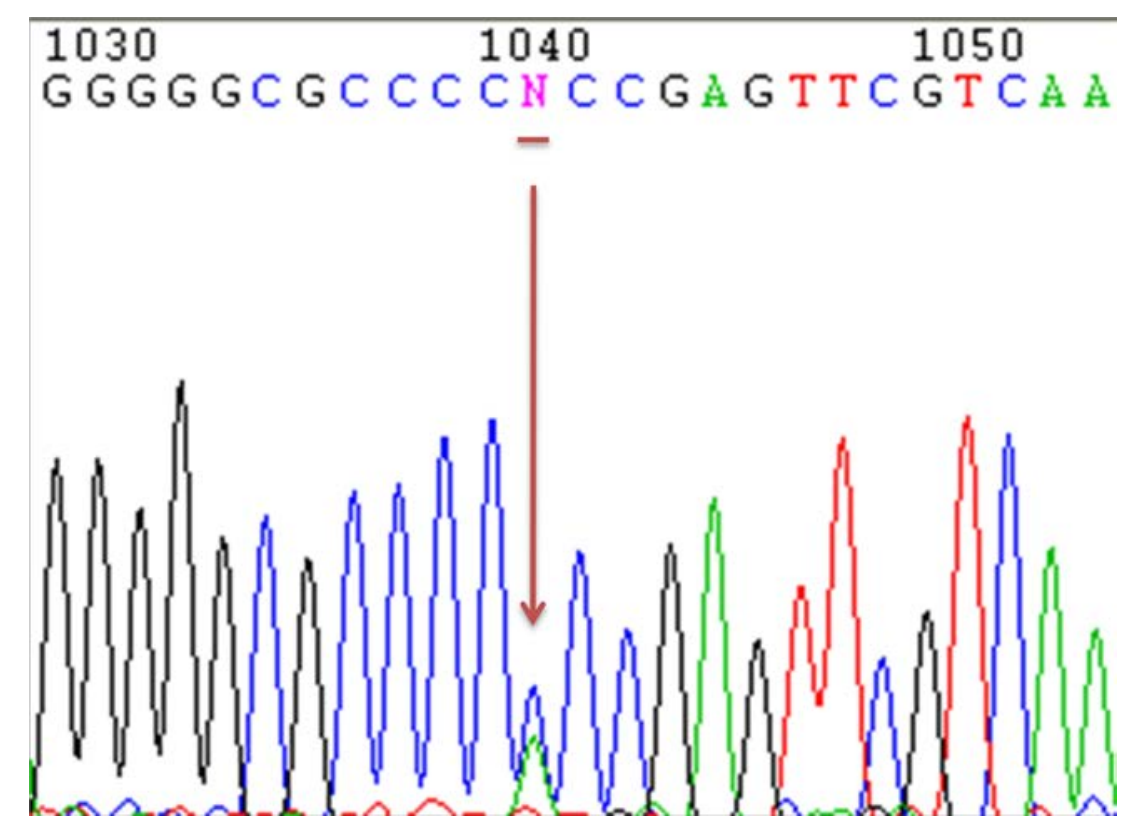

Figura 23. Mutación encontrada en el exón 3 del gen ALK1 en paciente 16678

La alteración encontrada consiste en un cambio de base en la posición 244 del cDNA, de manera que donde debía existir una Cisteína (C), encontramos una Adenina (A). Este cambio también afecta a la proteína, pues cambia el aminoácido del codón 82, de manera que en vez de Treonina (Thr/T) encontramos una Prolina (Pro/P) en su lugar.

El estudio posterior de los 3 hijos y 2 de sus nietos puso de manifiesto la presencia de la mutación en dos de los hijos y en uno de los nietos (tabla 9): 
Tabla 9. Estudio mutacional en descendientes paciente 16678

\begin{tabular}{|ccc|}
\hline FAMILIAR & $\begin{array}{c}\text { CRITERIOS } \\
\text { CURAÇAO }\end{array}$ & MUTACIÓN \\
\hline $\mathbf{1 6 7 1 7}$ & $1+2+3$ & Presente \\
\hline $\mathbf{1 6 7 1 8}$ & 3 & Ausente \\
\hline $\mathbf{2 2 9 1 1}$ & $1+2+3$ & Presente \\
& & \\
\hline $\mathbf{2 2 9 1 2}$ & - & Ausente \\
& & \\
\hline $\mathbf{2 2 9 1 3}$ & - & Presente \\
& & \\
\hline
\end{tabular}

1.Epistaxis; 2. Telangiectasias;3. Historia familiar; 4. Malformaciones arteriovenosas

La mutación no está descrita en las bases de datos ni ha sido publicada previamente, por lo que se decidió realizar un estudio poblacional para intentar descartar que la alteración encontrada no fuera un polimorfismo poblacional.

Dicho estudio se realizó sobre una muestra de 100 individuos sanos, seleccionados aleatoriamente en la población general, mediante análisis de heterodúplex, no encontrándose la alteración en ningún caso (figura 24)

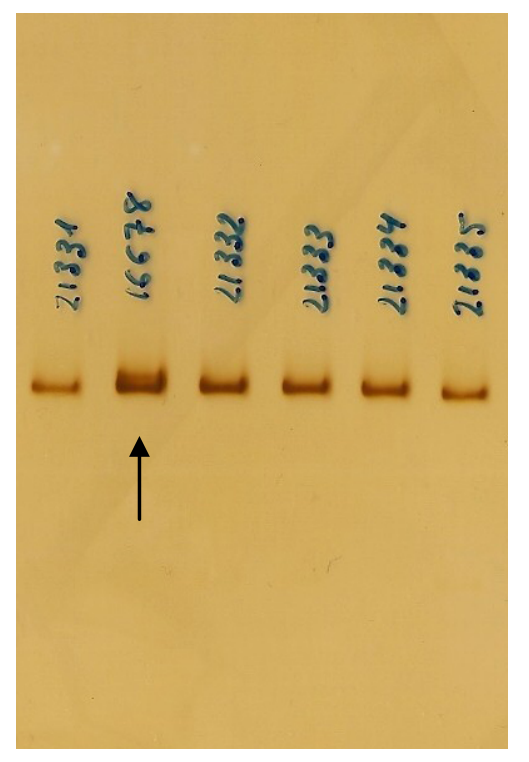

Figura 24. Heterodúplex de exón 3 del gen ALK1 
Como la mutación encontrada es de tipo “missense” y desconocíamos su efecto sobre la proteína, se realizó un estudio “in silico” con la intención de predecir si su efecto es patogénico y en consecuencia, capaz de inducir la expresión fenotípica de la enfermedad. Para llevarlo a cabo, usamos las herramientas bioinformáticas descritas en el apartado de material y métodos. Como mostramos en la tabla 10, todos los programas consideran la alteración como neutral o no patogénica.

Tabla 10. Estudio “in silico” para mutación T82P

\begin{tabular}{|c|c|c|c|c|c|c|c|c|}
\hline Mutación & $\begin{array}{c}\text { PolyPhen } \\
2\end{array}$ & Valor & SIFT & Valor & SNP33D & Valor & PMut & Valor \\
\hline T82P & $\mathrm{N}$ & 0.002 & $\mathrm{~N}$ & 0.98 & $\mathrm{~N}$ & 1.82 & $\mathrm{~N}$ & 0.1783 \\
\hline
\end{tabular}

El estudio de conservación del amonoácido entre especies muestra que no es estable y aunque la prolina no aparece en ninguna especie, podemos suponer que su alteración no tendrá efectos importantes (figura 25).

\begin{tabular}{|c|c|c|c|}
\hline & JERY: & & \\
\hline IeffXP 534796.21 & EDICTED: similar to Serine/threonine-protein ... & . . REEGRHPQEHRGCGNLNEELCRGR & FVNHYCCYSPLCNHNVSLVLEATQ $\ldots$ \\
\hline flXP 001145379.1 & EDICTED: activin A receptor type II-like $1 \ldots$ & . REEGRHPQEHRGCGLHRELCRGR & T FVNHYCCDSHLCNHIVSLVLEATQ... \\
\hline refiNP 071888.1 & tivin A receptor type II-like 1 [Rattus norve... & . REQGRHPQVYRGCGSLNQELCLGR & T FVNHHCCYR SECNHNVSLMLEATQ. \\
\hline refiNP 001078948.1 & hypothetical protein LOC534536 [Bos taurus] ... & ...WEDG-HLREYRGCMMHPEVCRAR: & FVNHYCCYSPLCNHNVSLTLEATQ $\ldots$ \\
\hline fINP 001017357.11 & tivin A receptor, type I [Xenopus tropical... & $\ldots$ NNDGVLVSQ-KGCFQVYEQTCKTP & DQAVECCQSDLCMMNITVKLTGRT $\ldots$ \\
\hline JIAC98806.11 & e I TGF B receptor [Gallus gallus] & . INDGAKVYQ-KGCFQVYEQTCKTPA & \begin{tabular}{l|l}
$S$ & $D Q A V E C C Q Y L C M N I T A K L P S S$
\end{tabular}. \\
\hline INP 57 & rerio] >g... & ...SNDVITEK--RGCPASKRMTCSAT & SHVVECCSQHMCNANVSLIRLLIT . . \\
\hline$f \mid X P \quad 856$ & EICTED: similar to activin A type I receptor... & ...INDGFHVYQ-KGCFQVYEQTCKTP & EQAVECCQGDWCNRNITAQLPTSF $\ldots$ \\
\hline fIXP 001373601.1 & EDICTED: similar & ..INDGVQVYQ-KGCFQVYEQTCKTP & DQAVECCQGNWCNGNITAQLPTSK. \\
\hline EfIXP 856199.11 & EDICTED: similar to activin A type I receptor... & . INDGFHVYQ-KGCFQVYEQTCKTP & GQAVECCQGDWCNRNITAQLPTSF. \\
\hline mb|CAG09327.11 & lamed protein product [Tet & . VVSAGALVYQ-KGCFKVYEQTCKTPA & DQVVECCY $G H L C N L N S S V E L P V K A$. \\
\hline b|AA100044.11 & url1 protein [Danio rerio] & . ------HERVVRGCEQT-AEQCYVP & GVYTKCCYTHHCNANLTM----PE. \\
\hline b|AAB 40073.11 & ivin receptor-like kinase [F & 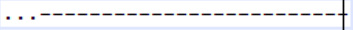 & 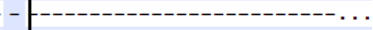 \\
\hline$f \mid X P=9$ & EDIC & . $-0-0-0-0-0-0-0-0-0-0----$ & 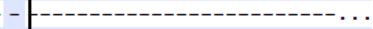 \\
\hline ADEAT 35 & ing & . RDQYGHESVSRGCTTTHEQLCKRH & TYNIECCT $G$ DYCNNGTFPALPPVE. \\
\hline emb|CAC85283.11 & 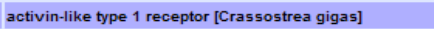 & 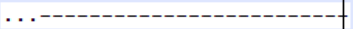 & - \\
\hline gb|AAA28878.11 & tein >gi|746132|prf||2017214B recept... & ...RDADGQVQESRGCSTSPDQISKRN & FVNVVCCAGDYCNEGDFLPFDSND $\ldots$ \\
\hline emb|CAF87400.11 & amed protein product [Tetraodon nigroviridis] & 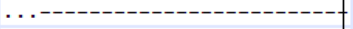 & 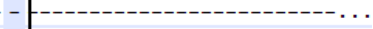 \\
\hline refiXP 001360323.1 & 15112-PA [Drosophila pseudoobscura] >gi & 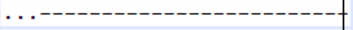 & 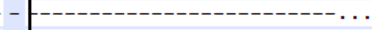 \\
\hline reflXP $308147.3 \mid$ & SANC & 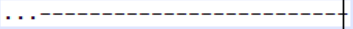 & 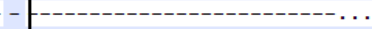 \\
\hline refiXP 79 & & 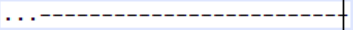 & - \\
\hline & & & FVMECCKNEDYCN--VHLSPRLMQ \\
\hline & & . $K S S G Q T V T Q E R Q C I Q Q D D L Y P R D$ & $\begin{array}{ll}\text { F } & \text { CAHPYCCNTHMCNKNPKVIPEL- }\end{array}$ \\
\hline & & & \\
\hline
\end{tabular}

Figura 25. Conservación aminoácido Treonina en diferentes especies

\section{PACIENTE 19988 (ALK-1 c.924 C>A; p.Cys308X)}

El probando es un varón de 53 años de edad, natural de la provincia de Salamanca (Castilla y León, España), residente habitual en la zona norte de Francia, de raza caucásica, con antecedentes personales de consumidor habitual de grandes cantidades de alcohol diarias, que acude al Servicio de Urgencias del Hospital Universitario de Salamanca (HUS) por epistaxis masiva no controlable en el centro de 
Salud al que pertenece el núcleo rural donde pasaba sus vacaciones, necesitando permanecer ingresado en la planta de O.R.L. durante 48 horas.

El paciente refiere epistaxis de repetición que se habían iniciado en torno a los 20 años de edad, acompañadas de la aparición progresiva de telangiectasias en dedos de la mano. Las epistaxis le habían producido cuadros de anemia severa que, en alguna ocasión, habían requerido transfusión de concentrados de hematíes y había sido tratado en dos ocasiones con embolización a nivel nasal (última en 1992). Durante años fue tratado con ácido tranexámico vía oral, siendo efectivo y disminuyendo la frecuencia de las epistaxis; sin embargo, éstas se reproducían siempre que viajaba de vacaciones a su pueblo, relacionándolo con una mayor sequedad ambiental.

Entre los antecedentes familiares del paciente, refiere epistaxis en su hijo y uno de sus nietos (figura 26).

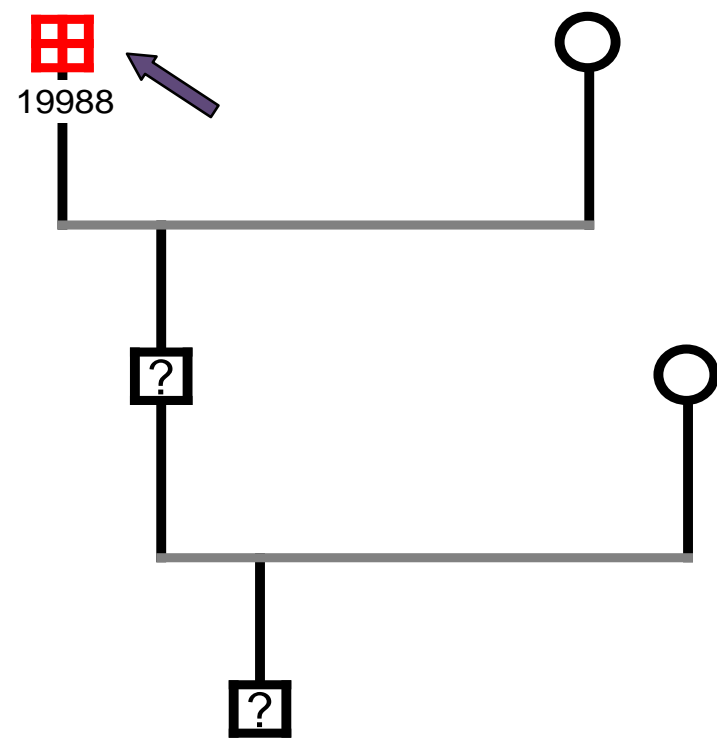

Figura 26. Árbol genealógico paciente 19988

Dado que el diagnóstico clínico fue realizado en Francia y no hemos podido acceder a su historial, carecemos de información relacionada con posibles malformaciones vasculares mayores. Durante sus ingresos en España no se le realizaron pruebas, excepto analíticas de control que eran normales. 
Dada las características clínicas de la paciente y la escasa información disponible, decidimos realizar estudio de ambos genes ALK1 y ENG, amplificándose los 9 exones codificantes del gen ALK1 y los 13 correspondientes al gen ENG

. La secuenciación del gen ALK1 puso de manifiesto la presencia de una mutación en el exón 7 de este gen (figura 27)

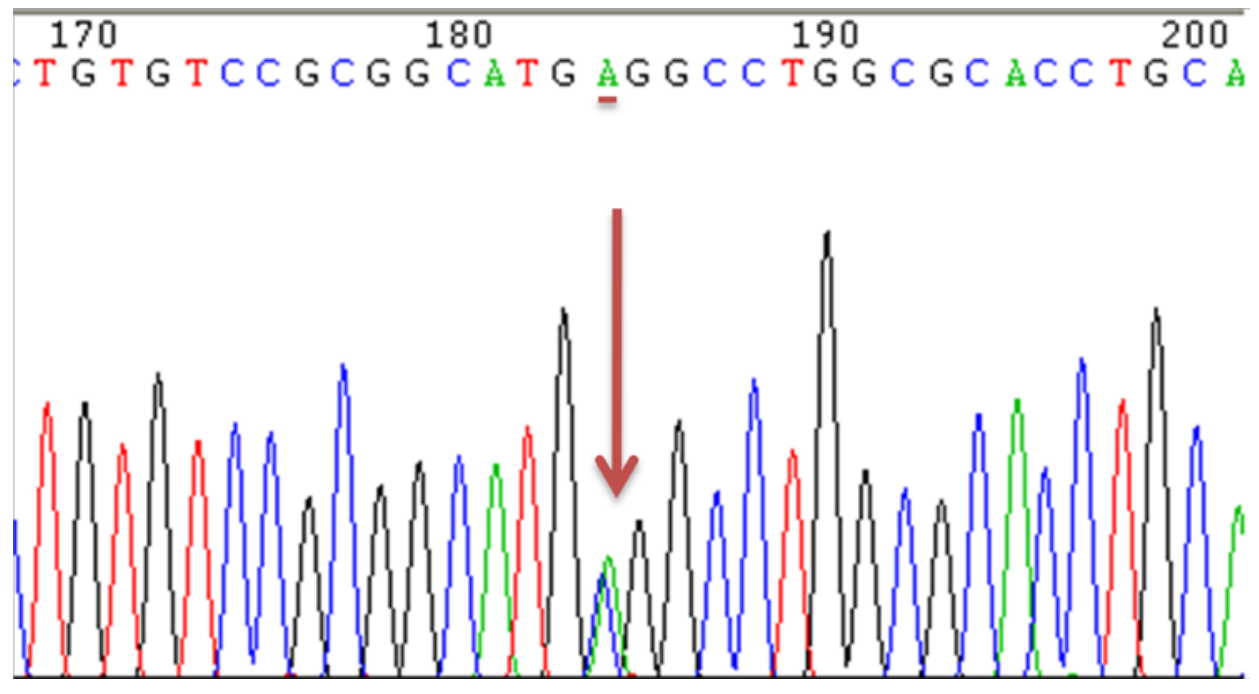

Figura 27. Mutación encontrada en el paciente 19988

La alteración encontrada consiste en un cambio de base en la posición 924 del cDNA, de manera que donde debía existir una cisteína (C), encontramos una Adenina (A). Esto se traduce en la formación de un codón de parada, lo que impide la transcripción correcta de la proteína (p. Cys308X)

Una vez encontrada la mutación, se propuso ampliar el estudio a los descendientes familiares del paciente, lo cual fue rechazado debido a que todos vivían en Francia y prefirieron realizarlo en su localidad de residencia.

La mutación encontrada está descrita previamente como patogénica (Berg JN et al, 1997)

\section{PACIENTE 17580 (ENG C.1686+1 G>A)}

El probando es una mujer de 34 años de edad, natural de la provincia de Salamanca (Castilla y León, España), de raza caucásica, sin antecedentes personales de interés, que acude al Servicio de Radiología del Hospital Universitario de Salamanca 
(HUS) para realización de pruebas de imagen para descartar lesiones pulmonares, ya que había sido diagnosticada clínicamente de la enfermedad en su ciudad de residencia (Valladolid, España)

La paciente presentaba epistaxis frecuentes desde la infancia, con telangiectasias en lugares característicos. Tras consultar con especialistas en Medicina Interna decidió iniciar estudio de despistaje con el fin de detectar posibles malformaciones arteriovenosas. Aunque carecemos de los informes de las pruebas realizadas a la paciente, por la entrevista confirmamos la presencia de múltiples malformaciones vasculares pulmonares, que habían requerido embolización en un hospital diferente al nuestro.

Entre los antecedentes familiares del paciente, refiere epistaxis en uno de sus 4 hijos, sin reconocer ascendentes afectados (figura 28)

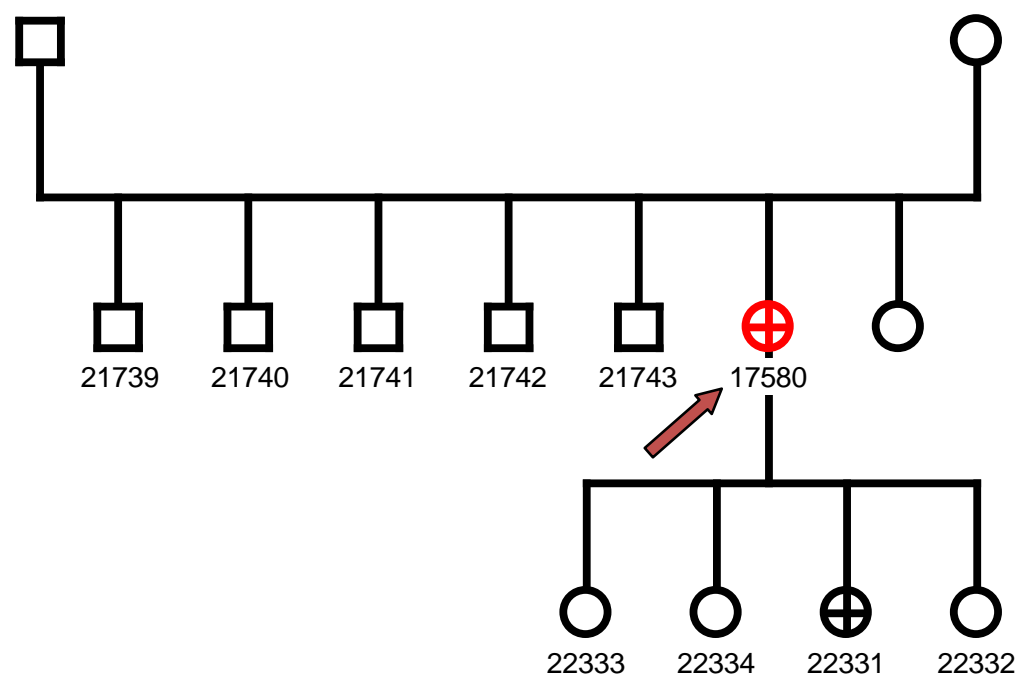

Figura 28. Árbol genealógico paciente 17580

Dado el inicio precoz de los síntomas, así como el grado de afectación visceral, decidimos iniciar el estudio por el gen Endoglina. La secuenciación de este gen permitió encontrar una mutación en el intrón 12 de ENG (figura 29): 


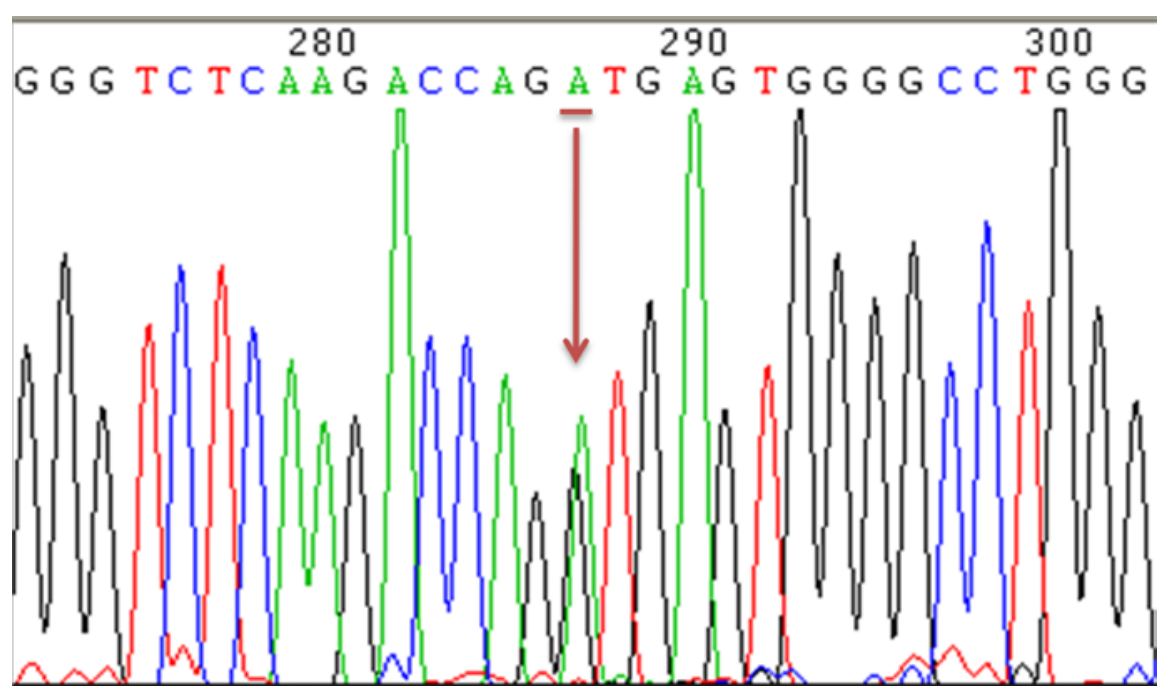

Figura 29. Alteración molecular hallada en el paciente 17580

La mutación encontrada consiste en un cambio de base en la posición 1686+1 del cDNA, de manera que donde debía existir una Guanina (G), encontramos una Adenina (A).

El estudio familiar puso de manifiesto que dos de sus hijos eran portadores de la mutación (tabla 11):

Tabla 11. Familiares de 17580 estudiados y sus resultados

\begin{tabular}{|ccc|}
\hline FAMILIAR & $\begin{array}{c}\text { CRITERIOS } \\
\text { CURAÇAO }\end{array}$ & MUTACIÓN \\
\hline $\mathbf{2 1 7 3 9}$ & 3 & Ausente \\
\hline $\mathbf{2 1 7 4 0}$ & 3 & Ausente \\
\hline $\mathbf{2 1 7 4 1}$ & 3 & Ausente \\
\hline $\mathbf{2 1 7 4 2}$ & 3 & Ausente \\
\hline $\mathbf{2 1 7 4 3}$ & 3 & Ausente \\
\hline $\mathbf{2 2 3 3 1}$ & 3 & Presente \\
\hline $\mathbf{2 2 3 3 2}$ & 3 & Presente \\
\hline $\mathbf{2 2 3 3 3}$ & 3 & Ausente \\
\hline $\mathbf{2 2 3 3 4}$ & 3 & Ausente \\
\hline
\end{tabular}

1.Epistaxis; 2. Telangiectasias;3. Historia familiar; 4. Malformaciones arteriovenosas 
La mutación encontrada no está descrita previamente.

\section{PACIENTE 18013 (ALK-1 c.641 G>A; p.Gly214Asp)}

El probando es una mujer de 36 años de edad, natural de la provincia de Salamanca (Castilla y León, España), de raza caucásica, con antecedentes personales de migrañas con y sin aura, que mantenía revisiones periódicas en el Servicio de Neurología del Hospital Universitario de Salamanca (HUS) por este motivo. En una de sus múltiples revisiones, refiere padecer episodios de repetición consistentes en alteraciones sensitivo-motoras en ambos hemicuerpos, que afectaban en ocasiones al lenguaje y de los que se recuperaba de manera espontánea en un breve periodo de tiempo, sin secuelas. Se realizaron estudios de neuroimagen donde se encontró una imagen de infarto asintomático parietal izquierdo e hiperintensidades puntiformes en sustancia blanca profunda de lóbulo frontal izquierdo.

A raíz de una intervención quirúrgica de varices en miembros inferiores, se le practicó una Rx tórax donde se observaba una imagen que requirió la realización de TC pulmonar, que confirmó que se debía a una malformación arterio-venosa pulmonar en base izquierda.

Posteriormente, se le realizó test de burbujas mediante doppler transcraneal, evidenciando microseñales en ACM bilaterales, sugerentes de comunicación derechaizquierda pulmonar.

Comentados los hallazgos con la paciente, se decide indagar más en su historia familiar y personal, destacando únicamente la presencia de epistaxis espontáneas desde la infancia, pero no se describen telangiectasias.

Ningún otro familiar presenta sintomatología, a excepción de migrañas sin aura y adenocarcinoma de mama en su madre (figura 30) 


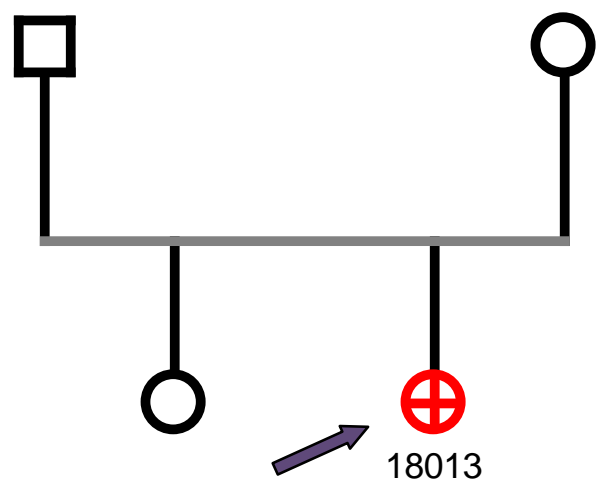

Figura 30. Árbol genealógico paciente 18013

Tras la sospecha clínica de padecer HHT, se decide realizar R.M.N. intentando evidenciar alguna malformación vascular a ese nivel (figura 31)

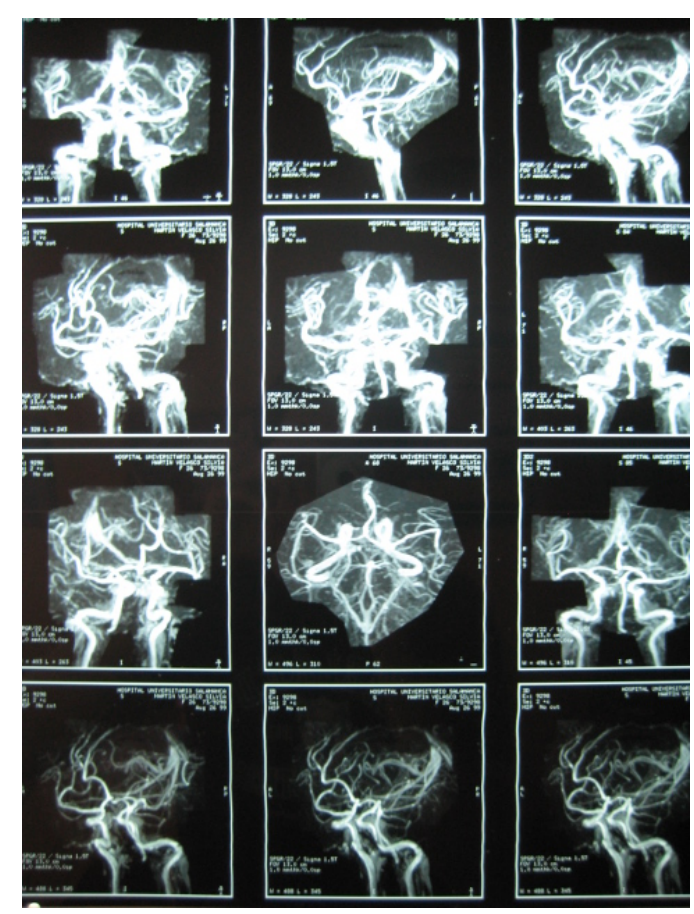

Figura 31. R.M.N. cerebral sin hallazgos valorables

Dada las características clínicas de la paciente, se decidió incluirla dentro del grupo HHT-2 y estudiar el gen ALK1. Una vez realizada la secuenciación de los diferentes exones, encontramos una mutación en el exón 6 (figura 32) 


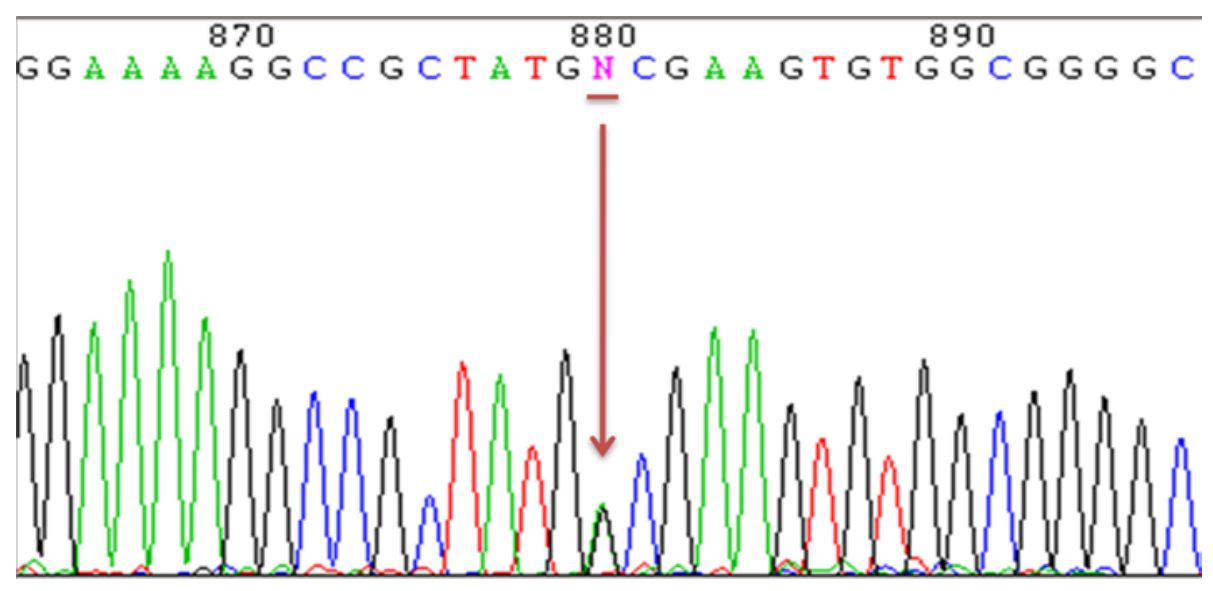

Figura 32. Mutación encontrada en el exón 6 de ALK-1 en paciente 18013

La alteración encontrada consiste en un cambio de base en la posición 641 del cDNA, de manera que donde debía existir una Guanina (G), encontramos una Adenina (A). Esto afecta a la transcripción proteica, de manera que donde debía existir una Glicina (Gly/G), existe una Acido Aspártico (Asp/D) en su lugar (p. Gly214Asp).

La mutación encontrada no está descrita previamente; por ello se realizó un estudio poblacional sobre 100 individuos sanos empleando la técnica del heterodúplex no encontrándolo en ningún caso (figura 33)

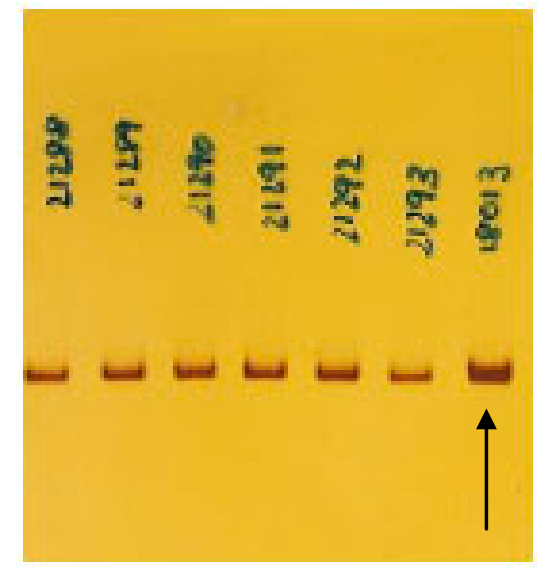

Figura 33. Heterodúplex de exón 6 de ALK-1

Debido a que la mutación es de tipo "missense”, se decidió realizar estudios “in silico” que permitieran predecir el comportamiento teórico sobre la proteína. Como 
puede observarse en la tabla 12, todos los programas predicen la mutación como patogénica, excepto PMut, que la considera neutral.

Tabla 12. Resultados de estudios in silico para la mutación

\begin{tabular}{|c|c|c|c|c|c|c|c|c|}
\hline Mutación & PolyPhen & Valor & SIFT & Valor & SNPS3D & Valor & PMut & Valor \\
\hline G214D & P & 2.436 & P & 1 & P & -3.07 & N & 0.2821 \\
\hline
\end{tabular}

El programa SIFT la considera claramente patológica (Figura 34)

cwdf mi yvgpshnalt eq $210 \mathrm{~K} 1.00 \quad \mathrm{RK}$

ywvt si quml kihfed ca $211 \mathrm{G} 1.00 \quad \mathrm{G}$

c wdf mi yvgpshnalt eq $212 \mathrm{R} 1.00 \quad \mathrm{KR}$

kqhindgepctsamvi wl 213Y 1.00 F Y

ywvt sr qpenlkihfed ca $214 \mathrm{G} 1.00 \quad \mathrm{G}$

wc mf i yhlvrtnpgkqad 215E 1.00 S E

y wt sr qpnmlkihgfedca $216 \mathrm{~V} 1.00 \mathrm{~V}$

- No tolerado - - Tolerado -

Figura 34. Resultado de la predicción por SIFT, donde se observa que el cambio no es tolerado

El estudio de conservación filogenética del aminoácido con el programa Polyphen pone de manifiesto que es un aminoácido muy conservado en varias especies, por lo que su alteración podría ser considerada como patogénica (figura 35). 


\begin{tabular}{|c|c|c|c|}
\hline emb|CAD20573.1] & transforming growth factor-beta type 1-like rece... & ...GLPLIVQRTIARQIQLVEIIGGGY & EVTSGRWRAENVAVKIFSSREE SW... \\
\hline IffiXP 001373499.11 & PREDICTED: similar to activin receptor-like ... & ...GLPLLVQRTIARTIVLeEIVGKGR & EVWHGNWCGEDVAVKIFSSRER DW... \\
\hline |AAH71181.11 & TGFBR1 protein [Homo sapiens] & ...GLPLIVQRTIARTIVQESIGKG & EVWRGKWR GEEVIVKIFSSREE SW.... \\
\hline ge|EAX11438.11 & activin A receptor, type l, isoform CRA_a [Homo s... & ... gipelvertvarQITLIECVGKGRY & EVWRGSWQGENVAVKIFSS DE SW... \\
\hline IeffXP 422170.2 & PREDICTED: similar to activin receptor-like kin... & ...GLPLLVQTIARTIIQEIVGR & EVWR GKWCGEDVZVKKIFSSRER SW.... \\
\hline fefiXP 001381285.11 & GA20910.PA [Drosophila pseudoobscura] >gi|54... & ... GLPLIVQR SIARQVQLCHVIGKGRE & EVWR GNWR GENVAVKIFSS EECSW.... \\
\hline IefiNP 477000.11 & baboon CG8224.PA, isoform A [Drosophila melanog... & 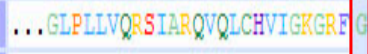 & EVWR GRWR GENVAVKIFSS EECSW.... \\
\hline gb|AAQ22445.1 & RE55648p [Drosophila melanogaster] & ...GLPLIVQ SIARQVQLCHVIGKG & EVWR GNWR GENVAVKIFSS EECSW.... \\
\hline IefiNP 478999.1 & baboon CG8224.PB, isoform B [Drosophila melanog... & ... gLPLIVQ SIAR QVQICHVIGKG: & EVWRGRWRENVIVKIFSSRECSW.... \\
\hline feflXP 001231301.11 & PREDICTED: similar to ALK-4 [Gallus gallus] & ...gLPLFVQRTVARTIVLQEIIGKGE & EVWR GNWRGGDVUKIFSSREE SW.... \\
\hline gb|AAH78772.11 & XALK4 protein [Xenopus laevis] & ...GLPLFVQRTVARTIVLeEIIGK & EVWR GKWR GGDVAVKIFSSREE SW.... \\
\hline tefiNP 571098.1 & bone morphogenetic protein receptor, type 1a [D... & ... GLPLIVQRTIR QIQTVMMTGKGRY & 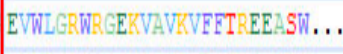 \\
\hline dbilBAC34898.11 & unnamed protein product [Mus musculus] & ...GLPELVQRVARQITLIECVGKGRY & EVWRGSWQQENVIVKIFSSRERKSW... \\
\hline tefiXP 001377323.11 & PREDICTED: similar to Bone morphogenetic pro... & ...-IPLIVQRTIARIQMVR QVGKGR. & EVWMGKWR GE KVAVIVERTTEEASW... \\
\hline IeffXP 588402.3 & PREDICTED: similar to ALK-4 [Bos taurus] & ... GLPLFVQRTVARTIVLQEIIGKGR. & EVWR GRWRGGDVAVKIFSSREERSW... \\
\hline
\end{tabular}

Figura 35. Conservación del aminoácido Glicina (G) en diferentes especies

\section{PACIENTE 19822 (SMAD4 c.1082 A>G; p.Arg361His)}

El probando es una mujer de 34 años de edad, natural de la provincia de Salamanca (Castilla y León, España), de raza caucásica, con antecedentes personales de osteoartropatía hipertrófica de posible origen pulmonar, que mantenía revisiones periódicas en el Servicio de Infecciosas del Hospital Universitario de Salamanca (HUS).

La paciente refería epistaxis de repetición que, en ocasiones, le habían producido intensas anemias que se habían corregido con transfusión de concentrados de hematíes. No presentaba lesiones cutáneas aparentes. No refería antecedentes familiares (figura 36)

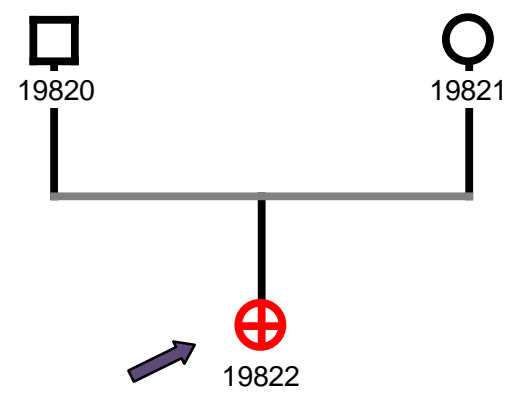

Figura 36. Árbol genealógico paciente 19822 
La paciente fue sometida a diversas pruebas diagnósticas con intención de filiar el origen de su osteoartropatía:

g) Rx tórax: múltiples imágenes nodulares periféricas, predominantes en lóbulos inferiores, de diferentes tamaños, algunas de hasta $1 \mathrm{~cm}$

h) T.A.C.A.R.: afectación pulmonar intersticial nodular bilateral

i) Biopsia pulmonar: malformación vascular múltiple, tipo fístula arterio-venosa congénita múltiple

j) Espirometría: normal

k) Angiografía pulmonar: múltiples telangiectasias. Fístulas arterio- venosas bilaterales de gran tamaño (figura 37)

l) Arteriografía pulmonar: fístulas arterio- venosas en campos inferiores derechos. Telangiectasias en ambos campos pulmonares

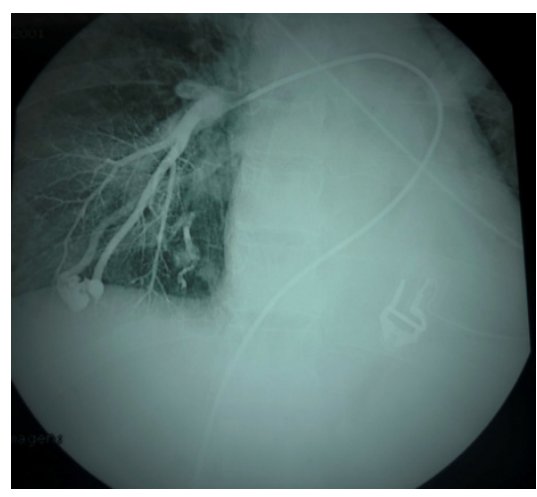

Figura 37. Fístula AV pulmonar, observándose la arteria aferente y eferente

Con estos hallazgos se planteó el diagnóstico clínico de HHT, completando la exploración con los siguientes estudios:

a) O.R.L.: telangiectasias en mucosa nasal y faríngea

b) Oftalmología: lesiones hemorrágicas en conjuntiva tarsal de ambos ojos, mayores en ojo derecho

Debido a un episodio de dolor abdominal en fosa ilíaca derecha se realizó una colonoscopia, encontrándose pólipos colónicos múltiples, el mayor a nivel de colon transverso y un adenocarcinoma entérico de apéndice ileocecal que requirió colectomía subtotal con anastomosis ileo-rectal, extirpación de pólipo rectal y apendicectomía. 
Dada las características clínicas de la paciente se decidió iniciar el estudio molecular por el gen SMAD4, pensando en la posibilidad de que padeciera un síndrome combinado entre HHT y poliposis juvenil.

Para ello se amplificaron los 14 exones codificantes del gen SMAD4 encontrándose una mutación en el exón 8, de tipo missense, consistente en un cambio de aminoácido en la posición 1082, de manera que donde tendría que haber una Adenina (A) encontramos una Guanina (G). Este cambio también afecta a la proteína, de modo que el codón de la posición 361 deja de ser Arginina (Arg/R) para ser Histidina (His/H) (figura 38)

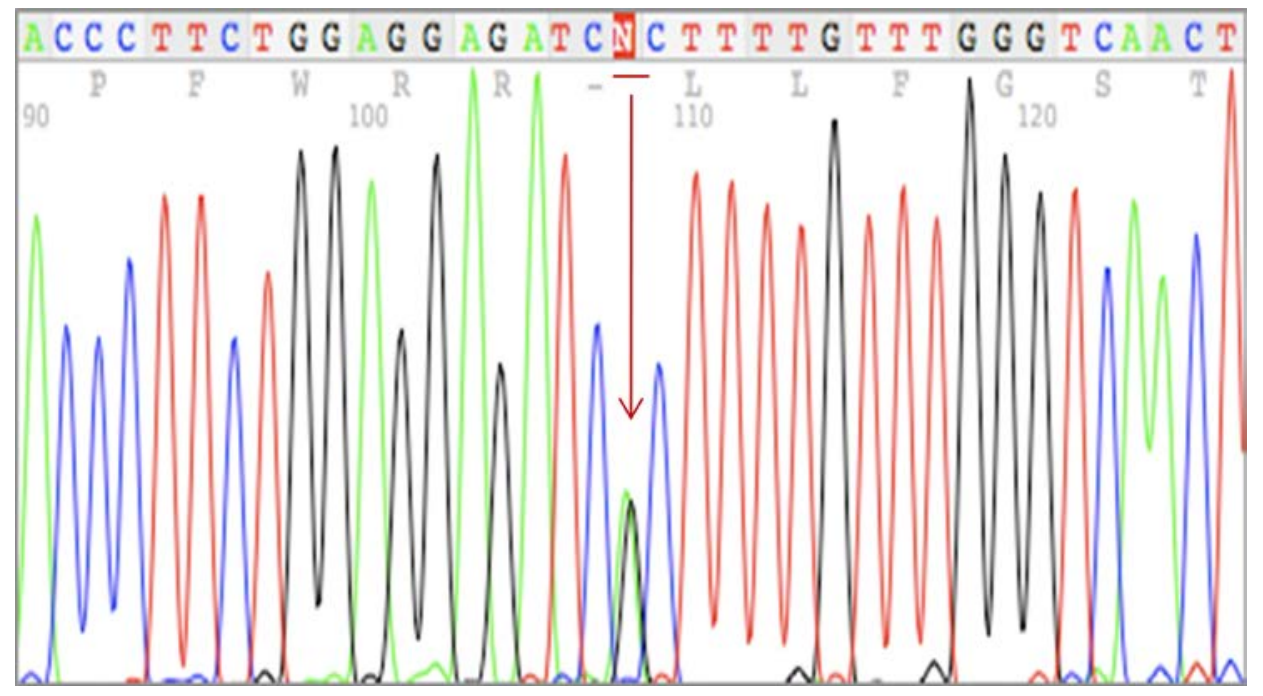

Figura 38. Mutación encontrada en paciente 19822

Como al resto de pacientes donde se ha encontrado una mutación, también se propuso realizar el estudio a sus familiares, a fin de identificar si la mutación es heredada o si se presentaba “de novo”. Tras tomar muestras a sus padres, ninguno de ellos presentaba la alteración descrita (tabla 13).

Tabla 13. Estudio en familiares paciente 19822

\begin{tabular}{|ccc|}
\hline FAMILIAR & $\begin{array}{c}\text { CRITERIOS } \\
\text { CURAÇAO }\end{array}$ & MUTACIÓN \\
\hline 19820 & - & Ausente \\
\hline 19821 & - & Ausente \\
\hline
\end{tabular}

1.Epistaxis; 2. Telangiectasias;3. Historia familiar; 4. Malformaciones arteriovenosas 
La mutación encontrada está descrita previamente (Kim IJ et al, 2000).

\section{PACIENTE 12241 (ENG C.1256_1268 del13; p.S419MfSX490)}

El probando es un varón de 41 años de edad, natural de la provincia de Salamanca (Castilla y León, España), de raza caucásica, con antecedentes personales de consumo habitual de alcohol y fumador, que acude a su médico de familia por presentar epistaxis de repetición, así como sangrado por labio superior y lengua y alteraciones de la visión.

En la exploración física se observan telangiectasias tanto en el labio como en la lengua (figura 39) y datos analíticos de anemia ferropénica.
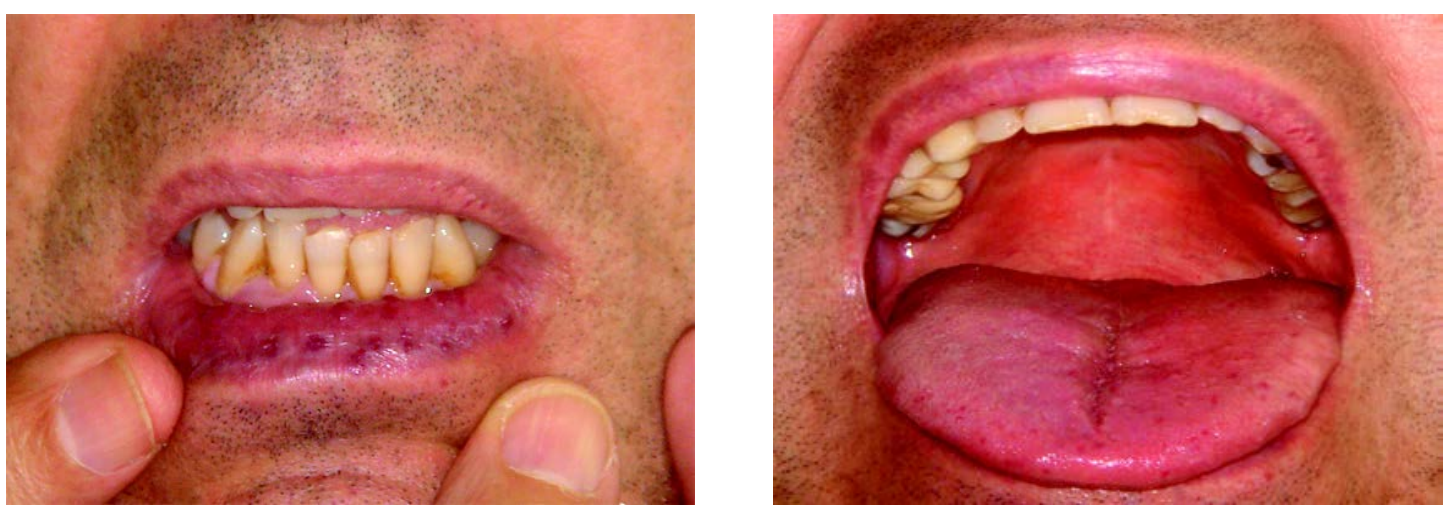

Figura 39. Telangiectasias en lugares típicos

El paciente refería que múltiples descendientes y ascendientes presentaban lesiones mucocutáneas similares a las suyas, así como epistaxis desde edades tempranas (figura 40) 


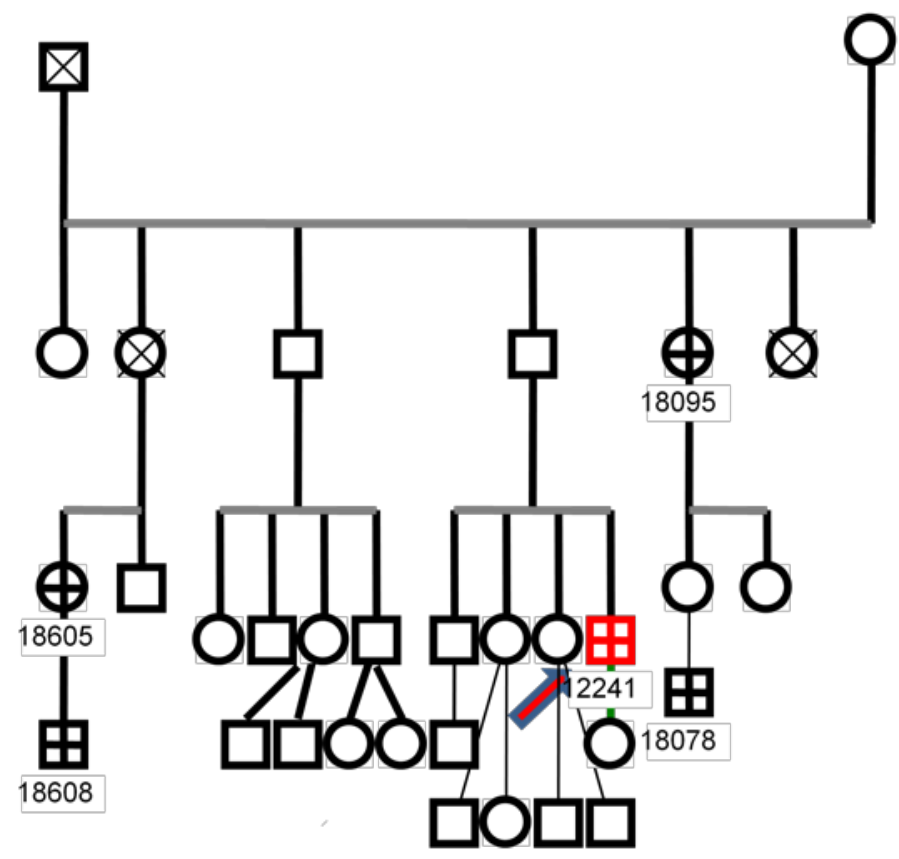

Figura 40. Árbol genealógico paciente 12241

Al paciente se le realizaron diversas exploraciones, buscando posibles malformaciones arteriovenosas orgánicas:

a) Oftalmología: sin lesiones oculares

b) Rx tórax: sin hallazgos valorables

c) R.M.N. cerebral: sin hallazgos valorables

d) Angio R.M.N. cerebral: sin hallazgos valorables

e) Ecografía abdominal: lesión compatible con hemangioma hepático (figura 41)

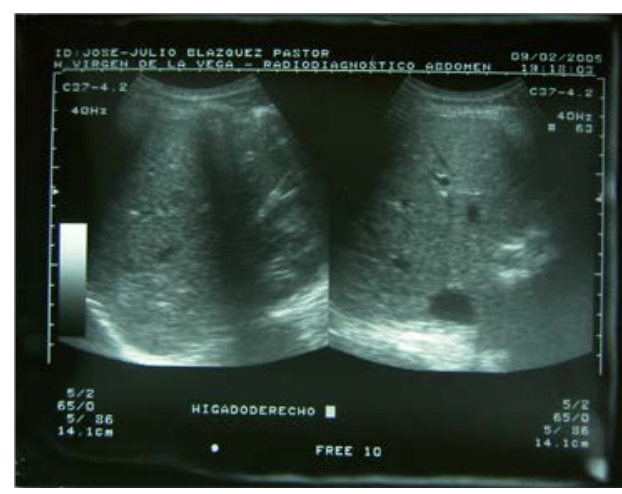

Figura 41. Hemangioma hepático

Desconocemos si, posteriormente, el paciente se ha realizado más pruebas diagnósticas, ya que trasladó su residencia habitual a otra provincia 
Dada las características clínicas del paciente y la edad de aparición de los síntomas, decidimos iniciar el estudio por el gen ENG, encontrando una mutación en el exón 9A (figura 42).

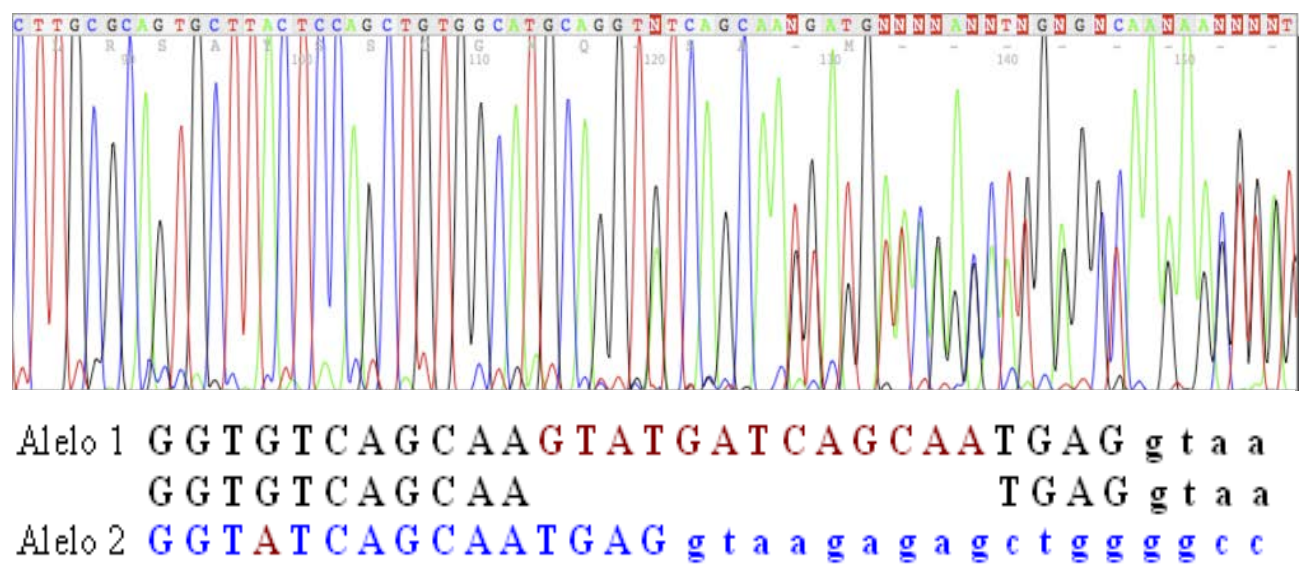

Figura 42. Mutación en el paciente 12241

La mutación consiste en un de cambio de sentido (missense) en el codón 416, que codifica para el mismo aminoácido Valina y una deleción de 13 nucleótidos en la región codificante, que supone un cambio en la fase de lectura y la aparición de un codón prematuro de parada.

Una vez encontrada la alteración, se propuso ampliar el estudio a los familiares del paciente, encontrando la mutación en 4 de ellos (figura 43 y tabla 14):

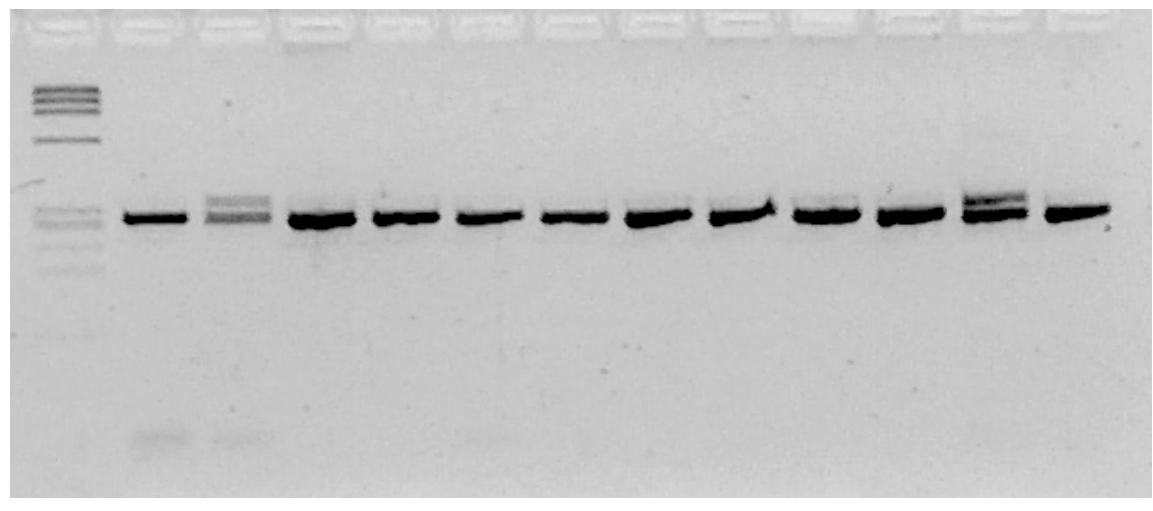

Figura 43. Electroforesis en gel de agarosa de algunos miembros familia 12241 
Tabla 14. Resultado de estudios en familiares de 12241

\begin{tabular}{|ccc|}
\hline FAMILIAR & $\begin{array}{c}\text { CRITERIOS } \\
\text { CURAÇAO }\end{array}$ & MUTACIÓN \\
\hline 10148 & - & Ausente \\
\hline 18078 & - & Presente \\
\hline 18079 & - & Ausente \\
\hline 18093 & - & Ausente \\
\hline 18094 & - & Ausente \\
\hline 18095 & - & Presente \\
\hline 18575 & - & Ausente \\
\hline 18576 & - & Ausente \\
\hline 18577 & - & Ausente \\
\hline 18578 & - & Ausente \\
\hline 18579 & - & Ausente \\
\hline 18580 & - & Ausente \\
\hline 18581 & - & Ausente \\
\hline 18582 & - & Ausente \\
\hline 18605 & - & Ausente \\
\hline 18606 & - & Aresente \\
\hline
\end{tabular}

1.Epistaxis; 2. Telangiectasias;3. Historia familiar; 4. Malformaciones arteriovenosas

La mutación encontrada no está descrita previamente.

\section{PACIENTE 22530 (ENG C.361-2 A>G)}

El probando es un varón de 2 años de edad, descendiente de una familia centroeuropea, aunque residentes en Barcelona (España). El diagnóstico clínico se 
realizó en el Servicio de Neurología del Hospital Sant Joan de Deu, en donde ingresa por cuadro de epistaxis recurrentes asociado a crisis convulsivas generalizas.

Tanto la madre como sus dos tías maternas y su abuela presentaban episodios recurrentes de epistaxis, metrorragias y enterorragias, requiriendo en ocasiones la realización de transfusiones por cuadro anémico. Además, la madre presenta telangiectasias en mucosa bucal (figura 44)

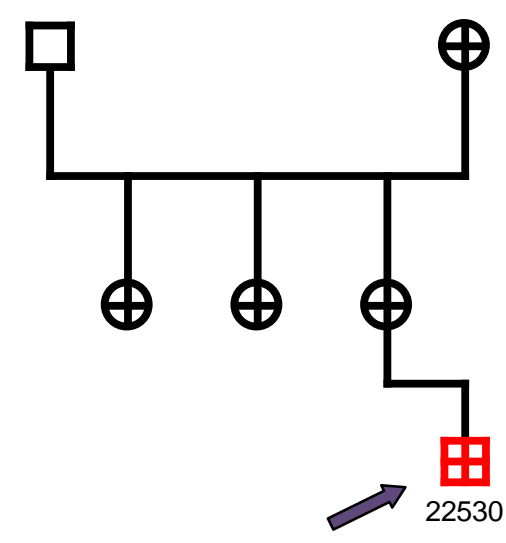

Figura 44. Árbol genealógico paciente 22530

Durante el ingreso se realizaron diversas pruebas diagnósticas, encontrándose lo siguiente:

- R.M.N. cerebral: hemorragia subaracnoidea, complicado con signos de haber padecido pequeñas hemorragias intraparenquimatosas

- Fondo de ojo: hemorragias retinianas

Debido a la presentación de sintomatología a tan temprana edad y la alta penetrancia familiar, se decide iniciar el estudio por el gen ENG, realizando secuenciación directa de los 14 exones codificantes, encontrándose una alteración en el intrón 3, en la zona de splicing, en la posición c. 361 -2 (figura 45), consistente en un cambio de aminoácido, de manera que donde debería encontrarse una Adenina (A), encontramos una Guanina (G). 


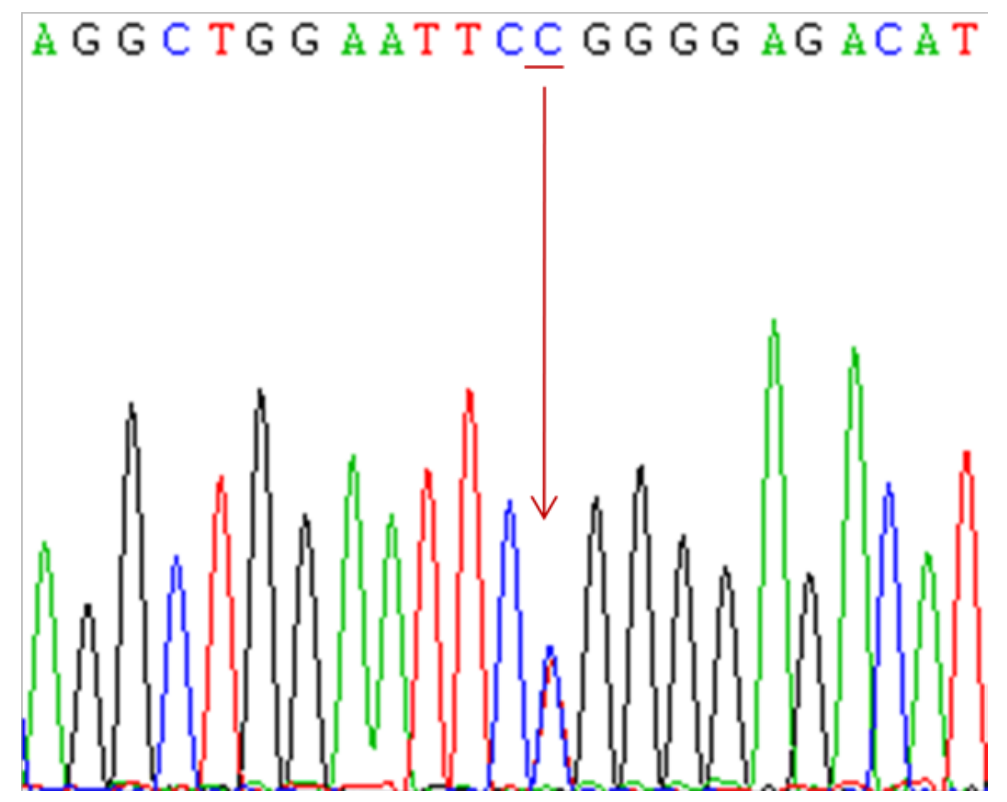

Figura 45. Mutación encontrada en el intrón 3 de ENG en paciente 22530, imagen inversa

La mutación encontrada está descrita previamente y se considera patogénica (Gallione et al., 1998).

\section{PACIENTE 23043 (ALK-1 c.656 G>A; p.Gly219Asp)}

El probando es una mujer de 51 años, procedente de la zona centro de la Península y remitida para estudio genético tras acudir a consulta externa de Medicina Interna, donde la paciente refiere en la anamnesis cuadro de epistaxis recurrentes desde hace varios años, causándole cuadros de anemia ferropénica tratadas con hierro oral, y presentando en la exploración física múltiples telangectasias a nivel de mucosa oral y nasal. Refiere haber padecido diversos ingresos hospitalarios por episodios de hemorragia digestiva, sin aportar en el informe la existencia de malformaciones a ese nivel. La paciente presentaba antecedentes familiares por vía materna (figura 46). 


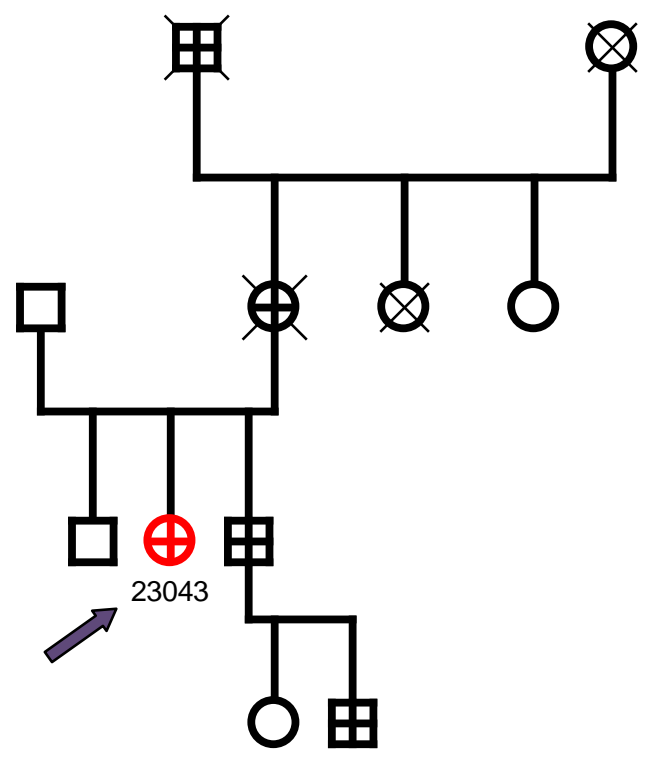

Figura 46. Árbol genealógico paciente 23043

Dada la edad de la paciente y su origen geográfico, se decide iniciar estudio por el gen ALK1, encontrando una mutación de tipo missense en el exón 6, consistente en un cambio de nucleótido en la posición 656, de manera que donde debía existir una Guanina (G) hay una Adenina (A), lo que provoca un cambio en el codón 219, que cambia de ser una Glicina (Gly/G) a ser un Ácido Aspártico (Asp/D) (figura 47)

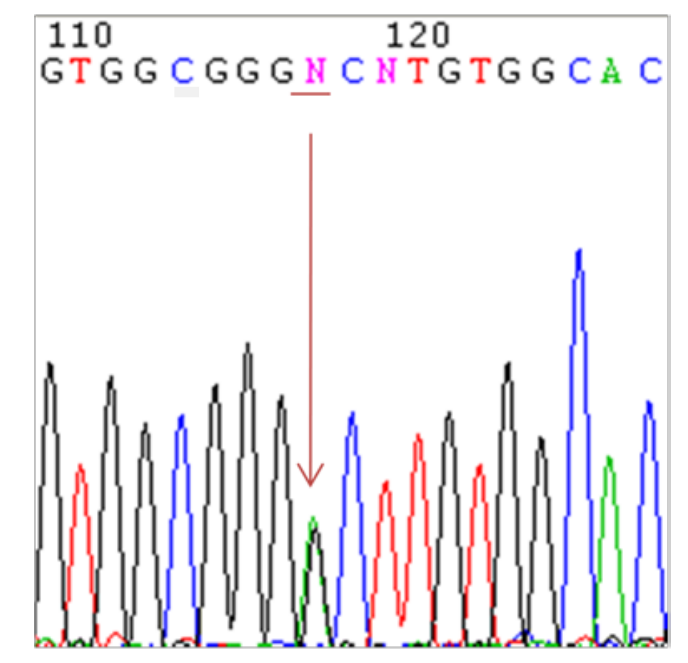

Figura 47. Mutación encontrada en el exón 6 de ALK1 en paciente 23043

Esta mutación está descrita previamente como patogénica (Lenato et al. 2006) 


\section{PACIENTE 23120 (ALK-1 c.1135 G>A; p.Glu379Lys)}

El probando es una mujer de 73 años de edad, derivada desde el servicio de Medicina Interna del Hospital Clínico de Salamanca para realizar estudio genético, donde había consultado por presentar desde hace varios años episodios de epistaxis de repetición asociadas a la aparición progresiva de lesiones mucocutáneas en diversas localizaciones faciales. Así mismo, al ser interrogada por posibles antecedentes familiares, refiere clínica similar en una hermana con la mantenía escasa relación personal, por lo que fue imposible indagar más datos sobre la posible enfermedad y su agregación familiar.

Ante la sospecha de padecer HHT, se procedió al estudio de ENG y ALK1, encontrándose una alteración en el exón 8 de ALK1 (figura 48)

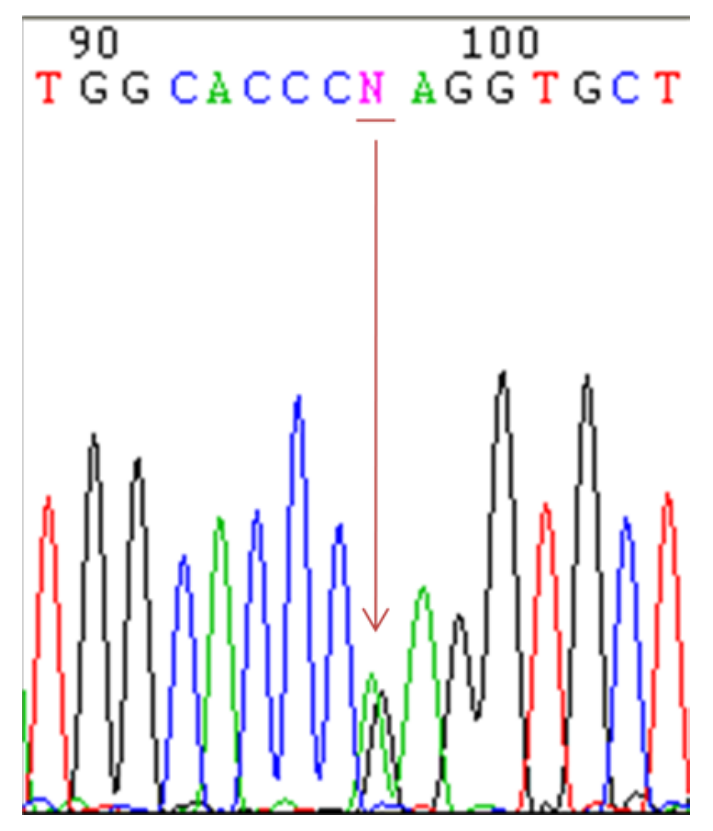

Figura 48. Mutación encontrada en el paciente 23120

La mutación encontrada es de tipo missense y consiste en un cambio de nucleótido en la posición 1135 del cDNA, de manera que donde debía existir una Guanina (G) hay una Adenina (A), lo que genera un cambio de aminoácido en la posición 379 de la proteína y donde debía existir un Ácido Glutámico (Glu/E) existe una Lisina (Lys/K).

La mutación encontrada ya está descrita previamente como patogénica (Lesca et al. 2004) 
En el momento del estudio, la paciente estaba siendo sometida a diversas pruebas diagnósticas a fin de descartar la presencia de malformaciones arteriovenosas que pudieran afectar a su calidad de vida. 
DISCUSIÓN 

La enfermedad de Rendu-Osler-Weber o Telangiectasia Hemorrágica Hereditaria (HHT; OMIM 187300 y 600376) es un trastorno complejo que se hereda con un patrón autosómico dominante y afecta a 1 de cada 5.000-8.000 nacidos vivos (Faughnan et al., 2009). Desde un punto de vista fisiopatológico la enfermedad se caracteriza por el desarrollo de malformaciones arteriovenosas o por la conexión entre arteriolas y vénulas sin capilares intermediarios (Govani and Sholvin, 2009). Dependiendo de la localización de las lesiones vasculares, la presentación clínica es variable, siendo la manifestación más recurrente la existencia de epistaxis y la complicación más importante la hemorragia masiva. El diagnóstico precoz de la enfermedad es importante para evitar las complicaciones que producen las fístulas arteriovenosas.

Actualmente la enfermedad está infradiagnosticada, ya que se requiere una aproximación multidisciplinar que no está disponible en todos los hospitales. La “International HHT Foundation” ha desarrollado una guías de práctica clínica que facilitan el diagnóstico precoz de la enfermedad que contemplan como criterios diagnósticos los definidos en Curaçao en 1999 (Shovlin et al, 2000). Así, el diagnóstico de la enfermedad puede realizarse si los sujetos muestran tres citerios de Curaçao. En nuestra serie hemos incluido 24 probandos de los que 14 presentaban hasta tres criterios y, por lo tanto, estaban diagnosticados fenotípicamente de HTT. Todos los probandos habían presentado epixtasis y 17 probandos tenían telangiectasias, que son las manifestaciones más frecuentes en todas las series (Revisado en Giovani and Shovlin 2009, Richards-Yutz et al., 2010, Dupuis-Girod, 2010). La incidencia de AVM en nuestra serie fue del 52\%, ligeramente superior a la comunicada en otros estudios (Letteboer et al., 2006), predominando las lesiones hepáticas. No obstante, nuestra serie es muy corta por lo que es difícil establecer comparación con las otras series.

La mayor parte de los casos de HHT (HHT tipo 1) se asocian con mutaciones en el gen ENG, que codifica la proteína endoglina (OMIM 187300) (McAllister et al., 1994), un coreceptor de TGF- $\beta$ o con mutaciones en el gen ACVRL1 (HHT tipo 2) (OMIM 600376) (Johnson et al., 1996), que codifica la proteína ALK1, un receptor tipo 1 de TGF- $\beta$. Además, existen casos en los que las manifestaciones clínicas de HHT se solapan con poliposis intestinal y en los que la mutación tiene lugar en el gen MADH4, que codifica la proteína SMAD4 (OMIM 175050) (Gallione et al., 2004). Finalmente, se han descrito algunas familias asociadas a alteraciones en los cromosomas $5 q$ y 7q, 
aunque no se han caracterizado los genes de estos loci (Bayrak-Toydemir, et al., 2006; Cole et al., 2005).

Dada la gran variabilidad clínica, las guías indican que la detección de mutaciones en los genes antes señalados en individuos presíntomaticos con historia familiar o con la presencia de uno de los criterios de Curaçao tiene valor diagnóstico (Faughnan et al., 2009), motivo por el que incluimos 10 probandos que cumplían sólo uno o dos criterios.

En nuestro trabajo hemos estudiado los genes ENG y ACVRL1 en los 24 probandos y hemos encontrado 10 casos portadores de mutaciones patogénicas. De los 14 pacientes que cumplían tres o cuatro criterios de Curaçao y, por lo tanto, tenían un fenotipo evidente de HHT, 6 pacientes (42\%) no presentaban mutaciones puntuales en los genes ENG y ACVRL1.

Se ha sugerido que las mutaciones génicas en pacientes con HHT se detectan con más frecuencia en mayores de 20 años (Ricchards-Yutz et al., 2010). En nuestra serie, los 6 pacientes en los que no encontramos mutación eran mayores de 40 años en el momento del diagnóstico. La mayoría de las mutaciones en estos pacientes se localizaron en el gen ACVRL1 (5 casos) y sólo tres casos presentaba mutación en ENG, lo que confirma una mayor incidencia de mutaciones en el locus ACVRL1 en población española ya descrita en trabajos previos de otros grupos (Fontalba et al, 2008).

En nuestro estudio hemos encontrado un total de 8 mutaciones localizadas en el gen ACVLR1. De ellas, dos no estaban descritas previamente

El paciente 18013 presentaba dos de los 4 criterios de Curaçao, por lo que, en principio, se puede encuadrar dentro del grupo “incierto” de padecer la enfermedad. Sin embargo, la presencia de epistaxis asociadas a la presencia de múltiples malformaciones arteriovenosas en los órganos considerados diana para esta enfermedad (cerebro, pulmón), sugería el diagnóstico clínico de HHT y se solicitó el estudio genético como confirmación diagnóstica.

El estudio del gen ACVLR1 mostró la presencia de una mutación en el exón 6 (c. 641G>A) (figura 32). La mutación es de tipo missense, es decir, se produce un cambio de un único nucleótido en la secuencia, modificando el aminoácido que se codifica, ya que en vez de una Glicina, el cambio genera la aparición de un Ácido 
Aspártico en la posición 214 (p.G214A). El exón 6 del gen ACVLR1 es uno de los puntos donde se agrupan gran cantidad de mutaciones en las diferentes series consultadas, ya que forma parte del dominio intracelular (Fontalba et al, 2008; Sadick et al, 2009). Este cambio tiene relevancia, pues el estudio filogenético muestra que el aminoácido Glicina se conserva en las diferentes especies, por lo que podría considerarse como importante para la supervivencia de las mismas y su modificación podría suponer una desventaja evolutiva (figura 35). Por otra parte, diferentes programas bioinformáticos, como Polyphen, consideran el cambio como patogénico para el ser humano (Tabla 12). Al ser una mutación no descrita hasta el momento, decidimos realizar un estudio poblacional para comprobar que la alteración no está presente en individuos sanos y apoyar así los datos arrojados por los programas informáticos predictivos. Para ello realizamos el estudio sobre una población de 100 individuos sanos, comprobando que la alteración no aparecía en ninguno de ellos. Por todo ello, consideramos la mutación descrita como patogénica.

El paciente 16678 estaba siendo estudiado en el Servicio de Digestivo de su hospital de referencia, donde le habían realizado el diagnóstico clínico de la enfermedad hace años y desde donde solicitaron un estudio genético que corroborase dicho diagnóstico con el fin de realizar el estudio en sus 3 hijos, alguno de los cuales presentaba clínica de epistaxis y telangiectasias en lugares típicos. El paciente presentaba epistaxis de repetición, telangiectasias en lengua, dedos de las manos y labios y realizaba seguimiento en este servicio por haber padecido en diversas ocasiones hemorragias digestivas altas (HDA). Con todos estos datos, el paciente se incluyó en el grupo de diagnóstico “definitivo” según Curaçao, pues presenta los 4 criterios clínicos necesarios para ello.

Al realizar el estudio genético, encontramos una mutación en el exón 3 del gen. La mutación es de tipo missense, ocasionando un cambio de un único nucleótido en la posición 244, de manera que donde debía existir una Cisteína, encontramos una Adenina (c. 244C>A) (Figura 23). Este cambio también genera un cambio en el aminoácido 82 de la proteína, de manera que donde antes había una Treonina, ahora hay una Prolina (pT82P).

El estudio predictivo sobre el carácter patogénico de esta mutación en los diferentes programas informáticos, mostró que la Treonina no es un aminoácido 
conservado en todas las especies y los estudios de predicción de patogenicidad sugieren que la mutación no es patogénica (Tabla 10). Sin embargo, el hecho de que la mutación provoca una sustitución de un aminoácido esencial por otro que no lo es, el estudio poblacional en 100 individuos sanos, que no mostró la mutación en ninguno de ellos y el estudio genético de la familia, en el que la mutación se encontró sólo en aquellos individuos que padecían clínica compatible con la enfermedad (Figura 20 y Tabla 9) nos permite sugerir que la mutación es patogénica. Es necesario realizar estudios funcionales para confirmar nuestra hipótesis.

El estudio del gen ENG nos permitió encontrar un total de 10 mutaciones, de las cuales 5 eran polimorfismos ya descritos, 3 mutaciones en la región intrónica (una ya publicada en las bases de datos) y 2 mutaciones no descritas en la región exónica.

El paciente 17580 presentaba tres de los cuatro criterios clínicos de Curaçao, siendo considerado posible o sospechoso de padecer la enfermedad, pero no tenía ningún ascendiente con clínica compatible; no obstante, nuestro paciente presentaba gran cantidad de malformaciones arteriovenosas a nivel pulmonar desde la adolescencia, que habían obligado a realizar diversas técnicas quirúrgicas para su control, así como sangrados tan masivos que había requerido transfusión de concentrado de hematíes en múltiples ocasiones, por lo que se solicitó el estudio genético para confirmar el diagnóstico.

El estudio del gen ENG mostró una mutación en la posición +1 del intrón 11, en la secuencia canónica de procesamiento (IVS11 +1 G>A) (Figura 29). Estas mutaciones inducen una alteración en el proceso de maduración del RNA que se acompaña habitualmente de la pérdida del exón previo, en este caso el exón 10, un cambio en la fase de lectura y la aparición de un codón prematuro de parada. Para confirmar esta hipótesis es necesario disponer de RNA de la paciente y analizarlo

El estudio familiar no mostró la presencia de la mutación ni en su madre ni en sus seis hermanos, pero sí estaba presente en dos de sus hijos, que ya habían comenzado a presentar sintomatología antes de cumplir 10 años, por lo que pensamos que se trata de una mutación “de novo” en la propositus que se transmite con un patrón de herencia autosómico dominante (Figura 28 y Tabla 11). 
El paciente 12241 fue estudiado tras acudir a consulta de Medicina Interna, donde se estableció un diagnóstico clínico “definitivo” después de referir epistaxis frecuentes, presentar telangiectasias en labios y lengua y por la gran cantidad de familiares que presentaban una clínica similar o más grave que la suya propia.

Tras analizar el gen ENG localizamos dos mutaciones en el exón 9A, consistentes en una pérdida de 13 pares de nucleótidos al final del mismo y la presencia de un cambio de nucleótido en el codón 416, que ya había sido descrito previamente en otras series como un polimorfismo asociado a la enfermedad (Figura 42). La deleción provoca un cambio en la fase de lectura, ya que afecta a un número de nucleótidos que no es múltiplo de 3 , generando un codón prematuro de parada en sentido 3', lo que altera la expresión proteica, pues la secuencia mutada no tiene semejanzas con la original y por ello ha sido considerada como mutación patogénica.

Además de estas mutaciones patogénicas hemos encontrado otras dos mutaciones que no hemos considerado patogénicas, una de ellas por ser una mutación silenciosa (p.S630S) y la otra por estar localizada en un intrón, lejos de la zona de procesamiento del RNA (c.1311+22 insT) que estaba presente en cuatro pacientes del estudio, alguno de los cuales presentaba mutaciones descritas como patogénicas en la región exónica según las bases de datos de la enfermedad.

En 6 casos donde no encontramos mutación en los genes ENG o ALK1, pero que presentaban malformaciones gastrointestinales, se realizó un estudio completo del gen SMAD4, a fin de intentar identificar si alguno de ellos podría estar afectado por el Síndrome Poliposis Juvenil - HHT (JPHT). De todos ellos, sólo se encontró mutación en el paciente 19822, que presentaba una alteración consistente en una mutación missense en el exón 8 del gen y que consistía en el cambio de un nucleótido de Adenina por uno de Guanina (c.1082 A>G) (Figura 38), cambio que afectaba al codón 361, de manera que donde debía expresarse el aminoácido Arginina, lo hace en su lugar una Histidina (p.R361H). La mutación se localiza en uno de los exones que forman parte del dominio MH2, lugar del gen donde se encuentran la casi totalidad de mutaciones descritas para este síndrome y que hasta hace poco tiempo se consideraba como la única zona del gen que se podía afectar en esta enfermedad.

Desde el punto de vista clínico, el paciente presentaba múltiples pólipos distribuidos por todo el colon, así como un adenocarcinoma a nivel del apéndice 
ileocecal, malformaciones vasculares pulmonares y un amplio historial de visitas al servicio de urgencias por episodios de epistaxis, que le habían provocado intensos cuadros de anemia tratados con hierro oral. Con estos antecedentes se solicitó el estudio genético que confirmara el diagnóstico clínico de HHT

La mutación estaba descrita en las bases de datos como patogénica, pero su importancia en nuestro estudio radica en el hecho de que es la primera mutación en este gen descrita en nuestro país y por tanto, es el primer caso reportado de este raro síndrome JPHT.

En conclusión, podemos establecer que el abordaje de esta enfermedad requiere un enfoque multidisciplinar donde los criterios clínicos permiten identificar a los pacientes y el estudio genético sirve como diagnóstico confirmatorio.

El hecho de que la clínica presentada sea tan común con otras enfermedades hace que nos planteemos la necesidad de instruir y concienciar a los diferentes estamentos sanitarios en la importancia de su diagnóstico, ya que si no se realiza un diagnóstico precoz, el desarrollo de las diferentes complicaciones puede tener un desenlace fatal para los pacientes. Así mismo, es importante seguir avanzando en el campo de la investigación molecular, pues gracias a ella podemos descubrir los diferentes mecanismos patogenéticos de la enfermedad e intervenir sobre ellos, lo que permitiría desarrollar nuevos tratamientos que mejoren la calidad de vida de los enfermos y eviten el desarrollo de las temidas complicaciones. 

1. Nuestro trabajo confirma la utilidad de los criterios de Curaçao para el diagnóstico clínico de la Enfermedad de Rendu-Osler-Weber (HHT)

2. El estudio genético permite detectar portadores de la enfermedad antes de que las manifestaciones clínicas permitan hacer el diagnóstico clínico de la misma

3. En nuestra serie, el gen ALK1 aparece mutado con mayor frecuencia que el gen ENG, independientemente de las características fenotípicas de los pacientes, lo que sugiere que este gen debe ser el prioritario a la hora de realizar estudios genéticos en pacientes con la Enfermedad de Rendu-Osler-Weber (HHT) en Castilla y León 


1. Abdalla SA, Pece-Barbara N, Vera S, Tapia E, Paez E, Bernabeu C et al. Analysis of ALK-1 and endoglin in newborns from families with hereditary haemorrhagic telangiectasia type 2. Hum Mol Genet 2000; 9:1227-37

2. Abdalla SA, Cymerman U, Johnson RM, Deber CM, Letarte M. Disease-associated mutations in conserved residues of ALK-1 kinase domain. Eur J Hum Genet 2003; 11:279-87

3. Abdalla SA, Gallione CJ, Barst RJ, Horn EM, Knowles JA, Marchuk DA et al. Primary pulmonary hypertension in families with hereditary haemorrhagic telangiectasia. Eur Respir J 2004; 23:373-7

4. Abdalla SA, Cymerman U, Rushlow D, Chen N, Stoeber G, Lemire E et al. Novel mutations and polymorphisms in genes causing hereditary haemorrhagic telangiectasia. Hum Mutat 2005; 25:320-1

5. Abdalla SA, Letarte $M$. Hereditary haemorrhagic telangiectasia: current views on genetics and mechanisms of disease. J Med Genet 2006; 43:97-110

6. Andersen PJ, Kjeldsen AD, Nepper-Rasmussen J. Selective embolization in the treatment of intractable epistaxis. Acta Otolaryngol 2005: 125(3): 293-297

7. Assar OS, Friedman CM, White RI. The natural history of epistaxis in hereditary haemorrhagic telangiectasia. Laryngoscope 1991; 101:977-80

8. Attisano L, Carcamo J, Ventura F, Weis FM, Massague J, Wrana JL. Identification of human activin and TGF beta type I receptors that form heteromeric kinase complexes with type II receptors. Cell 1993;75:671-80

9. Azoulay D, Precetti S, Emile JF, Ichai P, Gillon MC, Duclos-Vallee JC et al. [Liver transplantation for intrahepatic Rendu-Osler-Weber's disease: the Paul Brousse hospital experience]. Gastroenterol Clin Biol 2002: 26(10): 828-834

10. Baert AL, Casteels-Van Daele M, Broeckx J, Wijndaele L, Wilms G, Eggermont E. Generalized juvenile polyposis with pulmonary arteriovenous malformations and hypertrophic osteoarthropathy. Am J Roentgenol 1983; 14:661-2

11. Bayrak-Toydemir P, Mao R, Lewin S, McDonald J. Hereditary haemorrhagic telangiectasia: an overview of diagnosis and management in the molecular era for clinicians. Genet Med 2004;6:175-91

12. Bayrak-Toydemir P, McDonald J, Akarsu N, Toydemir RM, Calderón F, Tuncali T et al. A fourth locus for hereditary hemorrhagic telangiectasia maps to chromosome 7. Am J Med Genet A 2006: 140(20): 2155-2162

13. Bayrak-Toydemir P, McDonald J, Markewitz B, Lewin S, Miller F, Chou LS et al. Genotype- phenotype correlation in hereditary hemorrhagic telangiectasia: mutations and manifestations. Am J Med Genet A. 2006; 140(5): 463-470

14. Begbie ME, Wallace GMF, Shovlin CL: Hereditary haemorrhagic telangiectasia (OslerWeber-Rendi syndrome): a view from the $21^{\text {st }}$ century. Postgrad Med J 2003; 79:18-24

15. Berg JN, Gallione CJ, Stenzel TT, Johnson DW, Allen WP, Schwartz CE et al. The activin receptor-like kinasa 1 gene: genomic structure and mutations in hereditary hemorrhagic telangiectasia type 2. Am J Hum Genet. 1997 Jul; 61(1):60-7

16. Berg J, Porteous M, Reinhardt D, Gallione C, Holloway S, Umasunthar $T$ et al. Hereditary hemorrhagic telangiectasia: a questionnaire based study to delineate the different phenotypes caused by endoglin and ALK-1 mutations. J Med Genet 2003; 40:585-590 
17. Bergler W, Sadick H, Gotte K, Riedel F, Hormann K. Topical estrogens combined with argon plasma coagulation in the management of epistaxis in hereditary hemorrhagic telangiectasia. Ann Otol Rhinol Laryngol 2002: 111(3 Pt 1): 222-228

18. Berman MF, Hartmann A, Mast H, Sciacca RR, Mohr JP, Pile-Spellman J et al. Determinants of resource utilization in the treatment of brain arteriovenous malformations. AJNR Am J Neuroradiol 1999: 20(10): 2004-2008

19. Bideau A, Brunet G, Heyer E, Plauchu H, Robert J-M. An abnormal concentration of cases of Rendu-Osler disease in the Valserine valley of the French Jura: a genealogical and demographic study. Ann Hum Biol 1992; 19:233-47

20. Borsik M, Herbreteau D, Deffrennes D, Guichard JP, Aymard A, Merland JJ et al. Treatment of epistaxis in Rendu-Osler disease by intramucosal injection of ethibloc. Ann Otolaryngol Chir Cervicofac 1992: 109(5): 273-276

21. Bossler AD, Richards J, George C, Godmillow L, Ganguly A. Novel mutations in ENG and ACVRL1 identified in a series of 200 individuals undergoing clinical genetic testing for hereditary hemorrhagic telangiectasia (HHT): correlation of genotype with phenotype. Hum Mutat 2006; 27:667-75

22. Bown SG, Swain CP, Storey DW, Collins C, Matthewson K, Salmon PR et al. Endoscopic laser treatment of vascular anomalies of the upper gastrointestinal tract. Gut 1985: 26(12): 1338-1348

23. Brusgaard K, Kjeldsen AD, Poulsen $L$, Moss $H$, Vase $P$, Rasmussen $K$ et al. Mutations in endoglin and in activin recptor-like kinase 1 among Danish patients with hereditary haemorrhagic telangiectasia. Clin Genet 2004; 66:556-61

24. Buscarini E, Danesino C, Olivieri C, Lupinacci G, De Grazia F, Reduzzi L et al. Doppler ultrasonographic grading of hepatic vascular malformations in hereditary hemorrhagic telangiectasia - results of extensive screening. Ultraschall Med 2004:25(5):348355hyperplasia in subjects with hereditary hemorrhagic telangiectasia. Ultrasound Med Biol 2004: 30(9):1089-1097

25. Buscarini E, Danesino C, Plauchu H, de Fazio C, Olivieri C, Brambilla G et al. High prevalence of hepatic focal nodular hiperplasia in subjects with hereditary haemorrhagic telangiectasia. Ultrasound Med Biol 2004; 30:1089-97

26. Buscarini E, Plauchu H, García Tsao G, White RI,Jr.,Sabba C, Miller F et al. Liver involvement in hereditary hemorrhagic telangiectasia: consensus recommendations. Liver Int 2006:26(9): 1040-1046

27. Chavan A, Caselitz M, Gratz KF, Lotz J, Kirchhoff T, Piso $P$ et al. Hepatic artery embolization for treatment of patients with hereditary hemorrhagic telangiectasia and symptomatic hepatic vascular malformations. Eur Radiol 2004: 14(11): 2079-2085

28. Chrysant SG. Vascular remodeling: the role of angiotensin enzyme inhibitors. Am Hear J 1998; 135 (2Pt2): S21-30

29. Chilvers ER, Whyte MK, Jackson JE, Allison DJ, Hughes JM. Effect of percutaneous transcatheter embolization on pulmonary function, right-to-left shunt, and arterial oxygenation in patients with pulmonary arteriovenous malformations. Am Rev Respir Dis 1990: 142(2): 420-425

30. Cole S, Begbie M, Wallace $G$, Shovlin C. A new locus for hereditary haemorrhagic telangiectasia (HHT3) maps to chromosome 5. J Med Genet 2005; 42:577-82 
31. Cox KL, Frates RC, Wong A, Gandhi G. Hereditary generalized juvenile polyposis associated with pulmonary arteriovenous malformation. Gastroenterology 1980; 78:1566-70

32. Cymerman U, Vera S, Karabegovic A, Abdalla S, Letarte M. Characterization of 17 novel endoglin mutations associated with hereditary haemorrhagic telangiectasia. Hum Mutat 2003; 21:482-92

33. Dakeishi M, Shioya T, Wada $\mathrm{Y}$ et al. Genetic epidemiology of hereditary hemorrhagic telangiectasia in a local community in the northern part of Japan. Hum Mut 2002; 19:140-8

34. David L, Mallet C, Mazerbourg S et al. Identification of BMP9 and BMP10 as functional activators of the orphan activin receptor-like kinase 1 (ALK1) in endothelial cells. Blood 2007; 109: 1953-1961

35. Derynck R, Zhang YE. Smad-dependent and Smad-independent pathways in TGF-beta family signaling. Nature 2003; 40:425:577-584

36. Dupuis-Girod S, Bailly S, Plauchu H. Hereditary hemorrhagic telangiectasia: from molecular biology to patient care. J Thromb Haemost 2010; 8: 1447-56

37. Dutton JA, Jackson JE, Hughes JM, Whyte MK, Peters AM, Ussov W et al. Pulmonary arteriovenous malformations: results of treatment with coil embolization in 53 patients. AJR Am J Roentgenol 1995: 165(5): 1119-1125

38. Elden L, Montanera W, Terbrugge K, Willinsky R, Lasjaunias P, Charles D. Angiographic embolization for the treatment of epistaxis: a review of 108 cases. Otolaryngol Head Neck Surg 1994: 111(1): 44-50

39. El-Harith HA, Kuhnau W, Schmidtke J et al. Hereditary hemorrhagic telangiectasia is caused by the Q490X mutation of the ACVRL1 gene in a large Arab family: support of homozygous lethality. Eur J Med Genet 2006; 49:323-330

40. Faughnan ME, Thabet A, Mei-Zahav M, Colombo M, Maclusky I, Hyland RH et al. Pulmonary arteriovenous malformations in children: outcomes of transcatheter embolotherapy. J Pediatr 2004: 145(6): 826-831

41. Faughnan M E, Palda V A, García-Tsao G, Geisthoff U W, McDonald J, Proctor D D et al. International Guidelines for the Diagnosis and Management of Hereditary Hemorrhagic Telangiectasia. J Med Genet 2009

42. Feng $X H$, Derynck R. A kinase subdomain of transforming growth factor-beta (TGFbeta) type I recptor determines the TGF-beta intracellular signaling specificity. EMBO J 1997; 16:3912-23

43. Fiorella ML, Ross D, Henderson KJ, White RI,Jr. Outcome of septal dermoplasty in patients with hereditary hemorrhagic telangiectasia. Laryngoscope 2005: 115(2): 301305

44. Fontalba A, Fernández-L A, García-Alegría E, Albiñana V, Garrido-Martín EM, Blanco FJ, et al. Mutation study of Spanish patients with Herediatry Hemorrhagic Telangiectasia. BMC Medical Genetics 2008,9:75

45. Frischmeyer PA, Dietz HC. Nonsense-mediated mRNA decay in health and disease. Hum Mol Genet 1999; 8: 1893-900

46. Fullbright RK, Skudlarski P, Lacadie CM, Warrenburg S, Bowers AA, Gore JC, et al. Functional MR imaging of regional brain responses to pleasant and unpleasant odors. Am J Neuroradiol 1998; 19:1721-6 
47. Gallione CJ, Klaus DJ, Yeh EY, Stenzel TT, Xue Y, Anthony KB et al. Mutation and expression analysis of the endoglin gene in hereditary hemorrhagic telangiectasia reveals null alleles. Human Mutat 1998; 11(4):286-94

48. Gallione CJ, Repetto GM, Legiius E, Rustig AK, Schelley SL, Tejpar S, et al. A combined syndrome of juvenile polyposis and hereditary hemorrhagic telangiectasia associated with mutations in MADH4 (SMAD4). Lancet 2004; 363(9412):852-859

49. Gallione CJ, Richards JA, Letteboer TG, Rushlow D, Prigoda NL, Leedom TP et al. SMAD4 mutations found in unselected HHT patients. J Med Genet 2006: 43(10): 793797

50. Gallione C, Aylsworth A, Beis J, et al. Overlapping spectra of SMAD4 mutations in juvenile polyposis (JP) and JP-HHT syndrome. Am J Med Genet A 2010; 152A:333-9

51. García - Tsao G, Korzenik J, Young L, Henderson K, Jain D, Byrd B, et al. Liver disease in patients with hereditary hemorrhagic telangiectasia. N Engl J Med 2000;343(13):931936

52. Geisthoff UW. Clinical aspects of hereditary hemorrhagic telangiectasia. Habilitation thesis, University of the Saarland, Homburg/Saar 2006

53. Gershon AS, Faughnan ME, Chon KS, Pugash RA, Clark JA, Bohan MJ et al. Transcatheter embolotherapy of maternal pulmonary arteriovenous malformations during pregnancy. Chest 2001: 119(2): 470-477

54. Ghosh M, Wang HD, McNeill JR. Role of oxidative stress and nitric oxide in regulation of spontaneous tone in aorta of DOCA- salt hypertensive rats. Br J Pharmacol. 2004 Feb, 141 (4): 562-73

55. Girerd B, Montani D, Coulet F et al. Clinical outcomes of pulmonary arterial hypertension in patients carrying an ACVRL1 (ALK1) mutation. Am J Respir Crit Care Med 2010; 181:851-61

56. Gougos A, Letarte M. Primary structure of endoglin, an RGD-containing glycoprotein of human endothelial cells. J Biol Chem 1990; 265:8361-4

57. Goumans M-J, Valdimarsdottir G, Itoh $S$ et al. Activin receptor-like kinase (ALK) 1 is an antagonistic mediator of lateral TGF- $\beta$ /ALK5 signaling. Mol Cell 2003; 12:817-828

58. Govani FS, Shovlin CL. Hereditary haemorrhagic telangiectasia: a clinical and scientific review. Eur J Hum Genet 2009: 17: 860-871

59. Gupta P, Mordin C, Curtis J, Hughes JM, Shovlin CL, Jackson JE. Pulmonary arteriovenous malformations: effect of embolization on right-to-left shunt, hypoxemia, and exercise tolerance in 66 patients. AJR Am J Roentgenol 2002: 17982: 347-355

60. Guttmacher AE, Marchuk DA, White RI. Hereditary hemorrhagic telangiectasia. New Engl J Med 1995: 333:918-24

61. Hahn SA, Schutte M, Hoque TMS, Moskaluk CA, da Costa LT, Rozenblum E. DPC4, a candidate tumor suppressor gene at human chromosome 18q21.1. Science 1996: 271: 350-354

62. Hanes FM. Multiple hereditary telangiectases causing hemorrhage (Hereditary Hemorrhagic Telangiectasia). 1909, Bull. Johns Hopkins Hosp: 20: 63-75

63. Hanks SK, Quinn AM, Hunter T. The protein kinase family: conserved features and deduced phylogeny of the catalytic domains. Science 1988; 241:42-52

64. Haq AU, Glass J, Netchvolodoff CV, Bowen LM. Hereditary hemorrhagic telangiectasia and danazol. Ann Intern Med 1988: 109(2): 171 
65. Harrison RE, Flanagan JA, Sankelo M, Abdalla SA, Rowell J, Machado RD et al. Molecular and functional analysis identifies ALK-1 as the predominant cause of pulmonary hypertension related to hereditary haemorrhagic telangiectasia. J Med Genet 2003; 40: 865-71

66. Hashimoto M, Tate E, Nishii T, Watarai J, Shioya T, White RI. Angiography of hepatic vascular malformations associated with hereditary hemorrhagic telangiectasia. Cardiovasc Intervent Radiol 2003: 26(2): 177-180

67. Hitchings $A E$, Lennox PA, Lund VJ, Howard DJ. The effect of treatment for epistaxis secondary to hereditary haemorrhagic telangiectasia. Am J Rhinol 2005: 19(1): 75-78

68. Howe JR, Roth S, Ringold JC, Summers RW, Jarvinen HJ, Sistonen P et al. Mutations in the SMAD4/DPC4 gene in juvenile polyposis. Science 1998; 280:1086-8

69. Howe JR, Bair JL, Sayed MG, Anderson ME, Mitros FA, Petersen GM et al. Germline mutations of the gene encoding bone morphogenetic protein receptor $1 \mathrm{~A}$ in juvenile polyposis. Nat Genet 2001; 28:184-7

70. lanora AA, Memeo M, Sabba C, Cirulli A, Rotondo A, Angelelli G. Hereditary hemorrhagic telangiectasia: multi-detector row helical CT assessment of hepatic involvement. Radiology 2004: 230(1): 250-259

71. Ingrosso M, Sabba C, Pisani A, Principi M, Gallitelli M, Cirulli A et al. Evidence of smallbowel involvement in hereditary hemorrhagic telangiectasia: a capsule-endoscopic study. Endoscopy 2004: 36(12): 1074-1079

72. Johnson DW, Berg JN, Gallione CJ, McAllister KA, Warner JP, Helmbold EA et al. A second locus for hereditary hemorrhagic telangiectasia maps to chromosome 12. Genome Res 5:21-8

73. Johnson DW, Berg JN, Baldwin MA, Gallione CJ, Marondel I, Yoon SJ et al. Mutations in the activin receptor-like kinase 1 gene in hereditary haemorrhagic telangiectasia type 2. Nat Genet 1996;13: 189-95

74. Karapantzos I, Tsimpiris N, Goulis DG, Van Hoecke H, Van Cauwenberge P, Danielides $\mathrm{V}$. Management of epistaxis in hereditary hemorrhagic telangiectasia by $\mathrm{Nd}$ :YAG laser and quality of life assessment using the HR-QoL questionnaire. Eur Arch Otorhinolaryngol 2005: 262(10): 830-833

75. Kim IJ, Ku JL, Yoon KA, Heo SC, Jeong SY, Choi HS et al. Germline mutations of the dpc4 gene in Korean juvenile polyposis patients. Int J Cancer 2000 May 15; 86(4): 529-32

76. Kjeldsen A, Vase P, Green A. Hereditary hemorrhagic telangiectasia: a population based study of prevalence and mortality in Danish patients. J Internal Med 1999; 245:31-39

77. Kjeldsen A, Kjeldsen J. Gastrointestinal bleeding in patients with hereditary hemorrhagic telangiectasia. Am J Gastroenterol 2000;95:415-8

78. Kjeldsen A, Vase P, Green A. [Hereditary hemorrhagic telangiectasia. A population based study on prevalence and mortality among Danish HHT patients]Ugeskr Laeger 2000: 162(25): 3597-3601

79. Kjeldsen AD, Oxhoj $H$, Andersen PE, Green A, Vase P. Prevalence of pulmonary arteriovenous malformations (PAVMs) and occurrence of neurological symptoms in patients with hereditary haemorrhagic telangiectasia (HHT). J Intern Med 2000; 248:255-62 
80. Kjeldsen AD, Moller TR, Brusgaard $\mathrm{K}$ et al. Clinical symptoms according to genotype amongst patients with hereditary haemorrhagic telangiectasia. J Int Med 2005; 258:349-55

81. Klepfish A, Berrebi A, Schattner A. Intranasal tranexamic acid treatment for severe epistaxis in hereditary hemorrhagic telangiectasia. Arch Intern Med 2001: 161(5): 767

82. Korzenik JR, Topazian MD, White R. Treatment of bleeding in hereditary hemorrhagic telangiectasia with aminocaproic acid. N Engl J Med 1994:331(18):1236

83. Krings T, Ozanne A, Chng SM, Alvarez H, Rodesch G, Lasjaunias PL. Neurovascular phenotypes in hereditary haemorrhagic telangiectasia patients according to age. Review of 50 consecutive patients aged 1 day-60 years. Neuroradiology 2005: 47(10): 711-720

84. Krings T, Chng SM, Ozanne A, Alvarez H, Rodesch G, Lasjaunias PL. Hereditary hemorrhagic telangiectasia in children: endovascular treatment of neurovascular malformations. Results in 31 patients. Neuroradiology 2005;47:946-54

85. Lacout A, Pelage J, Lesur $G$ et al. Pancreatic involvement in hereditary hemorrhagic telangiectasia: assessment with multidetector helical CT. Radiology 2010; 254:479-84

86. Lastres P, Martín-Pérez J, Langa C, Bernabeu C. Phosphorylation of the human transforming-growth-factor-beta-binding protein endoglin. Biochem J 1994; 301: 765-8

87. Lebrin F, Mummery CL. Endoglin-mediated Vascular remodeling: mechanisms underlying hereditary hemorrhagic telangiectasia. Trends Cardiovasc Med 2008; 18:2532

88. Lee DW, White RI, Jr., Egglin TK, Pollak JS, Fayad PB, Wirth JA et al. Embolotherapy of large pulmonary arteriovenous malformations: long-terms results. Ann Thorac Surg 1997: 64(4): 930-939; discussion 939-940

89. Legg JW: Lancet:1876; Dec 16; 856-857

90. Lenato GM, Lastella P, Di Giacomo MC, Resta N, Suppressa P, Pasculli G et al. DHPLCbased mutation analysis of ENG and ALK-1 genes in HHT Italian population. Hum Mutat, 2006 Feb; 27(2): 213-4

91. Lerut J, Orlando G, Adam R, Sabba C, Pfitzmann R, Klempnauer J et al. Liver transplantation for hereditary hemorrhagic telangiectasia: Report of the European liver transplant registry. Ann Surg 2006: 244(6): 854-862; discussion 862-854

92. Lesca $G$, Plauchu $H$, Coulet $F$, Lefebvre $S$, Plessis $G$, Odent $S$ et al. Molecular screening of ALK1/ACVRL1 and ENG genes in hereditary hemorrhagic telangiectasia in France. Hum Mutat, 2004 Apr; 23(4):289-99

93. Lesca $\mathrm{G}$, Olivieri $\mathrm{C}$, Burnichon $\mathrm{N}$, et al. Hereditary hemorrhagic telangiectasia: data from the French-Italian HHT network. Genet Med 2007;9:14-22

94. Letteboer TG, Zewald RA, Kamping EJ, de Haas G, Mager JJ, Snijder RJ et al. Hereditary haemorrhagic telangiectasia: ENG and ALK-1 mutations in Dutch patients. Hum Genet 2005; 116: 8-16

95. Letteboer TG, Mager JJ, Snijder RJ, Koeleman BP, Lindhout D, Ploos van Amstel JK et al. Genotype-phenotype relationship in hereditary haemorrhagic telangiectasia. J Med Genet 2006: 43(4): 371-377

96. Letteboer T, Mager H, Snijder R, et al. Genotype-phenotype relationship for localization and age distribution of telangiectases in hereditary hemorrhagic telangiectasia. Am J Med Genet A. 2008;146A:2733-9 
97. Longacre AV, Gross CP, Gallitelli M, Henderson KJ, White RI,Jr., Proctor DD. Diagnosis and management of gastrointestinal bleeding in patients with hereditary hemorrhagic telangiectasia. Am J Gastroenterol 2003: 98(1): 59-65

98. Lunsford LD, Kondziolka D, Flickinger JC, Bissonette DJ, Jungreis CA, Maitz AH et al. Stereotactic radiosurgery for arteriovenous malformations of the brain. J Neurosurg 1991: 75(4): 512-524

99. Lux A, Attisano L, Marchuk DA. Assignment of transforming growth factor beta 1 and beta 3 and a third new ligand to the type I receptor ALK-1. J Biol Chem 1999; 274:998492

100. Mahoney EJ, Shapshay SM. Nd-YAG laser photocoagulation for epistaxis associated with hereditary hemorrhagic telangiectasia. Laryngoscope 2005: 115(2):373-375

101. Magger JJ, Overtoom TT, Blauw H, Lammers JW, Westermann CJ. Embolotherapy of pulmonary arteriovenous malformations: long-term results in 112 patients. J Vasc Interv Radiol 2004: 15(5): 451-456

102. Matsumoto S, Mori H, Yamada Y, Hayashida T, Hori Y, Kiyosue H. Intrahepatic porto-hepatic venous shunts in rendu-osler-Weber disease: imaging demonstration. Eur Radiol 2004: 14(4):592-596

103. McAllister KA, Grogg KM, Johnson DW, Gallione CJ, Baldwin MA, Jackson CE et al. Endoglin, a TGF- $\beta$ binding protein of endothelial cells, is the gene for hereditary haemorrhagic telangiectasia type 1. Nat Genet 1994;8:345-51

104. McAllister KA, Baldwin MA, Thukkani AK, Gallione CJ, Berg JN, Porteus ME et al. Six novel mutations in the endoglin gene in hereditary haemorrhagic telangiectasia type 1 suggest a dominant-negative effect of receptor function. Hum Mol Genet 1995; 4: 1983-5

105. McDonald J, Gedge F, Burdette A, Carlisle J, Changkuoth JB, Fox M, et al. Multiple Sequence Variants in Hereditary Hemorrhagic Telangiectasia Cases. J Mol Diagn 2009, 11:569-575

106. McDonald J, Damjanovich K, Millson A, Wooderchak W, Chibuk JM, Stevenson DA, et al. Molecular diagnosis in hereditary hemorrhagic telangiectasia: findings in a series tested simultaneously by sequencing and deletion/duplication analysis. Clin Genet 2010

107. Memeo M, Stabile lanora AA, Scardapane A, Suppressa P, Cirulli A, Sabba C et al. Hereditary haemorrhagic telangiectasia: study of hepatic vascular alterations with multi-detector row helical CT and reconstruction programs. Radiol Med 2005:109(1-2): $125-138$

108. Morgan T, McDonald J, Anderson C, Ismail M, Miller F, Mao R et al. Intracranial hemorrhage in infants and children with hereditary hemorrhagic telangiectasia (OslerWeber-Rendu syndrome). Pediatrics 2002: 109(1): E12

109. Morgan MK, Zurin AA, Harrington T, Little N. Changing role for preoperative embolisation in the management of arteriovenous malformations of the brain. J Clin Neurosci 2000: 7(6): 527-530

110. Muller B, Kleschyov AL, Gyorgy K and Stoclet JC. Inducible NO synthase activity in blood vessels and heart: new insight into cell origin and consequences. Physiol Res 2000: 49: 19-26 
111. Ng PC, Henikoff S. SIFT: predicting amino acid changes that affect protein function. Nucleic Acids Res,2003; 31:3812-3814

112. Ocran K, Rickes S, Heukamp I, Wermke W. Sonographic findings in hepatic involvement of hereditary haemorrhagic telangiectasia. Ultraschall Med 2004:25(3):191-194

113. Osler W. On a family form of recurring epistaxis, associated with multiple telangiectases of the skin and mucous membranes. Bull. Johns Hopkins Hospital: 1901, $12,333-337$

114. Osler W. On multiple hereditary telangiectases with recurring haemorrhages. Quarterly Journal of Medicine: 1907, 1, 53-58

115. Paquet ME, Pece-Barbara N, Vera S, Cymerman U, Karabegobic A, Shovlin C et al. Analysis of several endoglin mutants reveals no endogenous mature or secreted protein capable of interfering with normal endoglin function. Hum Mol Genet 2001; 10: $1347-57$

116. Park SO, Lee YJ, Seki T et al. ALK5 and TGFBR2-independent role of ALK1 in the pathogenesis of hereditary hemorrhagic telangiectasia type 2. Blood 2008; 111: 633642

117. Pasculli G, Resta F, Guastamacchia E, Di Gennaro L, Suppressa P, Sabba C. Health-related quality of life in a rare disease: herediatry hemorrhagic telangiectasia (HHT) or Rendu-Osler-Weber disease. Qual Life Res 2004: 13(10): 1715-1723

118. Pece N, Vera S, Cymerman U, White RIJ, Letarte M. Mutant endoglin in hereditary haemorrhagic telangiectasiatype $\mathrm{I}$ is transiently expressed intracellularly and is not a dominant negative. J Clin Invest 1997; 100: 2568-79

119. Plauchu H, de Chadarevian JP, Bideau A, Robert JM. Age-related clinical profile of hereditary hemorrhagic telangiectasia in an epidemiologically recruited population. Am J Med Genet 1989: 32(3): 291-297

120. Pollak JS, Saluja S, Thabet A, Henderson KJ, Denbow N, White RI, Jr. Clinical and anatomic outcomes after embolotherapy of pulmonary arteriovenous malformations. J Vasc Interv Radiol 2006: 17(1): 35-44; quiz 45

121. Porteus ME, Burn J, Proctor SJ. Hereditary haemorrhagic telangiectasia: a clinical analysis. J Med Genet 1992: 29(8): 527-530

122. Prigoda NL, Savas S, Absalla SA, Piovesan B, Rushlow D, Vandezande $K$ et al. Hereditary haemorrhagic telangiectasia: mutation detection, test sensitivity and novel mutations. J Med Genet 2006: 43(9): 722-728

123. Proctor DD, Henderson KJ, Dziura JD, Longacre AV, White RI,Jr. Enteroscopic evaluation of the gastrointestinal tract in symptomatic patients with hereditary hemorrhagic telangiectasia. J Clin Gastroenterol 2005: 39(2): 115-119

124. Ravard G, Soyer P, Boudiaf M, Terem C, Abitbol M, Yeh JF et al. Hepatic involvement in hereditary hemorrhagic telangiectasia: helical computed tomography features in 24 consecutive patients. J Comput Assist Tomogr 2004: 28(4): 488-495

125. Rendu HJLM. Epistaxis répétées cuez un sujet porteur de petits angiomes cutanés et muqueux. Gaz de Hôp: 1896; 49:1322

126. Richards-Yutz J, Grant K, Chao EC, Walther SE, Ganguly A. Update on molecular diagnosis of hereditary hemorrhagic telangiectasia. Hum Genet 2010; 128:61-77 
127. Sabba C. A rare and misdiagnosed bleeding disorder: hereditary hemorrhagic telangiectasia. J Thromb Haemost 2005; 3:2201-2210

128. Sabba C, Pasculli G, Lenato GM et al. Hereditary hemorrhagic telangiectasia: clinical features in ENG and ALK1 mutation carriers. J Thromb Haemost 2007; 5:114957

129. Sadick H, Hage J, Goessler U, Stern-Straeter J, Riedel F, Hoermann K, Bugert P. Mutation analysis of "Endoglin" and "Activin receptor-like kinase" genes in German patients with hereditary hemorrhagic telangiectasia and the value of rapid genotyping using an allele-specific PCR-technique. BMC Medical Genetics 2009; 10:53

130. Saitoh M, Nishitoh H, Amagasa T, Miyazono K, Takagi M, Ichijo H. Identification of important regions in the cytoplasmic juxtamembrane domain of type I receptor that separate signaling pathways of transforming growth factor-beta. J Biol Chem 1996; 271:2769-75

131. Sanz-Rodríguez F, Fernández LA, Zarrabeitia R, Pérez-Molino A, Ramirez JR, Coto $E$ et al. Mutation analysis in Spanish patients with hereditary haemorrhagic telangiectasia: deficient endoglin up-regulation in activated monocytes. Clin Chem 2004; 50:2003-11

132. Sargeant IR, Loizou LA, Rampton D, Tulloch M, Bown SG. Laser ablation of upper gastrointestinal vascular ectasias: long term results. Gut 1993: 34(4): 470-475

133. Scharpfenecker M, van Dinther M, Liu Z et al. BMP-9 signals via ALK1 and inhibits bFGF-induced endothelial cell proliferation and VEGF-stimulated angiogenesis. J Cell Sci 2007;120: 964-972

134. Shovlin C, Hughes J, Scott J, Seidman C, Seidman J. Characterization of endoglin and identification of novel mutations in hereditary haemorrhagic telangiectasia. Am J Hum Genet 1997; 61:68-79

135. Shovlin C, Guttmacher A, Buscarini E, Faughnan M, Hyland R, Westermann C, et al. Diagnostic criteria for hereditary hemorrhagic telangiectasia (Rendu- OslerWeber Syndrome). Am J Med Genet 2000; 91(1):66-67

136. Shovlin $\mathrm{CL}$, Jackson JE. Pulmonary arteriovenous malformations and other pulmonary-vascular abnormalities. Chapter 54. In: Mason RJ, Broaddus C, Martin T, King Jr MD, Schraufnagel DMD, Murray JF, Nadel JA, editors. Murray and Nadel's Textbook of Respiratory Medicine ( $5^{\text {th }}$ edition). Pennsylvania: ElsevierSaunders;2010.1261-73

137. Shovlin CL, Hereditary haemorrhagic telangiectasia: Pathophysiology, diagnosis and treatment. Blood Reviews 2010; 24: 203-219

138. Snyder LH, Doan CA: Clinical and experimental studies in human inheritance: is the Homozygous form of multiple telangiectasia lethal? J Lab Clin Med 1944; 29:12111216

139. Spetzler RF, Martin NA, Carter LP, Flom RA, Raudzens PA, Wilkinson E. Surgical management of large AVM's by staged embolization and operative excision. J Neurosurg 1987; 67(1): 17-28

140. Sutton HG: Medical Mirror: 1864 (London)1, 769-781

141. Suzuki J, Onuma T, Kayama T. Surgical teatment of intracranial arteriovenous malformation. Neurol Res 1982; 4(3-4): 191-207 
142. ten Dijke P, Ichijo H, Franzen P, Schulz P, Saras J, Toyoshima $\mathrm{H}$ et al. Activin receptor-like kinases: a novel subclass of cell-surface receptors with predicted serine/threonine kinase activity. Oncogene 1993; 8:2879-87

143. ten Dijke $\mathrm{P}$, Yamashita $\mathrm{H}$, Ichijo $\mathrm{H}$, Franzen $\mathrm{P}$, Laiho $\mathrm{M}$, Miyazono $\mathrm{K}$ et al. Characterization of type I receptors for transforming growht factor-beta and activin. Science 1994; 264:101-4

144. ten Dijke $P$, Arthur HM. Extracellular control of TGF- $\beta$ signaling in vascular development and disease. Nat Rev Mol Cell Biol 2007;8:857-869

145. ten Dijke P, Goumans MJ, Pardali E. Endoglin in angiogenesis and vascular diseases. Angiogenesis 2008; 11:79-89

146. Trembath RC, Thomson JR, Machado RD, Morgan NV, Atkinson C, Winship I et al. Clinical and molecular genetic features of pulmonary hypertension in patients with hereditary haemorrhagic telangiectasia. N Engl J Med 2001; 345:325-34

147. Touyz RM. Molecular and cellular mechanisms regulating vascular function and structure. Implications in the pathogenesis of hypertension. Can J Cardiol 2000; 16:1137-1146

148. Van Cutsem E, Rutgeerts P, Vantrappen G. Treatment of bleeding gastrointestinal vascular malformations with oestrogen-progesterone. Lancet 1990: 335(8695):953-955

149. Vase $P$, Grove $O$. Gastrointestinal lesions in hereditary hemorrhagic telangiectasia. Gastroenterology 1986: 91(5): 1079-1083

150. Vincent P, Plauchu H, Hazan J, Faure S, Weissenbach J, Godet J. A third locus for hereditary haemorrhagic telangiectasia maps to chromosome 12q. Hum Mol Genet 1995;4:945-9

151. Weber FP. Multiple hereditary developmental angiomata (telangiectases) of the skin and mucous membranes associated with recurring haemorrhages. Lancet: $19071 ; 160-162$

152. Weon YC, Yoshida $Y$, Sachet $M$, Mahadevan J, Alvarez $H$, Rodesch $G$ et al. Supratentorial cerebral arteriovenous fistulas (AVFs) in children: review of 41 cases with 63 non choroidal single-hole AVFs. Acta Neurochir (Wien) 2005: 147(1): 17-31; discussion 31

153. Westermann CJ, Rosina AF, DeVries V, de Coteau PA. The prevalence and manifestations of hereditary hemorrhagic telangiectasia in the Afro-Caribbean population of the Netherlands Antilles: a family screening. Am J Med Genet Part A 2003; 116A: 324-328

154. Wieser R, Wrana JL, Massague J. GS domain mutations that constitutively activate T beta R-I, the downstream signalling component in the TGF-beta recptor complex. EMBO J 1995; 14:2199-208

155. Yoshida Y, Weon YC, Sachet M, Mahadevan J, Alvarez H, Rodesch $G$ et al. Posterior cranial fossa single-hole arteriovenous fistulae in children: 14 consecutive cases. Neuroradiology 2004: 46(6). 474-481

156. Yoshimoto T, Kayama T, Suzuki J. Treatment of cerebral arteriovenous malformation. Neurosurg Rev 1986: 9(4): 279-285

157. Zhang H, Du Y, Cohen RA, Chobanian AV and Brecher P. Adventitia as a source of inducible nitric oxide synthase in the rat aorta. Am J Hypertens 12:467-475,199 

A: Adenina

ACM: arteria cerebral media

ACVRL1: activin A receptor type II-like 1

AMPS: 2- acrylamido-2-methylpropane sulfonic acid

ALK-1: activin like kinasa type 1

ARN: ácido Ribonucleico

AVF: fistula de alto flujo

BLAST: Basic Local Alignment Search Tool

BMP: Bone Morphogenetic Proteins

C: citosina

CAVM: malformación arteriovenosa cerebral

CIAA: cloroformo alcohol isoamílico 24:1

CO2: dióxido de carbono

CSIC: Centro Superior de Investigaciones Científicas

CVM: malformación vascular cerebral

ddH2O: agua didestilada

DNA: ácido desoxiribonucleico

DVA: anomalías del desarrollo venoso

EDTA: ácido etilendiaminotetraacético

ENG: endoglina

G: guanina

HDA: hemorragia digestiva alta

HGMD: Human Gene Mutation Database 
HHT: telangiectasia hemorrágica hereditaria

HUS: Hospital Universitario de Salamanca

JPHT: poliposis juvenil telangiectasia hemorrágica

Kb: kilobase

MDE: methylenedioxyethylamphetamine

MIM: Mendelian Inheritance in Man

ND-YAG: láser de Neodimio-YAG

OMIM: Online Mendelian Inheritance in Man

O.R.L.: otorrinolaringólogo

PAVM: malformación arteriovenosa pulmonar

PCR: reacción en cadena de la Polimerasa

Pmut: Punctual mutation

Polyphen: Polymorphism Phenotyping

R.M.N.: Resonancia Magnética Nuclear

Rx: radiografía

SCUBA: self contained underwater breathing apparatus

SDS: dodenil sulfato sódico

SIFT: Sorting Intolerant From Tolerant

SMAD4: Mothers against decapentaplegic homolog 4

SNP: single nucleotide polymorphism (polimorfismo de un solo nucleótido)

T: timina

T.A.C.: tomografía axial computerizada

T.A.C.A.R.: tomografía axial computerizada de alta resolución 
TBE: solución tampón mezcla de TRIS, ácido bórico y EDTA

T $\boldsymbol{\beta R}$-I: receptor transmembrana beta tipo I

T及R-II: receptor transmembrana beta tipo II

TCD: doppler transcraneal

TEMED: tetramethylethylenediamine

TGF- $\beta$ : factor transformador de crecimiento tipo $\beta$

TRIS: trisaminomethane

TTCE: ecocardiografía de contraste transtorácico

US: ultrasonografía

UV: ultravioleta

VEGF: factor de crecimiento de endotelio vascular 

- Figura 1. Componentes de pared vascular. Página 15

- Figura 2. Tipos de remodelamiento vascular. Página 17

- Figura 3. Factores asociados con células lisas de la pared vascular. Página 19

- $\quad$ Figura 4. Exones de Endoglina. Página 23

- $\quad$ Figura 5. Estructura de ALK1. Página 24

- Figura 6. Estructura tridimensional de SMAD4. Página 27

- Figura 7. Mecanismo de señalización en células endoteliales. Página 27

- Figura 8. Estructuras de los receptores TGF- $\beta$. Página 28

- Figura 9. Vía de señalización celular mediada por proteínas SMAD. Página 30

- Figura 10. Vía de señalización mediada por ALK. Página 31

- Figura 11. Electroforesis de fragmentos amplificados por PCR. Página 44

- Figura 12. Formación de heterodúplex tras la desnaturalización y posterior renaturalización del producto de PCR en un individuo heterocigoto. Página 46

- Figura 13. Heterodúplex sin alteraciones correspondientes al exón 3 del gen ALK1. Página 46

- Figura 14. Distribución de pacientes por síntomas. Página 53

- Figura 15a. Pacientes con telangiectasias. Página 54

- Figura 15b. Localización de telangiectasias. Página 54

- Figura 16. Localización de las MAVs en órganos diana. Página 55

- Figura 17. Árbol genealógico probando 17853. Página 58

- Figura 18. Corte axial de Tc abdominal donde se observa malformación vascular hepática. Página 58

- Figura 19. Cromatograma del exón 10 del gen ALK1 en paciente 17853 donde se observa mutación en heterocigosis. Página 59

- Figura 20. Árbol genealógico probando 16678. Página 61

- Figura 21. Imágenes de malformaciones vasculares en mucosa gástrica. Página 61

- Figura 22. Fístulas arteriovenosas hepáticas. Página 62

- Figura 23. Mutación encontrada en el exón 3 de ALK1 en paciente 16678. Página 62

- Figura 24. Heterodúplex de exón 3 del gen ALK1. Página 63

- Figura 25. Conservación del aminoácido Treonina en diferentes especies. Página 64

- Figura 26. Árbol genealógico paciente 19988. Página 65 
- Figura 27. Mutación encontrada en el paciente 19988. Página 66

- Figura 28. Árbol genealógico paciente 17580. Página 67

- Figura 29. Alteración molecular hallada en el paciente 17580. Página 68

- Figura 30. Árbol genealógico paciente 18013. Página 70

- Figura 31. RMN cerebral sin hallazgos valorables. Página 70

- Figura 32. Mutación encontrada en el exón 6 de ALK1 en el paciente 18013. Página 71

- Figura 33. Heterodúplex de exón 6 de ALK1. Página 71

- Figura 34. Resultado de la predicción por SIFT, donde se observa que el cambio es tolerado. Página 72

- Figura 35. Conservación del aminoácido Glicina en diferentes especies. Página 73

- Figura 36. Árbol genealógico paciente 19822. Página 73

- Figura 37. Fístula AV pulmonar, observándose la arteria aferente y eferente. Página 74

- Figura 38. Mutación encontrada en paciente 19822. Página 75

- Figura 39. Telangiectasias en lugares típicos. Página 76

- Figura 40. Árbol genealógico paciente 12241. Página 77

- $\quad$ Figura 41. Hemangioma hepático. Página 77

- Figura 42. Mutación hallada en el paciente 12241. Página 78

- Figura 43. Electroforesis en gel de agarosa de algunos miembros de familia 12241. Página 78

- Figura 44. Árbol genealógico paciente 22530. Página 80

- Figura 45. Mutación encontrada en el intrón 3 de ENG en el paciente 22530, imagen inversa. Página 81

- Figura 46. Árbol genealógico paciente 23043. Página 82

- Figura 47. Mutación encontrada en el exón 6 de ALK1 en paciente 23043. Página 82

- Figura 48. Mutación encontrada en paciente 23120. Página 83 
- Tabla 1. Clasificación HHT. Página 21

- Tabla 2. Programa de PCR. Página 41

- Tabla 3. Relación de oligonucleótidos utilizados en el trabajo para amplificación por PCR de los exones 2 al 10 del gen ALK1. Página 41

- Tabla 4. Relación de oligonucleótidos utilizados en el trabajo para amplificación por PCR de los exones 1 al 13 del gen ENG. Página 42

- Tabla 5. Relación de oligonucleótidos utilizados en el trabajo para amplificación por PCR de los exones 1 al 11 del gen SMAD4. Página 43

- Tabla 6a. Mutaciones patogénicas conocidas. Página 56

- Tabla 6b. Polimorfismos conocidos. Página 56

- Tabla 7a. Mutaciones no conocidas. Página 57

- Tabla 7b.Polimorfismos no conocidos. Página 57

- Tabla 8. Estudio mutacional en descendientes paciente 17853. Página 60

- Tabla 9. Estudio mutacional en descendientes paciente 16678. Página 63

- Tabla 10. Estudio “in silico” para mutación T82P. Página 64

- Tabla 11. Familiares de 17580 estudiados y su resultado. Página 68

- Tabla 12. Resultados de estudio “in silico” para la mutación G214D. Página 72

- Tabla 13. Estudio en familiares paciente 19822. Página 75

- Tabla 14. Resultado de estudios en familiares de 12241. Página 79 